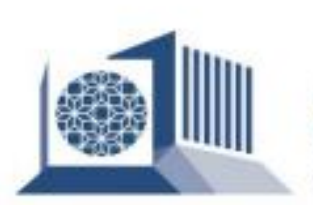

كلية الآداب والعلوم

College of Arts and Sciences

QATAR UNIVERSITY, hägol?

Qatar University

Graduate Studies

College of Art and Science

\title{
Determination of Pesticide Residues of Organochlorine in Some Local and Imported Foods in Qatar
}

\author{
A project in \\ The Department of Biological and Environmental Sciences \\ By \\ Noora Mahmoud Al-Shamary \\ Submitted in Partial Fulfillment \\ Of the Requirements \\ For the Degree of \\ Master of Science
}

May 2015

(C)2015 Noora Al-Shamary 


\section{COMMITTEE PAGE}

The Project of Noora Mahmoud Al-Shamary was reviewed and approved by the following:

We, the committee members listed below accept and approve the project of the student named above. To the best of this committee's knowledge, the project conforms the requirements of Qatar University, and we endorse this project for examination.

Name: Dr. Mohammad Ahmad Al-Ghouti

Signature: ................................ Date:

Name: Dr. Saeed Hashim Al-Meer

Signature:

Date:

Name: Dr. Talaat Abdel-Fattah Ahmad

Signature:..$\ldots \ldots \ldots \ldots \ldots \ldots \ldots \ldots \ldots \ldots \ldots \ldots \ldots$ Date: 


\begin{abstract}
The study was aimed to examine the residues of pesticide in vegetables and fruits in Qatar. The total numbers of samples that were collected were 127 samples of seven most consumed fresh vegetables and fruits from local and import production. The samples were then extracted using Acceleration Solvent Extractor (ASE) and cleaned up using two solid phase extraction (SPE): florisil and silica gel. Gas chromatography with an electron capture detector (GC/ECD) was used to analyze the ten organochlorine pesticides (OCPs). In addition, scan mode of gas chromatography with mass spectrometry (GC/MS) was used in to screen the pesticides residues in these vegetables and fruits. Ninety percent of the imported samples recorded residues above the MRL with at least one of the selected OCPs and about $30 \%$ of the local samples (mostly leafy vegetables) contained residues above the MRL. The most frequently detected OCPs in the samples were heptachlor (found in 75 samples) and was detected mostly in imported samples, g-chlordane (found in 22 samples) and a-chlordane (found in 19 samples). Two statistical analysis tests were used to determine significance (pair-difference t-test and analysis of variance (ANOVA)). In most of the comparisons between the washed and unwashed samples, no-significant differences were observed $(\mathrm{P}>0.05)$. Though, it seems that the effects of washing the samples with tap water differ in organochlorine residues based on the type of vegetables and fruits. The interaction between the washing treatment and countries for heptachlor on parsley showed significant difference. Accordingly, there
\end{abstract}


is a dire require for controlling program for residues of pesticides in food products, especially in imported food products.

\section{ملخص البحث}

كان الهدف من هذه الدراسة هو التعرف على بقايا المبيدات الحشرية في الأغذية في دولة قطر. تم تحليل 127 عينة لسبعة أنواع من الخضروات والفواكه الأكثر إستهلاكا في قطر من مصدرين: محلي ومستورد. تم استخلاص العينات بإستخدام جهاز (ASE) وبعدها تمت عملية التنظيف باستخدام نوعين من مستخلصات التظظف الصلبة: الفروليسيل(Slorisil) و السيليكا (Silica gel) ـ تم تحليل عشرة مركبات من الميبدات الكلورية العضوية باستخدام جهاز الفصل الطيفي للغازات (GC / MS), وكانت 90٪ من العينات المستوردة تفوق مستوى الحد الأعلى المسموح به في احدى من المبيدات الكلورية العضوية ، وحوالي 30٪ من العينات المحلية (ومعظمه من الخضروات الورقية) نحتوي على بقايا تفوق مستوى الدد الأعلى المسموح به. وبشكل عام, سباعي الكلور (heptachlor) وجد في (75 عينة) من العينات المستوردة في معظها، الكلوريدان الفا (وجد في 22 عينة) وعلى الكلوريدان بيتا (وجد في 19 عينة).تم استخدام نوعين من (a-chlordane) اختبارات التحليل الاحصائي هما (t-test) و (ANOVA) لتحديد مدى تباين العينات بإختلاف العوامل المؤثرة. وفي معظم المقارنات بين العينات المغسوله بالماء والغير مغسوله, لم يلاحظ أي اختلافات تذكر (P>0.05). ومع هذا, ييدو أن تأثير غسل العينات بالماء يأتر على بقايا المو اد الكلورية العضوية في بعض أنواع الخضروات و الفو اكه. وأظهرت نتائج الدقارنات بأن التفاعل بين تأثير الغسيل بالماء والدول المنتجة ينتج فرق كبير في بقايا سباعي الكلور (heptachlor). وفقا لذلك، هناك حاجة ماسة لوضع برنامج لرصد بقايا المبيدات في المحاصيل الغذائية، وخاصة في المحاصيل الغذائية المستوردة. 


\title{
LIST OF ABBREVIATIONS
}

\author{
ASE: Accelerated solvent extraction \\ DDT: dichlorodiphenyltrichloroethane \\ ECD: Electron-capture detector \\ EPA: Environmental Protection Agency \\ GC/ECD: Gas chromatography/ Electron-capture detector \\ GC/MS: Gas chromatography/ Mass spectrometry \\ GC: Gas chromatography \\ LC: Liquid Chromatography \\ MRL: Maximum Residue Level \\ MS: Mass spectrometry \\ OCPs: Organochlorine Pesticides \\ PCBs: Polychlorinated biphenyls
}




\section{Table of Contents}

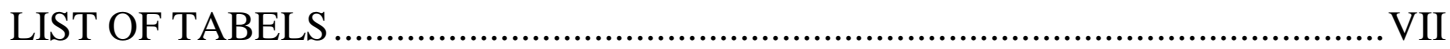

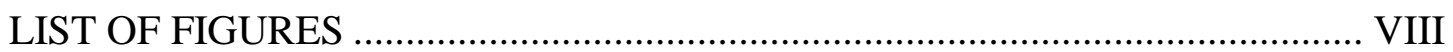

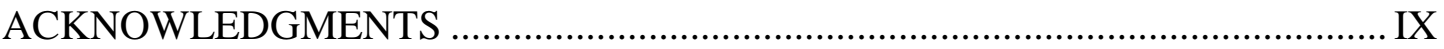

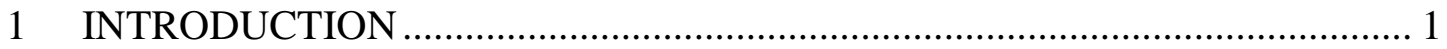

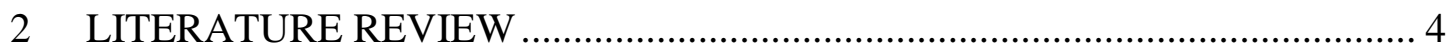

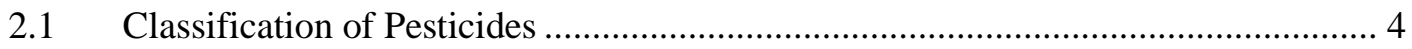

2.1.1 Pesticides Classification Based on Type of Pest They Control ............... 4

2.1.2 Pesticides Classification Based on Chemical Composition.................... 5

2.1.3 Pesticides Classification Based on Other Chemical Composition........... 7

2.1.4 Pesticides Classification Based on Organic Structure ………………...... 7

2.1.5 Pesticide Classification based on mode of Action ................................... 8

2.1.6 Pesticides Classification Based on Pesticidal Action .............................. 8

2.2 Positive and negative effects of using pesticides .............................................. 9

2.3 Pathways and routs of exposure of pesticides in nature......................................... 10

2.3.1 Pesticides in crops (Vegetables and Fruits) ..................................... 12

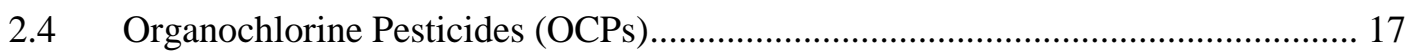

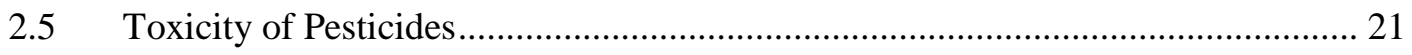

2.5.1 Acute toxicity ................................................................................. 21

2.5.2 Chronic Toxicity: ………………………................................... 24

2.5.3 Toxicity of the selected Organochlorine Pesticides ........................... 29

2.6 Pesticides use in the Arab countries................................................................... 32

2.7 Techniques used to analyze the residues of pesticides in food products ................. 34

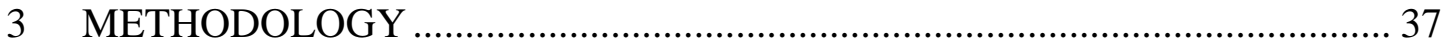

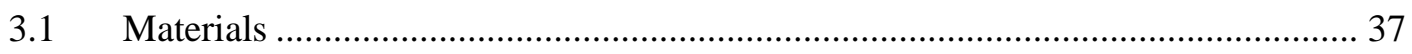

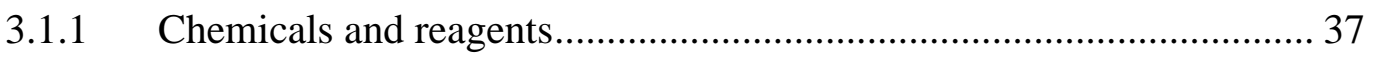

3.1.2 Glassware and general instruments............................................. 37

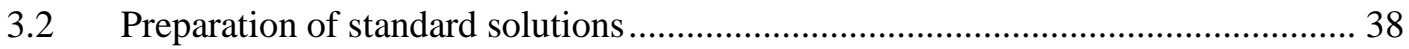




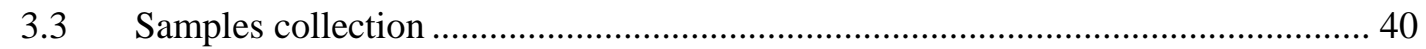

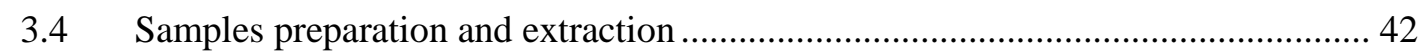

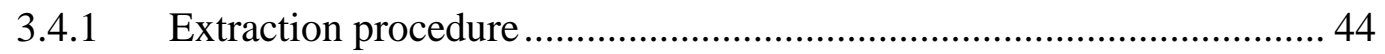

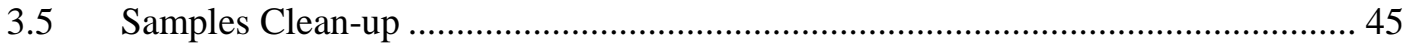

3.6 Quality Control and Quality Assurance Measures (QC/QA) ................................. 47

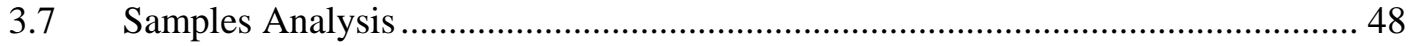

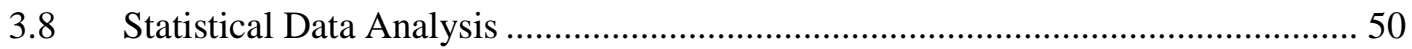

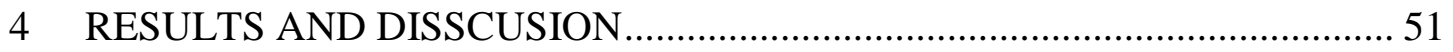

4.1 Organochlorine Residues in vegetables and fruit samples..................................... 54

4.2 Scanning of vegetables and fruit samples by GC/MS ..........................................5 59

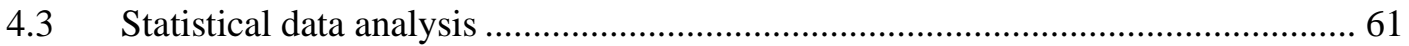

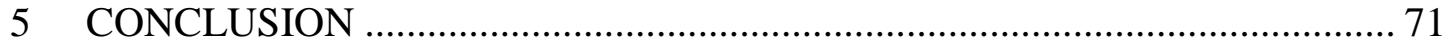

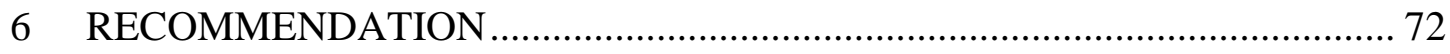

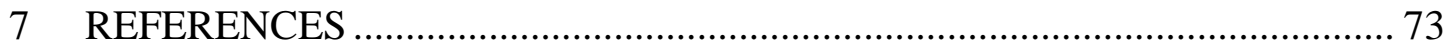

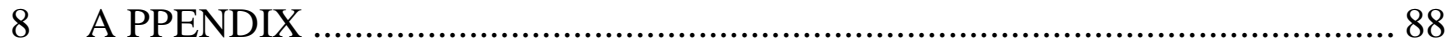




\section{LIST OF TABELS}

Table 1: Different pesticides and their target organism (Singh, 2012).

Table 2: Summary of reviewed articles reporting some of the selected organochlorine pesticides within the selected vegetables and fruit.

Table 3: Maximum Residual Level (MRL) of the selected vegetables and fruits...................16

Table 4: Mode of action of some pesticides....................................................22

Table 5:Classification of pesticides by hazard................................................23

Table 6:Total insecticides consumption in tones per year.........................................32

Table 7:Techniques for determination of pesticides residues in fruits and vegetabales.............36

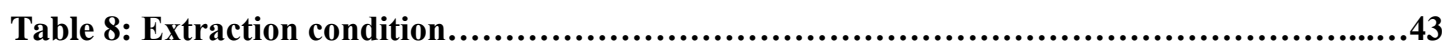

Table 9:Limit of Detection (LOD) and Limit of Quantitation(LOQ) calculated from the calibration line at low concentration ......................................................47

Table 10:Recovories of Decachlorobiphenyl................................................48

Table 11: Pair-differnce t-test for the imported parsley for the presence of heptachlor residue64

Table 12: Analysis of variance data for Heptachlor in parsley samples........................65

Table 13:The calculated LSD for all possible pairs of means of heptachlor in parsley.............67

Table 14:The overall means of all possible comparisons for heptachlor in parsley.................68

Table 15:Analysis of variance data for a-chlordane in watercress samples.......................69

Table 16: Analysis of variance data for methoxychlor in cucumber samples.....................................70

Table 17: Analysis of variance data for heptachlor in tomatoes samples...........................................70 


\section{LIST OF FIGURES}

Figure 1: Overview of the transport of pesticides in the environment (Rathore $\&$ Nollet, 2012)..10

Figure 2: The route of exposure of pesticides (including crops) (Fenik et al., 2011). .......................11

Figure 3: Structure of different organochlorine pesticides (Singh, 2012). ........................................18

Figure 4: Amount of pesticides used in kg/ha in selected Arab countries (Bashour, 2009). ...........33

Figure 5: Pesticides consumption in Saudi Arabia (Knoema Resource Statistics, FAO, 2013).....33

Figure 6: Preparation of standard solutions ...............................................................................................38

Figure 7: Chromatograph of 100ppb of the 10 selected OCPs by GC/ECD. ...................................39

Figure 8: Al-Mazrouah Hall, Umm Salal Ali area..........................................................................................40

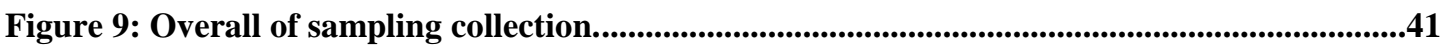

Figure 10: Extraction Procedure ..................................................................................................................44

Figure 11: Post extraction step............................................................................................................45

Figure 12: Cleanup procedure ...................................................................................................................46

Figure 13: GC/ECD and GC/MS instruments at Environmental Studies Center-Qatar

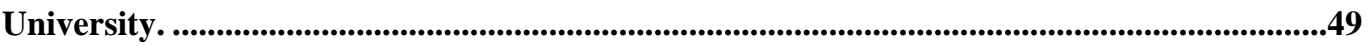

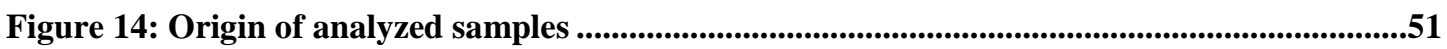

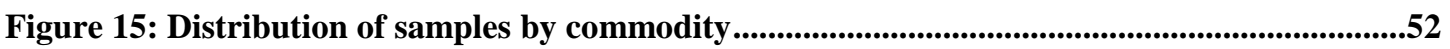

Figure 16: Percentages of selected vegetables and fruit in the three Markets (A, B \& C)..............53

Figure 17: Occurrence of residues of pesticide in fruit and vegetables samples................................54

Figure 18: Residues of OCPs found in local and imported samples ......................................................56

Figure 19: Residues of heptachlor in the local and imported samples..................................................58

Figure 20: Total ion chromatogram of imported cucumber by GC/MS.......................60 


\section{ACKNOWLEDGMENTS}

First, my success was only by Allah. I give deep thanks to Mr. Ismail AlShaikh from the Environmental Studies Center at Qatar University for his guidance and support since starting my master study. My special and heartily thanks to my supervisor Dr. Mohammad Al-Ghouti. It is with his supervision that this work came into existence. I am also deeply thankful to my committee members Dr. Talaat Ahmad and Dr. Saeed Al-Meer for their help and advices. I would like to thank my colleagues in Environmental Science master program who became my second family; Mohammad Shehadi, Rabab Ahmad, Feda Al-Hadad, Rukaya Ammar, Maryam AlKaabi and Salma Al-Hajri. They are good friends and were always willing to help and give their best suggestions. I also thank my family who encouraged me and prayed for me throughout the time of my research. This thesis is heartily dedicated to my parents who without their prayers and help I could not achieve this stage. 


\section{INTRODUCTION}

Fresh fruit and vegetables are significant sources of vitamins and minerals, thus they are an essential element of a healthy diet .On the other hand, fresh fruit and vegetables may contain toxic substances such as pesticides. Pesticides are several and diverse group of chemical compounds, which are applied to crops at various stages of cultivation and production and post-harvest treatment of agricultural products (Bakirci et al., 2014). With their environmental stability, ability to bioaccumulate and toxicity, environment contamination and human health effects have resulted duo to the increase use of pesticides (IARC, 2015; NTP, 2015 \& Bolognesi \& Merlo, 2011).

Due to the pesticides vulnerability to insect and disease attacks various types of pesticides are broadly used in vegetables and fruits. In general, pesticides are indiscriminately used and in huge amounts (Bempah et al., 2012). There are many types of pesticides which can be categorized into many classification based on the pest that they control, chemical composition, mode of action, etc. Based on chemical composition, they are classified into: organochlorine compounds, organophosphorus compounds, carbamates, pyrethroids and neonicotinoids (Mao, 2012).

Since the 1940s, organochlorine pesticides (OCPs) have broadly been used because of their effectiveness in the control of pests and diseases. OCPs were used to control pest on agricultural crops like cotton (Safiatou et al.2007). OCPs are known by their lipophilic properties and low water solubility (Bulut et al., 2011). 
Consequently, they can pose environment problems to human health as they easily accumulate in human adipose tissue. Based on their toxicity, many OCPs are already banned from use or trade in many countries. Though most of OCPs are no longer in use in many countries, they are still being found as residues in food products as means of environmental contamination (Ahmad et al., 2010 \& Feink et al., 2011).

To protect consumer health and to guarantee that food is safe, the controlling of residues of pesticide in food products must be pursued (Yang et al., 2013). Therefore, the allowed levels of pesticide residues in foodstuffs are legislatively controlled through setting maximum residue levels (MRLs). These MRLs limit the types and amount of pesticides that can be legally present in foods, as determined by various regulatory bodies which minimize consumer exposure to harmful or unnecessary intake of pesticides worldwide (Kmellara et al.,2010). Codex Alimentarius Commission (FAO/WHO, 2013) put values for MRL of OCPs in food items.

Recently, the government of Qatar has attempted to encourage agricultural production. Qatar's agricultural products (such as: vegetables and fruits) are consumed locally. Despite a noticeable increase in agricultural production in Qatar, however, this increase does not fulfill the need of residents in Qatar, and Qatar need to import large amounts of food products from other countries.

According to the Ministry of Environment, regulations and policies on pesticides have already been established and implemented. One of these policies is the ban of the use of extremely toxic pesticides and persistent pesticides that affect 
animals and human (Qatar National Implementation Plan (NIP) for Stockholm Convention on Persistent Organic Pollutants (POPs), 2011). OCPs are considered to be one of the POPs that can persist, bio-accumulate, and cause serious effects on human health. However, the lack of information on these pesticide residues in the imported food products has encouraged us to perform this research on determining the concentrations of OCPs in imported food and to compare the results with our local products.

The study was aimed to examine the occurrence of organochlorine pesticides residues in some local and imported vegetables and fruits in Qatar, as a prelude to assess the risks related to their consumption. In order to achieve this aim, the following specific objectives were carried out:

1. Determine the amount of 10 organochlorine pesticides (Heptachlor, aldrin, dieldrin, Endrin, a-chlordane, g-chlordane, endosulfane I, methoxychlor, $\alpha$-BHC and $\beta-\mathrm{BHC}$ ) in seven mostly consumed vegetables and fruits in Qatar using Gas chromatography-electron capture detector (GC-ECD).

2. Screen the residues of pesticides in these vegetables and fruits using scan mode of Gas chromatography- mass spectrometry (GC-MS).

3. Perform statistical analyses to data obtained. 


\section{LITERATURE REVIEW}

At various stages of cultivation and during the post-harvest storage of crops pesticides are applied (Bakirci et al., 2014). The use of pesticides is intended to prevent the destruction of food crops by controlling agricultural pests or unwanted plants and to improve plant quality (Bakirci \& Hisil, 2012). To guarantee the worldwide food supply, pesticides use in agriculture is still necessary (Jardim et al., 2014).

\subsection{Classification of Pesticides}

\subsubsection{Pesticides Classification Based on Type of Pest They Control}

Pesticides are often classified according to the type of target organism they control. Table 1 shows different types of pesticides and their target organism (Singh,

Table 1: Different pesticides and their target organism (Singh, 2012).

\begin{tabular}{|c|c|c|c|}
\hline Pesticide & Target Pest / Function & Pesticide & Target Pest / Function \\
\hline Acaricide & Mites, ticks & Growth regulator & Regulates insect and plant growth \\
\hline Algaecide & Algae & Herbicide & Weeds \\
\hline Anticoagulant & Rodents & Insecticide & Insects \\
\hline Attractant & Attracts insects or birds & Miticide & Mites \\
\hline Avicide & Birds & Molluscicide & Snails, slugs \\
\hline Bactericide & Bacteria & Nematicide & Nematodes \\
\hline Defoliant & Plant leaves & Piscicide & Fish \\
\hline Desiccant & $\begin{array}{l}\text { Disrupts water balance in } \\
\text { arthropods }\end{array}$ & Predacide & Vertebrate predators \\
\hline Fungicide & Fungi & Repellent & Repels vertebrates or arthropods \\
\hline Silvicide & Woody vegetation & Rodenticide & Rodents \\
\hline 2). & & & \\
\hline
\end{tabular}




\subsubsection{Pesticides Classification Based on Chemical Composition}

Another way to classify pesticides is to consider the chemical composition of pesticides products. The commonly utilized pesticides can be categorized into five classes, namely (Mao, 2012):

1. Organochlorine compounds: DDT, $\mathrm{BHC} / \mathrm{HCH}$, Aldrin, Endosulfan, Heptachlor, Methoxychlor,Chlordane, Dicofol.

2. Organophosphorus compounds: Parathion, Monocrotophos, Chlorpyrifos, Quinalphos, Phorate, Diazinon, Fenitrothion,Acephate, Dimethoate, Fenthion, Isofenfos, Phosphamidon, Temephos, Triazophos.

3. Carbamates: Aldicarb, Oxamyl, Carbaryl, Carbofuran, Carbosulfan, Methomyl, Methiocarb, Propoxur, Pirimicarb.

4. Pyrethroids: Allethrins, Deltametrin, Resmethrin, Cypermethrin, Permethrin, Fenvalerate, Pyrethrum.

5. Neonicotinoids: Acetamiprid, Imidacloprid, Nitenpyram, Thiamethoxam.

These types of pesticides played an major role in the increase of agricultural productivity and quality owing to their effectiveness in preventing, repelling or mitigating the effects of pests and diseases (Miao, 2013).

An organophosphate is an organic ester of phosphoric or thiophosphoric acid which is the basis of many insecticides, herbicides and nerve gases. Since these pesticides are very persistent compounds, they consider to be highly toxic to bees, 
wildlife, and humans according to the Environmental Protection Agency (EPA) (Bernal, 2012).

Carbamate compounds are compounds that are generally used as insecticides and they are esters of carbamic acid. These compounds are referred to as $\mathrm{N}$ methylcarbamates. There are many important benefits of using carbamate pesticides. Carbamate pesticides can protect and increase agricultural production and protect human and animal health from insect-vector-mediated diseases. Though, poisoning from these compounds may occur to humans and animals when they are overexposed (Gupta, 2014).

Pyrethroids are synthetic insecticides derived from the natural pyrethrins. Structurally they have 2 or 3 chiral centers. This means that they have 2 or 4 diastereomers and 4 or 8 enantiomers. The use of pyrethroids is extensive around the world (Corcellas et al., 2015). They are common in agronomics both on crops and directly over grain before storage, in veterinary on cattle and pets, as domestic insecticides and even for health purposes against scabies, lice or vectors of some diseases such as malaria or typhus (Barr et al., 2010).

A new class of insecticides known as Neonicotinoids share a general mode of action which is affecting the central nervous system of insects, resulting in paralysis and death. Sass 2014 stated that EPA mentioned that the neonicotinoid pesticides have uncertainties in identification, since their initial registration regarding the potential environmental fate and effects can relate to pollinators. 


\subsubsection{Pesticides Classification Based on Other Chemical Composition}

Singh 2012 classified pesticides into seven groups as follows (Singh, 2012):

1. Organotin compounds: Triphenyltin acetate, Trivenyltin chloride, Tricyclohexyltin, hydroxide, Azocyclotin.

2. Organomercurial compound: Ethyl mercuric chloride, Phenyl mercuric bromide.

3. Dithiocarbamate fungicides: Zineb, Maneb, Mancozeb, Ziram.

4. Benzimidizole compounds: Benomyl, Carbendazim, Thiophanate methyl.

5. Chlorphenoxy compounds: 2,4-D, TCDD, DCPA, 2,4,5-T, 2,4-DB, MCPA, MCPP.

6. Dipyridiliums: Paraquat, Diquat.

7. Miscellaneous: DNOC, Bromoxyl, Simazine, Triazamate.

\subsubsection{Pesticides Classification Based on Organic Structure}

According to the organic structure of pesticides compounds, they can be classified in to three groups (Singh, 2012):

1. Aliphatic compounds: Methyl bromide, Malathion, Glyphosate, Aldicarb, EPTC, Maneb.

2. Aromatic compounds: 2,4-D, Diuron, Carbaryl, Permethrin.

3. Heterocyclic ring compounds: Nicotine, Captan, Benomyl, Atrazine. 


\subsubsection{Pesticide Classification based on mode of Action}

Pesticides can affect different part in living organisms. They can be classified according to their mode of action they cause (Brown, 2013):

1. Nerve poisons: Organochlorine and Organophosphorus pesticides and Carbamates.

2. Anticoagulants: Warfarin.

3. Juvenile hormones: Azadirachtin, Fenoxycarb, Methoprrne, Hydroprene. Antifeedents: Neem, Citrus derived limonoids and their synthetic derivatives.

4. Repellents: Permethrin, Neem oil, Citronella oil.

\subsubsection{Pesticides Classification Based on Pesticidal Action}

Based on pesticidal action, pesticides can be classified in to two main groups (Singh, 2012):

1. Stomach insecticide: DDT, BHC/HCH, Methoxychlor, Lead arsenate, Paris green, $\mathrm{NaF}$.

2. Contact insecticide: Chlordane, Aldrin, Nicotine, Parathion. 


\subsection{Positive and negative impacts of using pesticides}

Using of pesticides in agriculture have many profits. These benefits include: production improvement, crop losses protection and vector disease control (Aktar et al., 2009). The yield of crops such as vegetables, corn, maize and cotton improved

and the losses of crops decreased as the application of pesticides including insecticides, fungicides, herbicides, rodenticides are introduced to protect crops from pests (Carvalho, 2006). The most effective treatment for vector-borne diseases is to kill the vectors. Insecticides are the efficient compounds that can kill and control the insects that can cause serious disease such as malaria, which daily cause death to about 5000 people (Ross, 2005).

However, the use of pesticides can cause many harm to the environment and human. Pesticides can be carried by wind or leached by torrential rains causing contaminations of water bodies and soils (Fenik et al., 2011). Although pesticides help in controlling insects and weeds, they can be toxic to a many other organisms such as non-target organisms (Bakırc1 et al., 2014 \& Aktar et al., 2009). Bioaccumulation and biomagnifications of these compounds consider as major problems associated with using them (Rowe, 2015). Many pesticides are stored in the body tissue since they are not able to be broken down.. Pesticides can cause direct threat to human health and life. Accumulation of pesticides in the body may be carcinogenic, neruotoxic and can disrupt hormonal and enzymatic regulation (Fenik et al., 2011). 


\subsection{Pathways and routs of exposure of pesticides in nature}

Pesticides can enter the environment via different pathways (Figure 1), such as transformation and degradation, volatilization, absorption and desorption, runoff to surface waters, uptake by plants, and transport to groundwater (Rathore \& Nollet, 2012).

Figure 1: Transport of pesticides in the environment (Rathore \& Nollet, 2012).

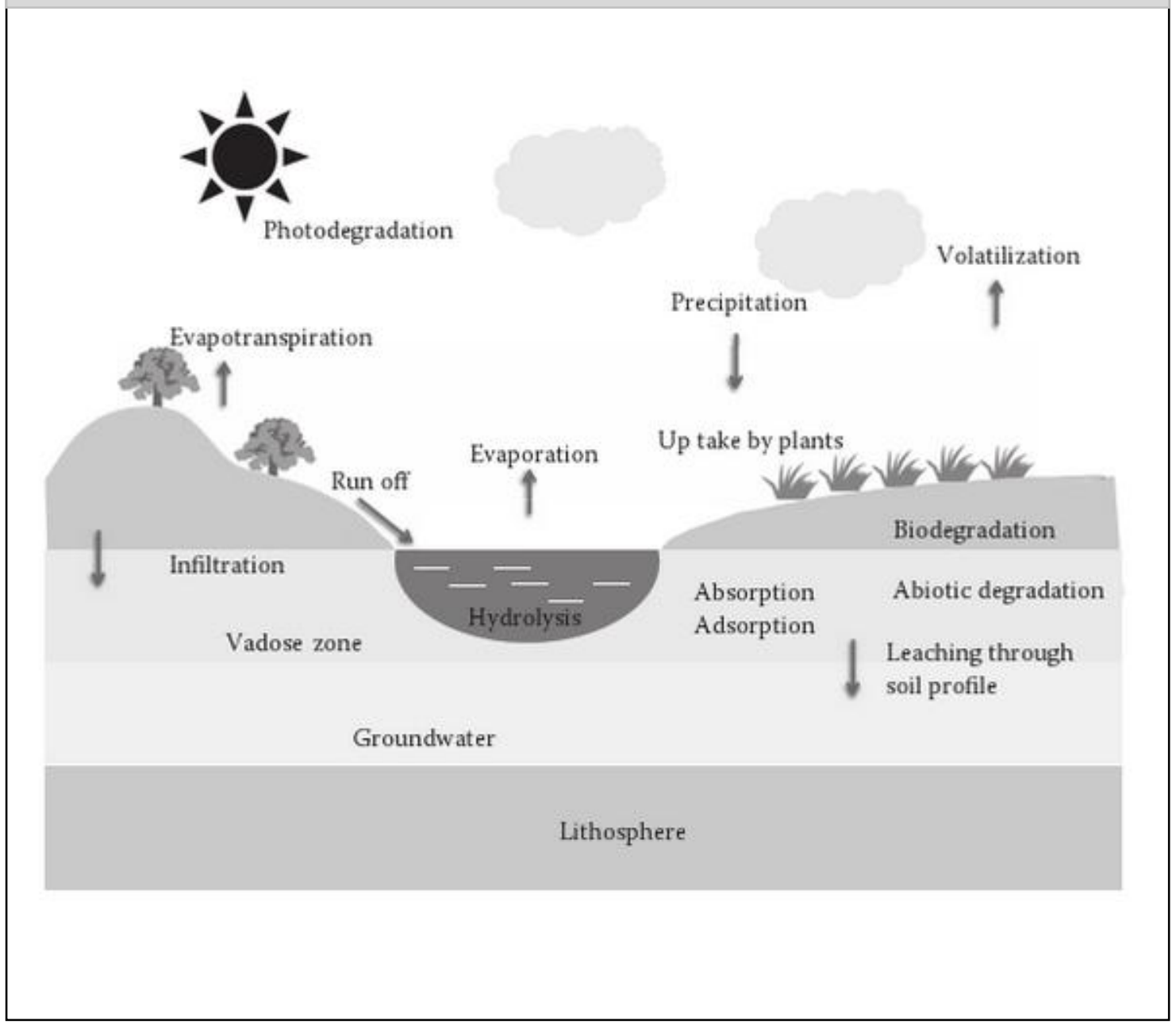


Therefore, pesticides have many routs of exposure Figure 2); they can circulate in to the air, water, soil, crops and human (Fenik et al., 2011). However, the major concerns are from consumption of pesticide laden food crops (Boobis et al., 2008). Pesticides are mainly transported from their source of application to neighboring crops and land by rain and wind. This transportation may be undesirable or harmful (Moreno et al., 2006).

Figure 2: The route of exposure of pesticides (including crops) (Fenik et al., 2011).

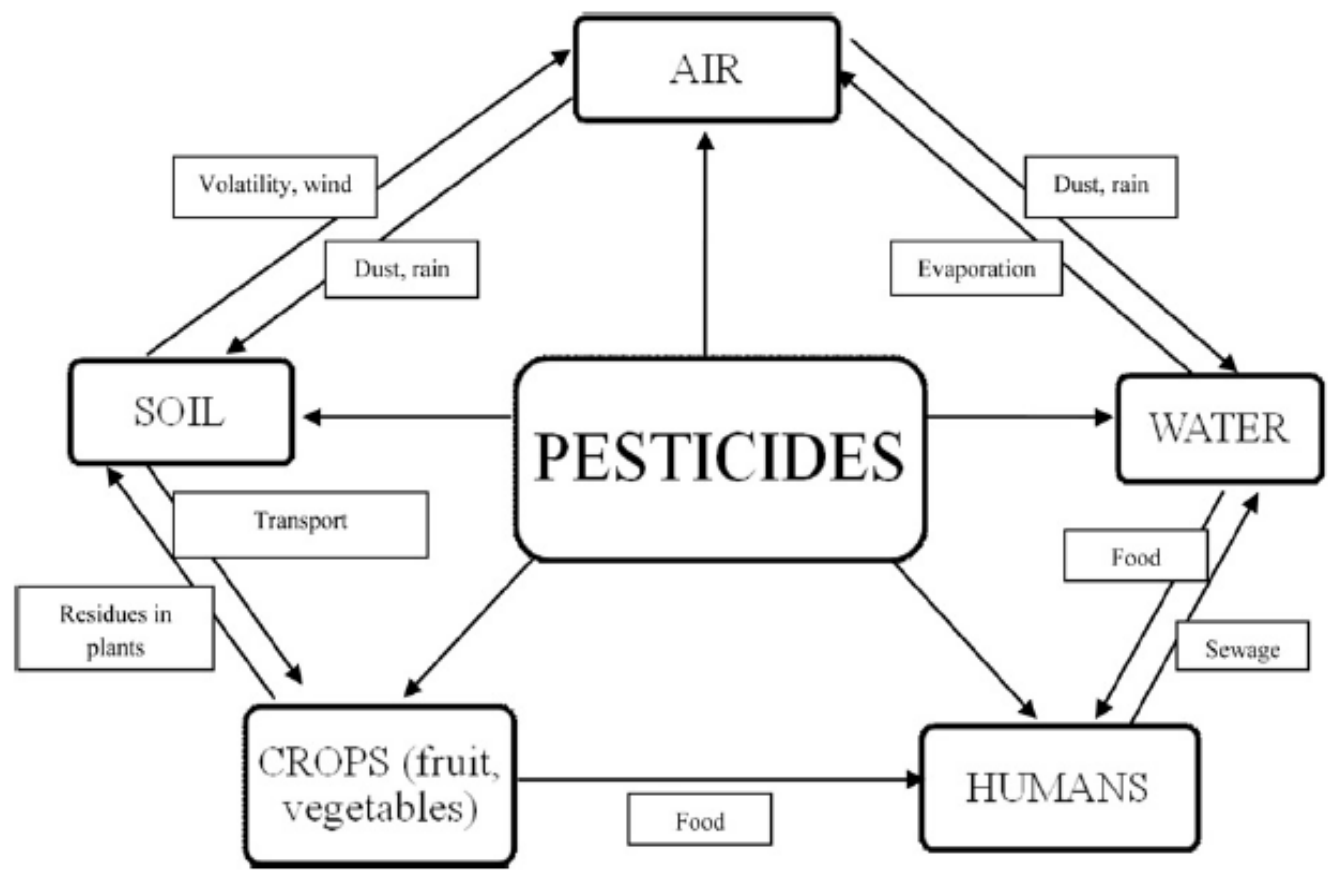




\subsubsection{Pesticides in crops (Vegetables and Fruits)}

Occurrence of residues of pesticide in food is the main consequence of application of pesticide on crops. More than a thousand compounds may be applied to agricultural crops to control unwanted pest such as insects and weeds (Ortelli, Edder, \& Corvi, 2006). Many Fruits and vegetables are marketed all over the world and no information is known about the compounds of pesticides that applied on the production process (Stan, 2000). Comparing to other food groups, vegetables and fruits often contain higher levels of residue of pesticide (Chen et al., 2011).

Recently, many researchers from various areas and different residue levels have reported the presence of different pesticides residues in fruits and vegetables (Bai, Zhou, \&Wang, 2006; Chen et al., 2011; Hjorth et al., 2011; Kneževic' \& Serdar, 2009; Osman, Al-Humaid, Al-Rehiayani, \& Al-Redha, 2010; Pico, la Farre, Soler, \& Barcelo, 2007).

Table 2 summarizes the concentration of selected organochlorine pesticides in selected vegetables from various regions of the world. For the fruits, strawberries and lemon, no data were reported for the selected organochlorine pesticides. Not all the selected OCPs were studied in the selected vegetables and fruits. There is a lack of information for the selected OCPs residues especially for lemon and strawberries. Only one study reported OCPs residues for parsley and watercress. 
Table 2: Summary of reviewed articles reporting some of the selected organochlorine pesticides within the selected vegetables and fruit.

\begin{tabular}{|c|c|c|c|c|c|c|}
\hline \multirow{2}{*}{ OCPs } & \multicolumn{3}{|c|}{ Cucumbers } & \multicolumn{3}{|c|}{ Tomatoes } \\
\hline & Concentration $(\mathrm{mg} / \mathrm{kg})$ & Country & Reference & Concentration (mg/kg) & Country & Reference \\
\hline a-BHC & $<0.1$ & Indonesia & (Shoiful et al., 2013) & & & \\
\hline b-BHC & $<0.1$ & Indonesia & (Shoiful et al., 2013) & & & \\
\hline Heptachlor & $<0.08$ & Indonesia & (Shoiful et al., 2013) & $0.045 * \pm 0.018$ & Ghana & (Bempah et al., 2011) \\
\hline Aldrin & $<0.03$ & Indonesia & (Shoiful et al., 2013) & & & \\
\hline \multirow{3}{*}{ Dieldrin } & $<0.04$ & Indonesia & (Shoiful et al., 2013) & $0.004 \pm 0.008$ & Ghana & (Bempah etal., 2012) \\
\hline & $0.010 \pm 0.004$ & Ghana & (Bempah et al., 2012) & $0.008 \pm 0.004$ & Ghana & (Bempah et al., 2011) \\
\hline & $0.022 \pm 0.009$ & KSA & (Osman et al., 2010) & & & \\
\hline Endrin & & & & $0.009 \pm 0.002$ & Ghana & (Bempah et al., 2011) \\
\hline a-Chlordane & $<0.06$ & Indonesia & (Shoiful et al., 2013) & & & \\
\hline g-Chlordane & $<0.03$ & Indonesia & (Shoiful et al., 2013) & & & \\
\hline \multirow{2}{*}{ Endosulfane I } & $0.04-0.11$ & Turkey & (Bakirci et al., 2014) & & & \\
\hline & 0.15 & $\mathrm{KSA}$ & (Salim et al., 2011) & & & \\
\hline Methoxychlor & $0.020 * \pm 0.002$ & Ghana & (Bempah et al., 2012) & $0.004 \pm 0.002$ & Ghana & (Bempah etal., 2012) \\
\hline \multicolumn{7}{|c|}{${ }^{1}$ Concentration \pm standard deviation } \\
\hline Concentration $\mathrm{R}$ & & & & & & \\
\hline
\end{tabular}




\begin{tabular}{|c|c|c|c|c|c|c|c|c|}
\hline \multicolumn{9}{|l|}{ Conti. Table 2} \\
\hline \multicolumn{3}{|c|}{ Potatoes } & \multicolumn{3}{|c|}{ Parsley } & \multicolumn{3}{|c|}{ Watercress } \\
\hline $\begin{array}{c}\text { Concentration } \\
(\mathrm{mg} / \mathrm{kg})\end{array}$ & Country & Reference & $\begin{array}{c}\text { Concentration } \\
(\mathrm{mg} / \mathrm{kg})\end{array}$ & Country & Reference & $\begin{array}{c}\begin{array}{c}\text { Concentration } \\
(\mathrm{mg} / \mathrm{kg})\end{array} \\
\end{array}$ & Country & Reference \\
\hline$<0.100$ & Indonesia & (Shoiful et al., 2013) & - & $\ldots$ & $\ldots$ & $\ldots$ & $\ldots$ & $\ldots$ \\
\hline $0.0140 \pm 0.006$ & Egypt & (Soliman, 2001) & $\ldots$ & $\ldots$ & $\ldots$ & $\ldots$ & $\ldots$ & $\ldots$ \\
\hline$<0.100$ & Indonesia & (Shoiful et al., 2013) & - & $\ldots$ & $\ldots$ & $\ldots$ & $\ldots$ & - \\
\hline$<0.080$ & Indonesia & (Shoiful et al., 2013) & - & - & - & - & - & - \\
\hline$<0.030$ & Indonesia & (Shoiful et al., 2013) & - & - & - & -- & - & - \\
\hline$<0.040$ & Indonesia & (Shoiful et al., 2013) & $\ldots$ & $\ldots$ & - & - & - & $\ldots$ \\
\hline$\ldots$ & $\ldots$ & - & - & - & $\ldots$ & $\ldots$ & - & - \\
\hline- & - & - & - & - & $\ldots$ & $\ldots$ & - & - \\
\hline$\ldots$ & $\ldots$ & - & - & - & $\ldots$ & $\ldots$ & - & - \\
\hline$<0.060$ & \begin{tabular}{|l|} 
Indonesia \\
\end{tabular} & (Shoiful et al., 2013) & - & - & - & - & - & - \\
\hline$<0.030$ & Indonesia & (Shoiful et al., 2013) & - & - & - & - & - & - \\
\hline- & - & - & 0.020 & $\mathrm{KSA}$ & (Salim et al., 2011) & 0.014 & $\mathrm{KSA}$ & (Salim et al., 2011) \\
\hline- & - & - & - & $\ldots$ & - & $\ldots$ & - & $\ldots$ \\
\hline _- & $\ldots$ & $\ldots$ & $\ldots$ & $\ldots$ & $\ldots$ & $\ldots$ & $\ldots$ & $\ldots$ \\
\hline
\end{tabular}




\subsubsection{Maximum Residue Level (MRL)}

Maximum Residue Level (MRL) for residues of pesticide is defined as the maximum concentration of residue $(\mathrm{mg} / \mathrm{kg})$ that is permitted by law in specific foodstuff (Al-Saeid \& Selim, 2013). To protect consumer health and to guarantee that food is safe, the monitoring of residues of pesticide in foodstuffs must be pursued. Therefore, the allowed levels of pesticide residues in foodstuffs are legislatively controlled through setting maximum residue levels (MRLs). These MRLs limit the types and amount of pesticides that can be legally present in foods, as determined by various regulatory bodies which aim at minimizing consumer exposure to harmful or unnecessary consumption of pesticides in the world.

In addition, MRLs help ensure adequate use of pesticides through authorization and registration and allow free movement of the products treated with pesticides (Kmellara et al.,2010; Knez evic’ \& Serdar, 2009). Table 3 shows the MRLs of the selected pesticides in the selected vegetables and fruits (FAO/WHO, 2013). 
Table 3: Maximum Residue Level (MRL) of the selected vegetables and fruit, According to Codex Alimentarius Commission (FAO/WHO, 2013).

\begin{tabular}{|c|c|c|c|c|c|c|c|c|c|c|}
\hline \multirow{2}{*}{$\begin{array}{c}\text { Selected } \\
\text { vegetables } \\
\text { and fruit }\end{array}$} & \multicolumn{10}{|c|}{ Maximum Residue Level/ $\mu \mathrm{g} / \mathrm{kg}$} \\
\hline & a-BHC & $\mathrm{b}-\mathrm{BHC}$ & Heptachlor & Aldrin & Dieldrin & Endrin & a-Chlordane & g-Chlordane & Endosulfane I & Methoxychlor \\
\hline Cucumbers & 10 & 10 & 10 & 20 & 20 & 10 & 10 & 10 & 50 & 10 \\
\hline Tomatoes & 10 & 10 & 10 & 10 & 10 & 10 & 10 & 10 & 500 & 10 \\
\hline Potatoes & 10 & 10 & 10 & 10 & 10 & 10 & 10 & 10 & 50 & 10 \\
\hline Parsley & 10 & 10 & 10 & 50 & 50 & 10 & 10 & 10 & 50 & 10 \\
\hline Watercress & 10 & 10 & 10 & 50 & 50 & 10 & 10 & 10 & 50 & 10 \\
\hline Strawberries & 10 & 10 & 10 & 10 & 10 & 10 & 10 & 10 & 50 & 10 \\
\hline lemon & 10 & 10 & 10 & 50 & 50 & 10 & 10 & 10 & 500 & 10 \\
\hline
\end{tabular}




\subsection{Organochlorine Pesticides (OCPs)}

Organochlorine pesticides (also known as chlorinated hydrocarbons where one or many hydrogen atoms replaced by the chlorine) are primarily insecticides with relatively low mammalian toxicity, fat soluble and normally persistent in the environment. Many chlorinated hydrocarbons have the ability to accumulate inside the body due to their lipophilic nature (Singh, 2012). Their main characteristics are:

1. Occurrence of carbon atoms, chlorine atoms, hydrogen atoms and oxygen atoms sometimes exist. Number and position of $\mathrm{Cl}$ in molecule decides the toxicity.

2. Presence of cyclic carbon chains including benzene ring.

3. Lack of any particular active intra-molecular sites.

4. They are nonpolar and lipophilic in nature and have a affinity to concentrate in the lipid rich tissues, thereby causing its bio-concentration, and biomagnifications at different trophic level in the food chain.

5. Chemically unreative, therefore highly persistent in the environment, resistant to microbial degradation.

Organochlorine group chemicals were first used as pesticides in the 1940s. Organochlorine compounds were used widely from 1945 to 1965 in different application including agriculture and in protection of the buildings timber and humans from a wide range of insect pests. After awareness that these compounds are highly persistent, legal action has been taken to phase out this class of insecticides 
(Singh, 2012). It includes DDT, Lindane, Endosulfan, Aldrin, Dieldrin, Chlordane, Heptachlor and Endrin (Figure 3).

Figure 3: Structure of different organochlorine pesticides (Singh, 2012).

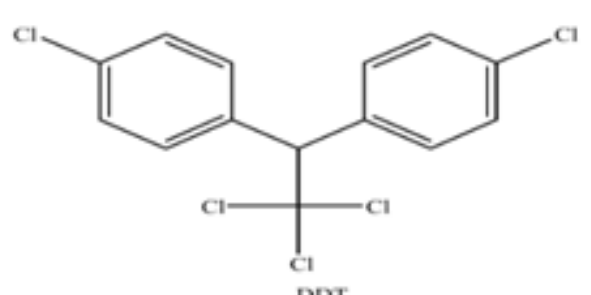

DDT<smiles>CCc1ccc(C(c2ccc(CC)cc2)C(Cl)Cl)cc1</smiles>

Ethyl- DDD

IUPAC : 1,1,1-trichloro-2,2-bis(4-chlorophenyl)ethane IUPAC: 1,1-dichloro-2,2-bis(4-ethylphenyl)ethane FORMULA: $\mathrm{C}_{14} \mathrm{H}_{9} \mathrm{Cl}_{5}$ FORMULA : $\mathrm{C}_{18} \mathrm{H}_{20} \mathrm{Cl}_{2}$<smiles>ClC1C(Cl)C(Cl)C(Cl)C(Cl)C1Cl</smiles>

$\mathrm{HCH}$

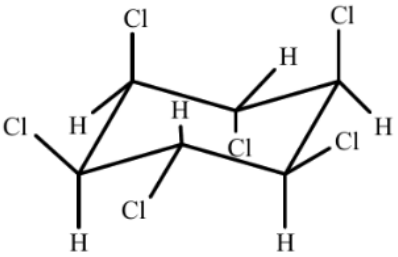

$\gamma-\mathrm{HCH}$

IUPAC: 1,2,3,4,5,6-hexachlorocyclohexane IUPAC: $1 \alpha, 2 \alpha, 3 \beta, 4 \alpha, 5 \alpha, 6 \beta$-hexachlorocyclohexane FORMULA: $\mathrm{C}_{6} \mathrm{H}_{6} \mathrm{Cl}_{6}$ FORMULA: $\mathrm{C}_{6} \mathrm{H}_{6} \mathrm{Cl}_{6}$

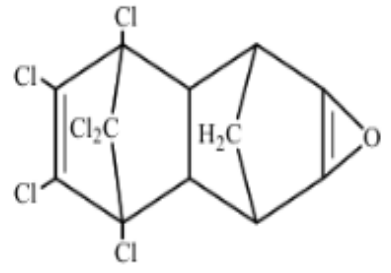

$$
\text { Endrin }
$$

IUPAC: (1R,4S,4AS,5S,6S,7R,8R,8aR)-1,2,3,4,10,10-hexachloro-1,4,4a,5,6,7,8,8a-octahydro-6,7-epoxy-1,4:5,8dimethanonaphthalene OR 1,2,3,4,10,10-hexachloro-6,7-epoxy-1,4,4A,5,6,7,8,8a-octahydro-EXO-1,4-exo-5,8-dimethanonaphthalene FORMULA: $\mathrm{C}_{12} \mathrm{H}_{8} \mathrm{CL}_{6} \mathrm{O}$ 


\section{Cont. Figure 3}

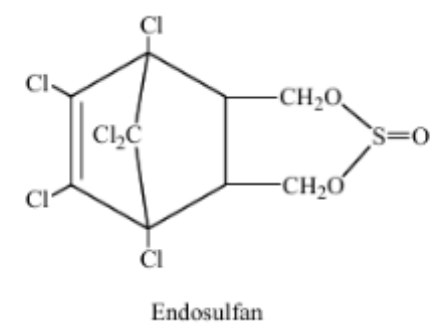

IUPAC: 1,4,5,6,7,7-hexachloro-8,9,10-trinorborn-5-en-2,3-ylenebismethylene sulphite or 6,7,8,9,10,10-hexachloro-1,5,5a,6,9,9ahexahydro-6,9-methano-2,4,3-benzodioxathiepine 3-oxide FORMULA: $\mathrm{C}_{9} \mathrm{H}_{6} \mathrm{Cl}_{6} \mathrm{O}_{3} \mathrm{~S}$

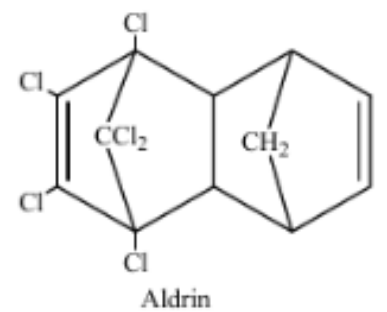

IUPAC: (1R,4S,4AS,5S,8R,8aR)-1,2,3,4,10,10-hexachloro-1,4,4a,5,8,8a-hexahydro-1,4:5,8-dimethanonaphthalene FORMULA: $\mathrm{C}_{12} \mathrm{H}_{8} \mathrm{CL}_{6}$

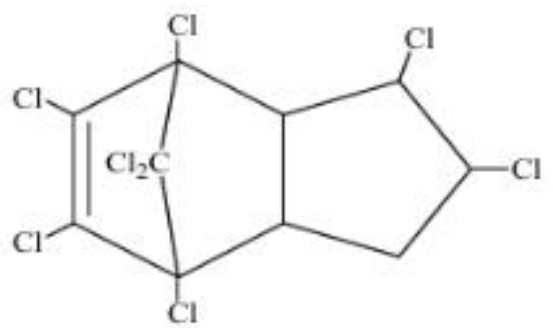

Chlordane

IUPAC: $1,2,4,5,6,7,8,8$-octachloro-2,3,3a,4,7,7a-hexahydro-4,7-methanoindene FORMULA: $\mathrm{C}_{10} \mathrm{H}_{6} \mathrm{CL}_{8}$ 


\section{Cont. Figure 3}

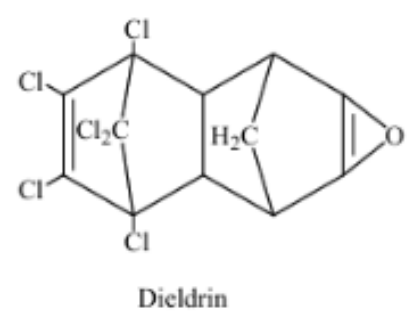

IUPAC: (1R,4S,4AS,5R,6R,7S,8S,8aR)-1,2,3,4,10,10-hexachloro-1 ,4,4a,5,6,7,8,8a-octahydro-6,7-epoxy-1,4:5,8dimethanonaphthalene OR 1,2,3,4,10,10-hexachloro-6,7-EPOXY-1,4,4a,5,6,7,8,8a-octahydro-ENDO-1,4-exo-5,8dimethanonaphthalene

FORMULA: $\mathrm{C}_{12} \mathrm{H}_{8} \mathrm{CL}_{6} \mathrm{O}$<smiles>ClC1=C(Cl)C2(Cl)C(Cl)C1C1C=CC(Cl)C12</smiles>

Heptachlor

IUPAC: 1,4,5,6,7,8,8-heptachloro-3a,4,7,7a-tetrahydro-4,7-methanoindene FORMULA: $\mathrm{C}_{10} \mathrm{H}_{5} \mathrm{CL}_{7}$<smiles>COc1ccc(C(c2ccc(OC)cc2)C(Cl)(Cl)Cl)cc1</smiles>

Methoxychlor

IUPAC: 1, 1, 1-Trichlori-2,2-bis(4-methoxyphenyl) ethane

FORMULA: $\mathrm{Cl6H} 15 \mathrm{Cl} 3 \mathrm{O} 2$ 


\subsection{Toxicity of Pesticides}

Pesticides are characterized by various degrees of toxicity to non-target species, including human beings, thus they are a diverse category of biologically active compounds. The majority of the currently used pesticides are acutely toxic to humans. Neurological effects, reproductive or development problems, and cancer may be consequences of pesticide exposure also can cause chronic health effects such as (Bolognesi \& Merlo, 2011).

Table 4 shows the most currently applied classes of synthetic pesticides. Pesticides on target species have many primary effects which are: sodium channel interference or neurotransmitter receptors interaction which lead to neurotoxicity, disruption of energy metabolism leading to paralysis, or blocking chitin synthesis causing growth inhibition (Bolognesi \& Merlo, 2011). Since the mechanism of action for organophosphates and carbamates is same, serious additive toxicity can be created (Bolognesi \& Merlo, 2011).

\subsubsection{Acute toxicity}

The serious and the less perilous manifestations of every pesticide are recognized by the WHO. The lethality of the specialized substance and its details are taken into account in the pesticides framework. Since the acute oral and dermal toxicity are typical procedures in toxicology, the acute oral and dermal toxicity to the rat are taken into account in the classification (WHO, 2006). 


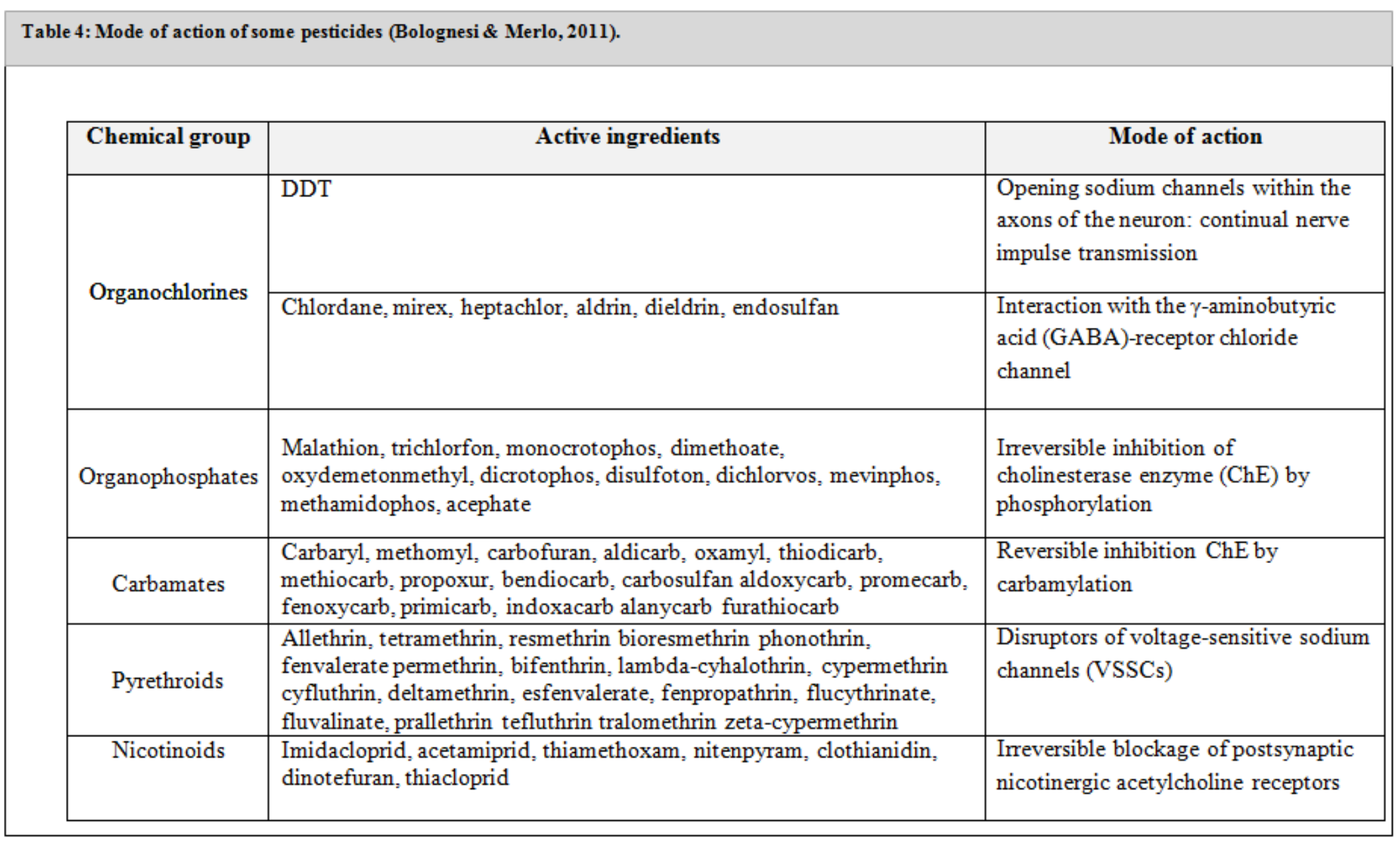


Most of the classifications are derived from the acute oral lethal dose $\left(\mathrm{LD}_{50}\right)$ (Table 5). Since handling pesticides has the highest dermal exposure, dermal toxicity must always be considered.

Table 5: Classification of pesticides by hazard (WHO, 2006).
\begin{tabular}{|c|l|l|l|l|l|}
\hline & \multicolumn{5}{|c|}{ LD50 for the rat (mg/kg bw) } \\
\hline \multirow{2}{*}{ Class } & & \multicolumn{2}{|c|}{ Oral } & \multicolumn{2}{c|}{ Dermal } \\
\cline { 3 - 6 } & & Solid & Liquid & Solid & Liquid \\
\hline Ia & Extremely hazardous & 5 or less & 20 or less & 10 or less & 400 or less \\
\hline Ib & Highly hazardous & $5-50$ & $20-200$ & $10-100$ & $40-400$ \\
\hline II & Moderately hazardous & $50-500$ & $200-2000$ & $100-1000$ & $400-4000$ \\
\hline III & Slightly hazardous & Over 500 & Over 2000 & Over 1000 & Over 4000 \\
\hline
\end{tabular}

Studies in developing countries have shown rates of annual frequency of severe pesticide poisoning in rural workers to be up 18.2 per 100 thousands full-time workers and 7.4 per million school children (Bolognesi \& Merlo, 2011). The occurrences found to be higher because of the utilization of banned pesticides in developed countries, the inadequate regulation, the absence of preparing and observation frameworks, and poor individual defensive gear in developing countries. The majority of cases regarding pesticide poison caused from carbamate or organophosphate. Inhibition of nervous system enzyme (acetyl cholinesterase) may occur from these two compounds. (Ecobichon, 2001).

The principle target of OCPs is the nervous system, in which a hyperexcitable state developed. Serious inebriation by these mixes causes myoclonic jolting 
developments, and after that summed up tonic-clonic shakings took after by trance state and respiratory depression (Bolognesi \& Merlo, 2011).

\subsubsection{Chronic Toxicity:}

Neurological effects

Discoveries from numerous epidemiological studies come with agreement with the theory that pesticide introduction may predispose the Parkinson's malady (Ritz et al, 2009). The Parkinson disease is the main common neurodegenerative movement disorders, which affects one percent of the population over 65 years. The main symptoms of this disease are akinesia, tremor, rigidity, and postural instability. Experimental studies point out the possibility that toxic environmental compounds, such as pesticides, may cause pathogenesis of Parkinson's disease through the inhibition of the mitochondrial function (Ritz et al, 2009).

Pesticide presentation worsen Parkinson's malady hazard demonstrated by the epidemiological studies which examin the danger of Parkinson. A deliberate audit of the accessible confirmation from studies directed in the United States shows that the danger of Parkinson's disease in subjects ever presented to pesticides is more than twofold contrasted with control subjects. (Bolognesi \& Merlo, 2011). Organochlorines, organophosphorus, chlorophenoxy esters, and botanicals have been recognized as particular classes of pesticides representing that may possibly cause the Parkinson disease development. Notwithstanding the epidemiological studies and 
experimental proofs, Parkinson's disease caused from pesticide still hard to presume (Benjamin et al, 2001).

\section{Carcinogenicity}

Pesticides are presently ordered by universal organizations and boards (for example: International Agency for Research on Cancer (IARC)) according to their possible properties for cancer-causing on the premise of the accessible proof from human and examining studies (IARC, 2015). Human studies are very complicated and hard to discovered, even though there is agreement that the strongest proof for making a causal connection between exposure to an operator and disease event in people originates from epidemiological studies. An operator can be sensibly recognized as a potential human cancer-causing agent by method for creature bioassays (Bolognesi \& Merlo, 2011).

The US NTP has grouped various dynamic fixings in pesticides as 'sensibly expected to be a human cancer-causing agent' and the IARC and the US EPA, taking after deliberate and thorough audits of the human and exploratory studies, have inferred that some compound mixes utilized as a part of pesticides (insect poisons, fungicides, herbicides, and other comparative mixes) are known, likely or conceivable cancer-causing agents (NTP, 2015). 


\section{Genotoxicity}

Genotoxic potential is an essential danger component for long term exposure impacts, for example, cancer-causing and conceptive toxicology (Padula et al, 2012). Genotoxic mixes are compounds that demonstrate by immediate or roundabout DNA harm or by a clastogenic occasion. The lion's share of pesticides have been tried in a wide assortment of mutagenicity examines that cover quality changes, chromosomal adjustments, and DNA harm. Test information uncovered that different agrochemical dynamic substances have mutagenic properties prompting diverse hereditary endpoints (Bolognesi \& Merlo, 2011). Notwithstanding some harshness in the consequences of fleeting tests, comparative profiles of genotoxic movement produced from pesticides with comparable synthetic structure. The genotoxic capability of agrochemical fixings give a frail reaction in a couple genotoxicity tests (Bolognesi \& Morasso, 2000).

Word related presentation to pesticides mixtures has been connected with an increment in genotoxic harm in various studies. The effect of dose increment of cytogenetic harm was likewise uncovered in some biomonitoring studies identified with the degree of introduction as amount of pesticides utilized the expansion of territory of pesticide application and lacking working conditions. The confirmation of a hereditary peril identified with presentation coming about because of the serious utilization of pesticides anxieties the requirements for instructive projects for ranchers to decrease the utilization of chemicals in agribusiness and to actualize insurance measure (Benjamin et al, 2001). 
The current exploratory proof recommends an irrelevant danger for the overall public presented to low levels of pesticide buildups. Notwithstanding, various open inquiries stay at present on genotoxic danger of pesticides for purchasers, for example, the wellbeing risk for rehashed ingestions of pesticide deposits and the potential genotoxic harm from concurrent introduction of a few dynamic mixes (Bolognesi \& Merlo, 2011).

\section{Reproductive Toxicity}

Introduction to pesticides may represent a danger to human propagation (Padula et al, 2012). Working with or applying pesticides fitting in with diverse synthetic classes, for example, organochlorines and organophosphates, which are utilized essentially as a part of rural settings, seems to reliably diminish richness and fecundability. Epidemiological proof proposes that abnormal state of introduction to DDT or DDE is connected with unfriendly fetal development and preterm conveyance. Word related presentation to dibromochloropropane influences male conceptive capacity delivering azospermia and oligospermia, germinal epithelium harm, hereditary adjustment in sperm, (for example, twofold Y-bodies), expanded rates of unconstrained premature births in wives of uncovered laborers, hormonal lopsided characteristics, and adjusted sex proportion in posterity (Padula et al, 2012). The constraint of the absence of a standard accepted measure of presentation are applied to all these studies have. The trial confirmation from creature studies is 
restricted and can't help in affirming the human information (Bolognesi \& Merlo, 2011).

Although a few pesticides cause conceptive or formative poisonous quality at high dosages in creature models, unfriendly wellbeing impacts in people presented to natural levels are hard to survey. Just a couple of pesticides such as DDT, herbicides, pentachlorophenol, dibromochloropropane, parathion, chlorophenoxyacetic, atrazine, parathion, and oxydemeton-methil, are referred to actuate formative deserts, for example, orofacial clefts, hypospadias, complete odd venous return, spina bifida, and appendage decrease in occupationally uncovered populaces. Studies concentrating on particular conception imperfections reported relationship between rural work and innate contortions including a marginally expanded danger for focal sensory system deformities. Watchful evaluation of introduction to particular pesticides in the further studies is expected to connection this impact to particular mixes or classes of pesticides (Bolognesi \& Merlo, 2011). 


\subsubsection{Toxicity of the selected Organochlorine Pesticides}

Heptachlor firmly associated just with dimyristoylphosphatidylcholine DMPC, which is a kind of phospholipid situated in the outside moiety of the human erythrocyte layer (Suwalsky et al, 1997). Extra examinations performed on frog thoughtful neural connections demonstrated a huge abatement in the potential contrast and short out current reactions after use of heptachlor. These outcomes have been deciphered as a hindrance of the dynamic transport of particles affected by the pesticide (Quevedo et al, 1997). It can be concluded, therefore, that toxic effects of heptachlor are related to its perturbation of the structure of phospholipid bilayer, which is important for cell membrane functions. Endosulfan, aldrin and dieldrin showed to act as antagonists of androgen receptors based on in vitro assay (Andersen et al., 2002; Li et al., 2008 \& Nativelle-Serpentini et al., 2003). They were examined to repress the aromatase protein (CYP19) and also repress the rate-restricting chemical of estrogen and rostenedione. Like different organochlorines, endosulfan and dieldrin adjust the estradiol digestion system by impelling CYP1 compounds (Badawi et al., 2000; Bradlow et al., 1995). Concentration of (5M) dieldrin and (1 M) endosulfan showed significant enhancement on the cell proliferation and ER transactivation gene response in MCF-7 cells as examined by vitro assay (Andersen $e t$ al., 2002). Endosulfan brought on adjustments in testicular capacities at high measurements. 
Methoxychlor has been indicated to prompt testicular apoptosis in rats taking after oral presentation to single measurements of $50 \mathrm{mg} / \mathrm{kg}$ b.wt (Vaithinathan et al., 2010). However, if the dosages contrasted with those commonplaces of word related and ecological exposures, the dosages tried are unrealistically high.

The $\alpha$-isomer of BHC among 8 isomers, has been ordered as a non-genotoxic cancer-causing agent on the grounds that it impels hepatocellular carcinomas in rodents with high measurement long haul organization yet needs mutagenicity in the Ames test (Nagasaki, 1975). Worry about the conceivable antagonistic wellbeing impacts of long haul introduction to this compound in people has prompted it being banned or confined in industrialized nations. Despite the fact that it has been named a non-genotoxic cancer-causing agent, a few examinations showed that high amassing of $\alpha$-BHC displayed restraining impact on liver tumor development impelled by some known cancer-causing agents in rat (Angsubhakorn et al, 1981) and (Thamavit et al, 1975). These results are raise concerns as to how $\alpha$-BHC plays a role in hepatocarcinogenesis (Puatanachokchai, 2006).

Shi et al. (2011) demonstrated that more than $30 \mu \mathrm{M}$ fixations of $\beta$-BHC prompted the apoptotic cell in Sertoli cells of rodent connected with FasL levels expanded articulation which could prompt the Fas initiation. Impel of apoptosis may occur duo to these two qualities. $\beta$-BHC has been demonstrated to incite actuation of caspase-3, which cause initiation of cell apoptosis (Khan et al., 2000) and caspase-8, which believed to be part in transduction of death signal (Said et al., 2004). 
Effects on the central nervous system which cause muscle contractions and hyperexcitability, and in severe cases death may be consequences of endrin ingestion (Curley et al. 1970 \& Runhaar et al. 1985). Exposure of animals to endrin causes central nervous system effects, particularly convulsions (Deichmann et al. 1970 \& Quick et al. 1989). In animals exposed to lethal doses of endrin, unspecific degeneration of the liver, kidney, and brain has been observed (Treon et al. 1955).

Massive doses of chlordane $(350 \mathrm{mg} / \mathrm{kg}$ ) administered intraperif (intraperit to laboratory rats produced progressive behavioral manifestations of poisoning: early perceptual intolerance with increased respiratory involvement; reflex muscular activity leading to ataxia; and, finally tonic paralysis and death (Hyde \& Falkenbegr, 1976). Chlordane probably causes cancer and can cause liver cancer, behavioral disorders in children, problems in the endocrine system, nervous system, digestive system, and liver (EPA, 2011). 


\subsection{Pesticides use in the Arab countries}

There is a lack of and a gap in the provision of recent data on the use of pesticides in Arab countries. Fewer than half the Economic and Social Commission for Western Asia member countries provided data for year 2000, and only two countries provided such data for year 2001 (Table 6). Syria and Yemen were the countries that showed the highest consumption of insecticides in year 2000 .

Table 6: Total insecticides consumption in tons per year (Bashour, 2009).
\begin{tabular}{lrr} 
Country & 2000 & 2001 \\
\hline Bahrain & 7 & 6 \\
\hline Iraq & 190 & $\ldots$ \\
\hline Jordan & 61 & $\ldots$ \\
\hline Oman & 91 & $\ldots$ \\
\hline Qatar & 60 & $\ldots 94$ \\
\hline Syria & 1,219 & $\ldots$ \\
\hline Yemen & 933 &
\end{tabular}

The data in Figure 4 shows that the rates of pesticides usage per hectare in 13 Arab countries in 2002. Lebanon, Kuwait and Qatar showed the highest consumption per hectare of pesticides among these countries. They are 2 to 3 times the rates used in Egypt, Jordan and Oman (Bashour, 2009). 
Figure 4: Amount of pesticides used in kg/ha in selected Arab countries (Bashour, 2009).

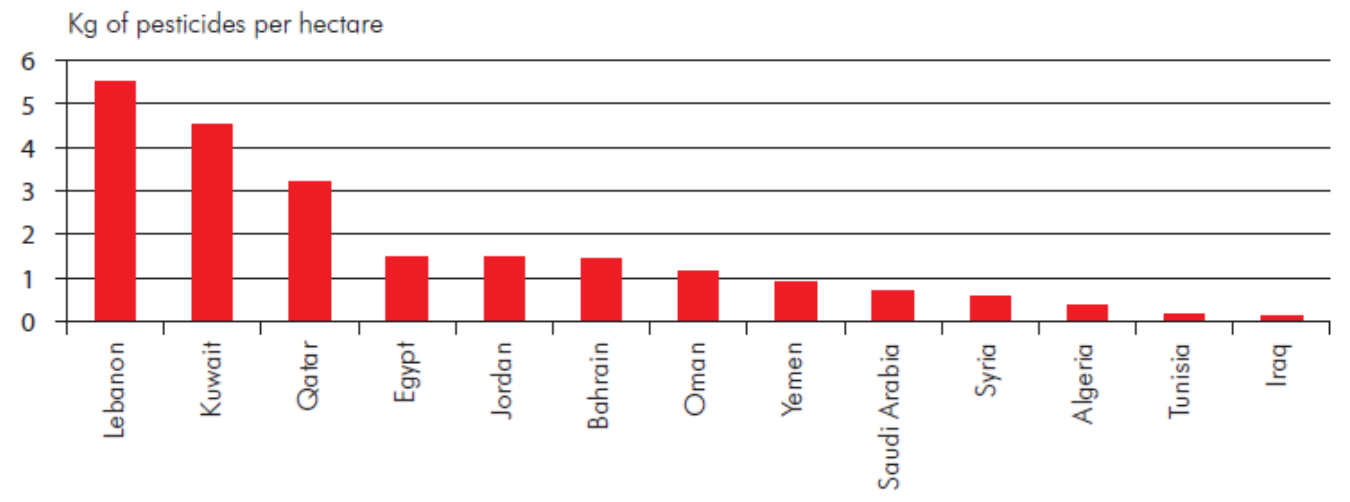

The Knoema Resource Statistics for Saudi Arabia (Figure 5) showed the annual pesticides consumption in tones in the years 2007, 2012 and 2013 according to the Food and Agriculture Organization. The rate of consumption of insecticides, fungicides and bactericides has been increased. No recent data is available for the use b consumption of pesticides in Qatar.

Figure 5: Pesticides consumption in Saudi Arabia (Knoema Resource Statistics, FAO, 2013)

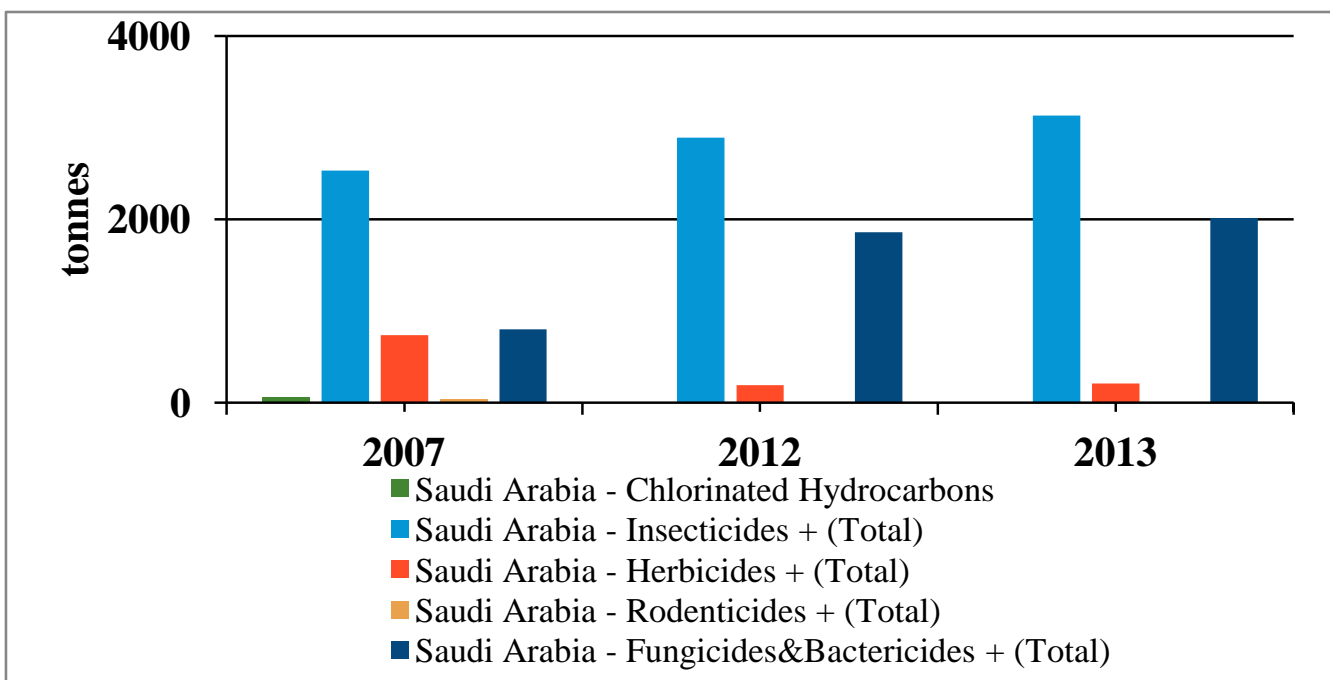




\subsection{Techniques used to analyze the residues of pesticides in food products}

Since pesticides have wide ranging chemistries within the contaminants, the analysis poses a number of challenges for laboratories and operators. Many techniques including: Gas chromatography-mass spectrometry (GC-MS), Gas chromatography-electron capture detector (GC-ECD), Gas chromatography/ flame photometric detector (GC/FPD), Liquid chromatography-mass spectrometry (LCMS) and High-performance liquid chromatography (HPLC) were used to analyze the residues of pesticides in many products such as: water, milk, fish, chicken, egg, meat, fruit and vegetables (Essumang et al., 2009; Ahmad, 2010; Jardim, 2014; Hjorth et al., 2011; Ortelli, Edder, \& Corvi, 2006; Knez`evic’ \& Serdar, 2009).

Chromatography is a set of laboratory techniques for the separation of mixtures (USDA, 2012). Gas chromatography (GC) is definitely one of the main techniques used for detection, identification and quantification of many groups of non-polar or semi-polar substances. GC has high separation power in combination with a wide range of detectors, thus it is a unique tool in the analysis of ultra trace levels of toxic compounds that may occur in foods and feeds since (Hajšlová, 2007).

GC with electron capture detector (ECD) is used to analyze halogenated compounds and is primarily used in the environmental, forensic and pharmaceutical markets. Within an ECD, when certain molecules pass by the detector, they capture some of the electrons in the sample and this reduces the current measured. The compensation for this reduction is recorded as a positive peak. The 
flame photometric detector (FPD) enables accurate and sensitive detections of volatile sulfur and phosphorus compounds. The principle of detection is done in a reducing flame by formation of excited sulfur and excited hydrogen phosphorous oxide species. The characteristic chemiluminescent emission from these species measured by a photomultiplier tube. Identification and quantification of a wide range of organic compounds are done by GC/MS. GC/MS separates the complex sample matrices into their component parts by utilizing a compound's intrinsic affinity for a stationary phase. Identification of compounds by their mass spectra is carried out by using mass Spectrometry Detection. The identification is done by comparing the obtained mass spectra (each compound has a single mass spectrum) with a mass spectral database.

Unlike gas chromatography, Liquid chromatography (LC) can be removed securely a very wide range of organic compounds from small drug metabolites molecules to peptides and proteins. An LC/MS is an HPLC system with a Mass Spectrometry Detector. The Mass Spectrometry Detector (MS) coupled with an LC scans the molecules and produces a full spectrum of high resolution, separating all ions having different masses.

Multi-residue methods based on LC/MS are increasing by being used in this field, however, GS/MS methods still play a significant role in analyzing residues and in some cases it becomes the only method of choice. Table 7 summarizes the techniques that were used to find out the pesticides residues in fruits and vegetables. 
Table 7: Techniques for determination of pesticides residues in fruit and vegetables

\begin{tabular}{|c|c|c|}
\hline Sample & Technique & Reference \\
\hline $\begin{array}{l}\text { Apples, Arugula, Apricot, Aubergine, Banana, } \\
\text { Bean, Carrot, Cabbage, Cherry, Cauliflower, Grape, } \\
\text { Cucumber, Kiwifruits, Leek, Lemon, Lettuce, } \\
\text { Orange, Mushroom, Peaches, Onion, Pear, Pepper, } \\
\text { Plum, Potato, Pomegranate, Purslane, Strawberry, } \\
\text { Tomato, Tangerine }\end{array}$ & $\begin{array}{l}\mathrm{GC}-\mathrm{ECD} \text { and } \\
\mathrm{GC}-\mathrm{MS}\end{array}$ & Bakirci et al., 2014 \\
\hline $\begin{array}{l}\text { Apple, Grape, Broccoli, Leafmustard, Cabbage, } \\
\text { Lettuce, Capsicum, Orange, Cauliflower, Pakchoi } \\
\text { cabbage, Peach, Chinese cabbage, Pear, Cucumber, } \\
\text { Radish, Eggplant, Spinach, Legumes, Tomato }\end{array}$ & $\mathrm{GC}-\mathrm{ECD}$ & Chen et al., 2011 \\
\hline Fruits and vegetables & $\mathrm{GC}-\mathrm{MS}$ & $\begin{array}{c}\text { Knez'evic' \& Serdar, } \\
2009\end{array}$ \\
\hline $\begin{array}{l}\text { Cherry, Apricot Peach Grape Pepper Tomato } \\
\text { Spinach Courgette Cucumber }\end{array}$ & $\mathrm{UPLC} / \mathrm{MS} / \mathrm{MS}$ & Bakirci\& Hisil, 2011 \\
\hline Cashew apple, guava, kaki and peach & $\begin{array}{c}\mathrm{GC}-\mathrm{ECD} \\
\mathrm{GC}-\mathrm{FPD} \text { and } \\
\mathrm{LC}-\mathrm{MS} / \mathrm{MS}^{1}\end{array}$ & Jardim, 2014 \\
\hline Fat vegetable matrices like avocado & $\begin{array}{c}\text { LP-GC-MS- } \\
\mathrm{MS}^{2}\end{array}$ & Moreno et al, 2006 \\
\hline
\end{tabular}

${ }^{1}$ Liquid Chromatography-Tandem Mass Spectrometry

${ }^{2}$ Low-Pressure Gas Chromatography-Tandem Mass Spectrometry 


\section{METHODOLOGY}

\subsection{Materials}

\subsubsection{Chemicals and reagents}

Organic solvents to dissolve and extract samples were acetone and hexane purchased from Sigma-Aldrich (USA). Standard solutions were prepared from the stock solution (100ppm) that were prepared from Pesticide Mix Standard (Z-014C-R, $1 \mathrm{~mL}, 2 \mathrm{mg} / \mathrm{mL}$ in Toluene: Hexane 1:1, 20 compounds) diluted in Hexane. Decachlorobiphenyl (M-8082-ISC-WL-10mL, $5 \mu \mathrm{g} / \mathrm{mL}$ in Hexane) was used as surrogate standard. The Pesticide Mix Standard and Decachlorobiphenyl were purchased from AccuStandard (USA). All standard solutions were stored in refrigerator at $4^{\circ} \mathrm{C}$. Anhydrous sodium sulfate was obtained from Fluka (SigmaAldrich (USA)). Dionex ASE Prep DE (Diatomacceous earth) was used in the extraction procedure.

\subsubsection{Glassware and general instruments}

An Accelerated Solvent Extractor (Dionex ASE 200 and ASE 350), solvent evaporator (Dionex SE 500), AS 220.R2 analytical balance, and Stuart- orbital shaker were used. Additionally, a mortar, pestle, extraction cells, cellulose filter disks, collection vials $(60 \mathrm{ml})$, caps, test tubes, pipettes and spatulas were used in the extraction protocol. Moreover, gloves, funnels, volumetric flasks, beakers, and GC 
vials were used. GC7890A/MS 5973 and GC6890N/ECD (Agilent, Santa Clara, USA) were used for the quantification analyses.

\subsection{Preparation of standard solutions}

100ppm stock standard solution was prepared by adding $1 \mathrm{~mL}$ of Pesticide Mix Standard (Z-014C-R, 1mL, 2mg/mL in Toluene: Hexane 1:1, 20 compounds) in to 20mL volumetric flask and add Hexane up to the mark. Calibration standard solutions were prepared from the $100 \mathrm{ppm}$ stock solution with a range between $5 \mathrm{ppb}$ to 1000 ppb. Figure 6 shows the preparation of standards in the ESC lab at Qatar University. The chromatogram of the prepared standard solution for 10 selected OCPs (Heptachlor, aldrin, dieldrin, Endrin, a-chlordane, g-chlordane, endosulfane I, methoxychlor, $\alpha-\mathrm{BHC}$ and $\beta-\mathrm{BHC}$ ) is shown in (Figure 7).

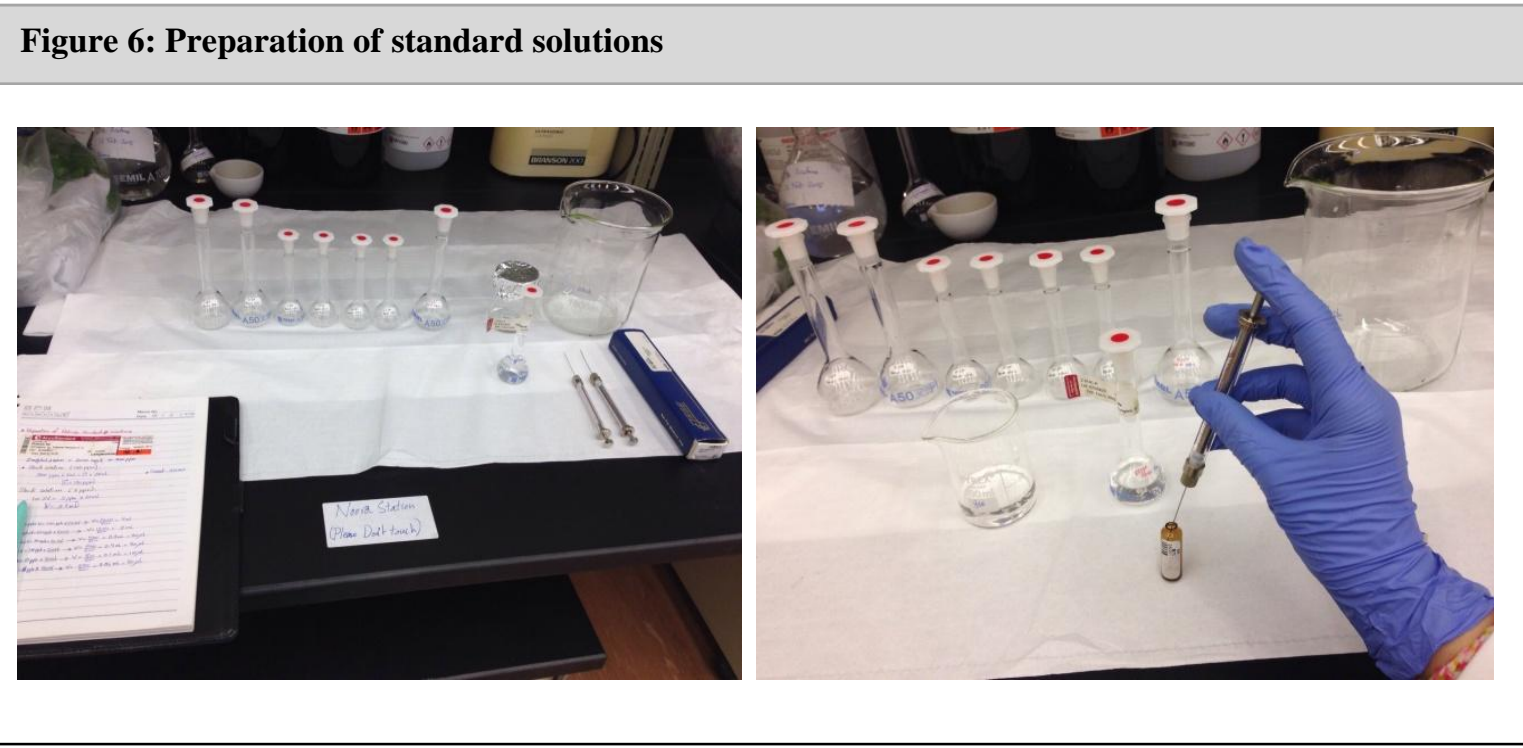


Figure 7: Chromatograph of 100ppb of the 10 selected OCPs by GC/ECD.

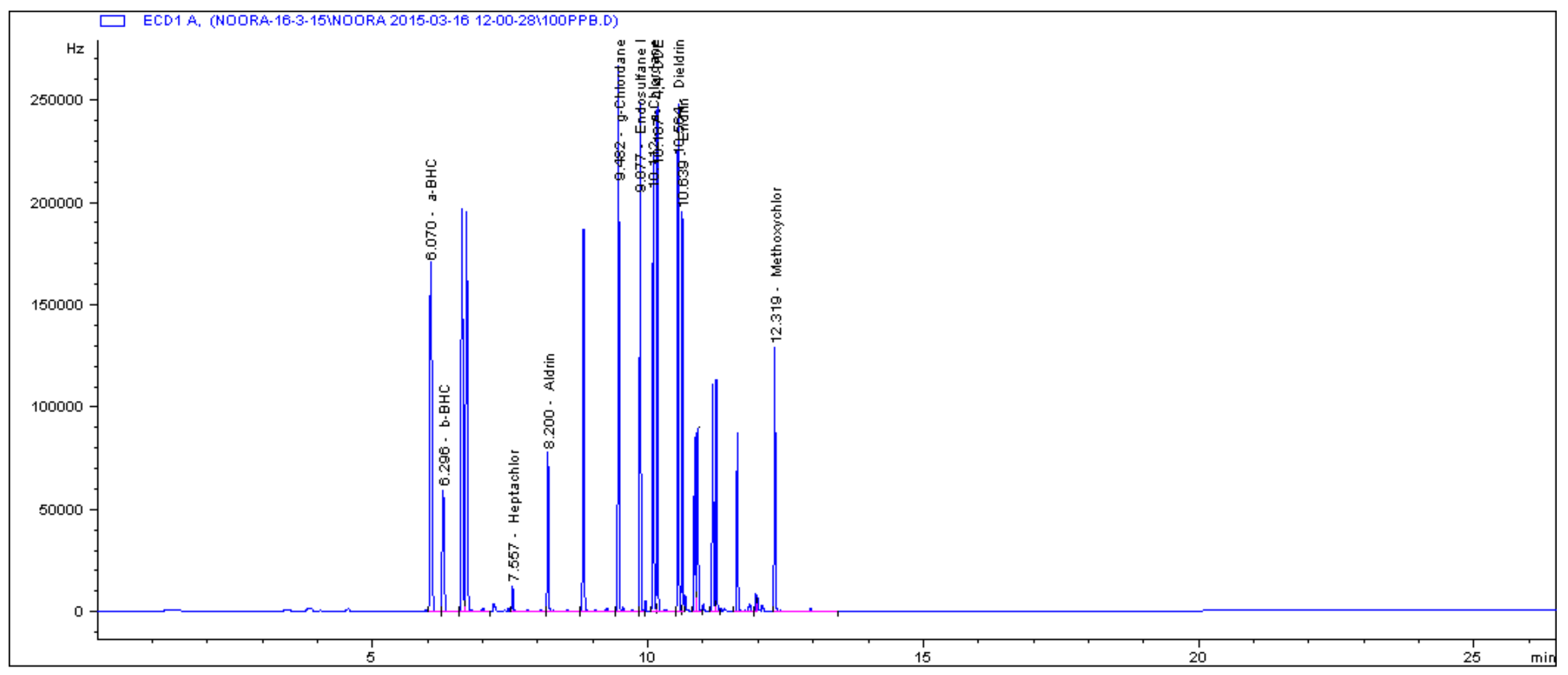




\subsection{Samples collection}

Various samples of vegetables and fruit from local and imported sources were sourced from different locations in Qatar. The local samples were collected from AlMazrouah hall located in Umm Salal Ali where they sell fresh domestic vegetables and fruits from the 34 of the most prominent local farms (Figure 8). Meanwhile, the imported samples had been collected from the local markets: Market1, Market2 and Market3. The samples of leafy vegetables (parsley and watercress), vegetables (cucumber, tomatoes and potatoes), and fruits (lemons and strawberries) of each crop had two samples (domestic and imported).

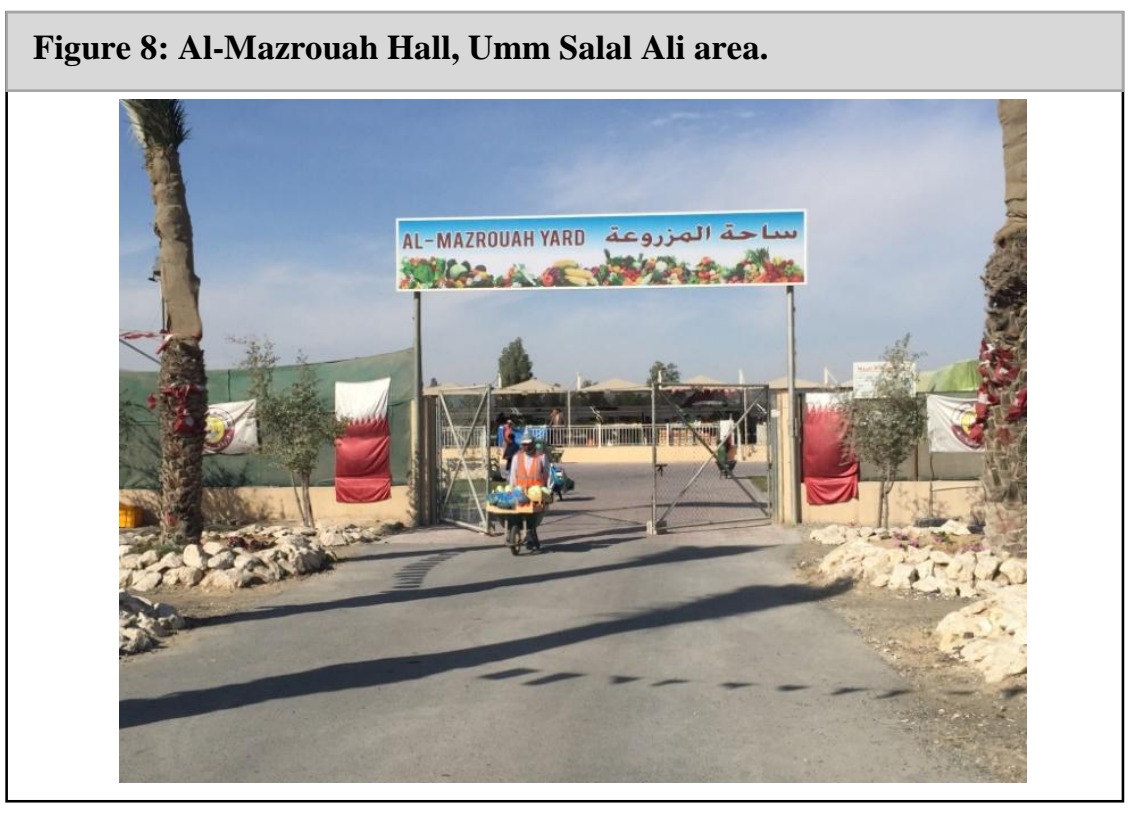

A total samples consist of 127 samples of seven vegetables and fruits were examined including two groups: local and imported, and two sub groups: washed and unwashed samples. The samples taken included: 26 samples of fruits and 101 samples 
of vegetables. Samples were extracted within 24 hours and stored at $4^{\circ} \mathrm{C}$ until the analysis.

The simple random sampling and stratified random sampling were used as sampling procedures for collecting the vegetables and fruits. For all vegetables and fruits except strawberries, simple random sampling was used. For strawberries sampling, the stratified random sampling procedure was used. The overall of sampling collection is shown in Figure 9.

\section{Figure 9: Overall of sampling collection.}

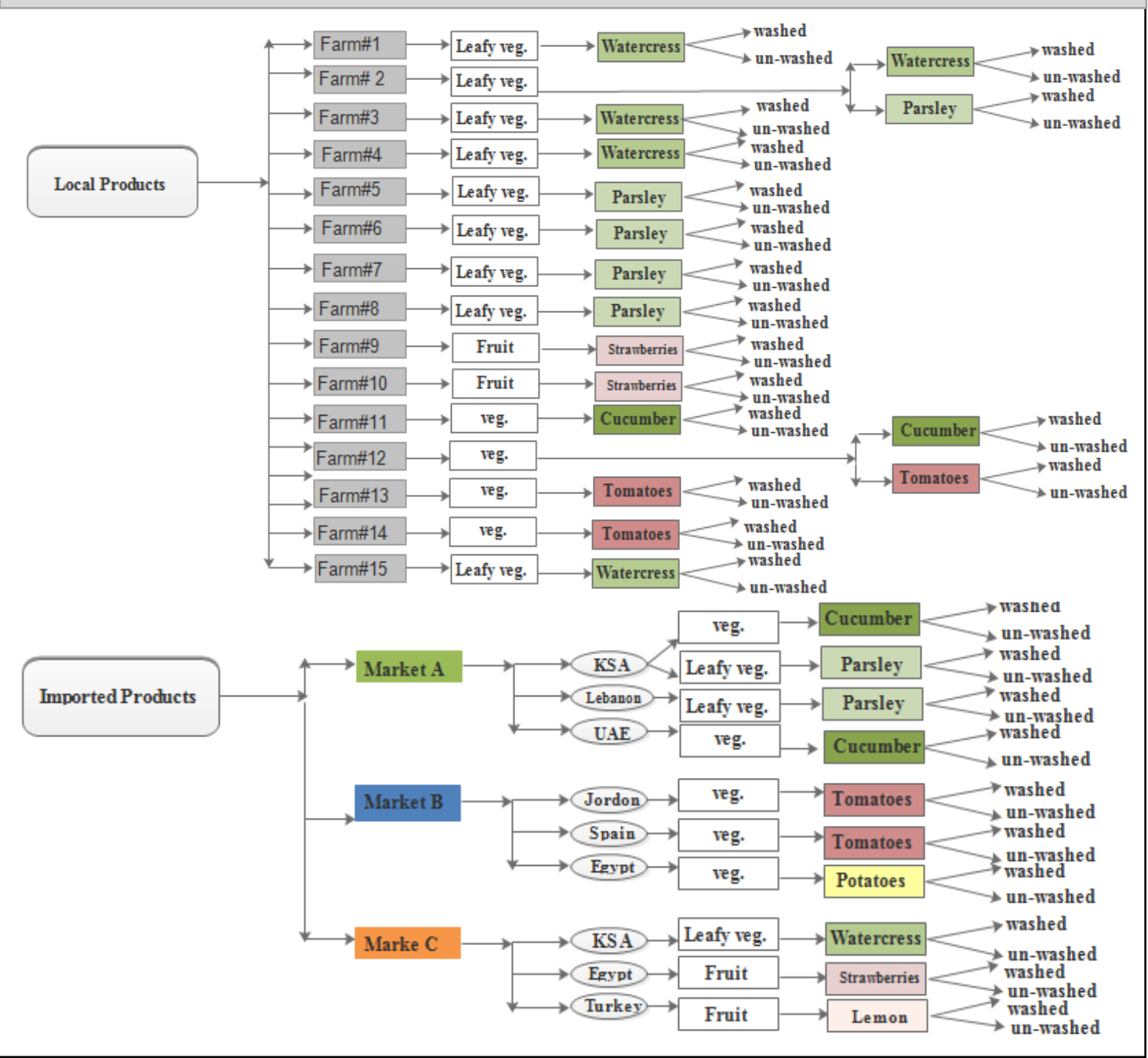




\subsection{Samples preparation and extraction}

Over the past 30 years, various methods have been published that are linked to particular analytical techniques for determining OCPs in food and environmental matrices. On the other hand, many books that summarize methods are available. For example, EPA methods for determination of OCPs in sediment and biological samples are outlined by Keith (Keith, 1996). Methods for separating, isolating and recovering of OCPs from sediment, soils and biological samples were reviewed and recommended by Wells and Hess (Wells \& Hess, 2000). Overview of modern analytical methodology for OCP and PCBs were provided by De Boer and Law (Boer \& Law, 2003).

The EPA Method 8081A (Appendix 2) was chosen as a reference method for the preparation and extraction method with some modification. Additionally, the Dionex Application Note 332 "Accelerated solvent extraction of pesticide residues in food products", 2012, was used as extraction method for vegetables and fruits (Appendix 3). The fresh fruits and vegetables samples were collected from farms and market a day before extraction. Each sample was divided in to two groups: washed sample with water and unwashed sample. No sample digestion is needed prior to extraction.

Samples were extracted using Dionex - Accelerated Solvent Extractor (ASE 200 and ASE 350). The extraction conditions are shown in Table 8. 
Table 8: Extraction Conditions (Dionex Application Note 332, 2012).

\begin{tabular}{ll}
\hline Temperature: & $100^{\circ} \mathrm{C}$ \\
\hline Pressure: & $1500 \mathrm{psi}^{*}$ \\
\hline Heatup Time: & $5 \mathrm{~min}$ \\
\hline Static Time: & $5 \mathrm{~min}$ \\
\hline Flush Volume: & $60 \%$ \\
\hline Purge Time: & $100 \mathrm{~s}$ \\
\hline Static Cycles: & $1-2$ \\
\hline Total Extraction Time: & $14-18$ min per sample \\
\hline Total Solvent Used: & $15-45 \mathrm{~mL}$ per sample
\end{tabular}

-Pressure studies show that 1500 psi is the optimum extraction pressure for all accelerated solwent extraction applications. 


\subsubsection{Extraction procedure}

The washed samples were washed under tap water for 2 min and dried by tissue

before weighing. Figure 10 shows the extraction procedure that was carried out.

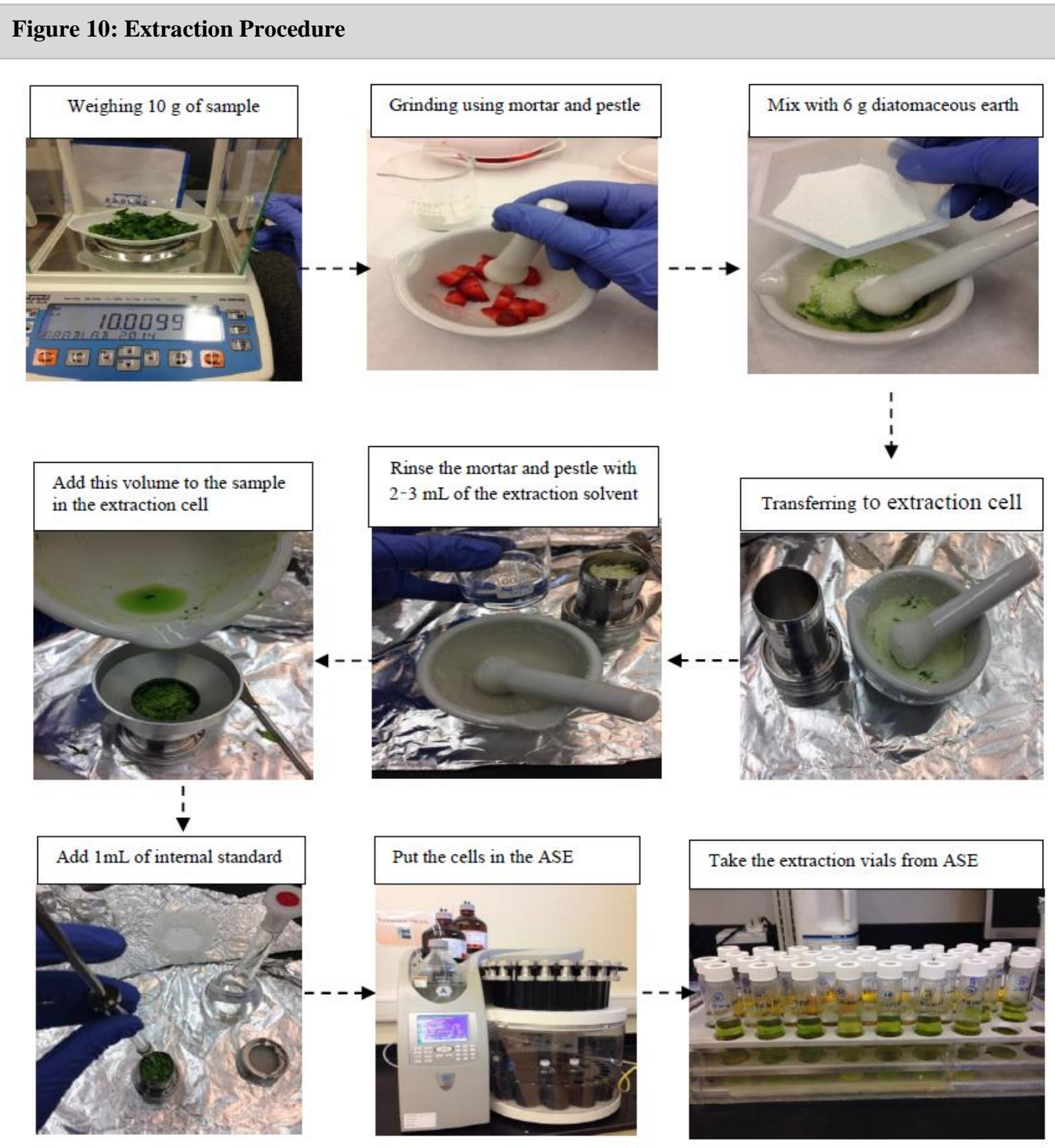




\subsection{Samples Clean-up}

A clean-up procedure is usually carried out to remove co-extracted compounds that may cause interference in the chromatographic determination or be detrimental to the analytical instrumentation. Following extraction, $5 \mathrm{~g}$ of anhydrous sodium sulfate were added to the collection vial to adsorb co-extracted water. The vial was shaken for $15 \mathrm{~s}$ and the water-free extract was decanted into a clean vial (Figure 11) (Appendix 3).

\section{Figure 11: Post extraction step}

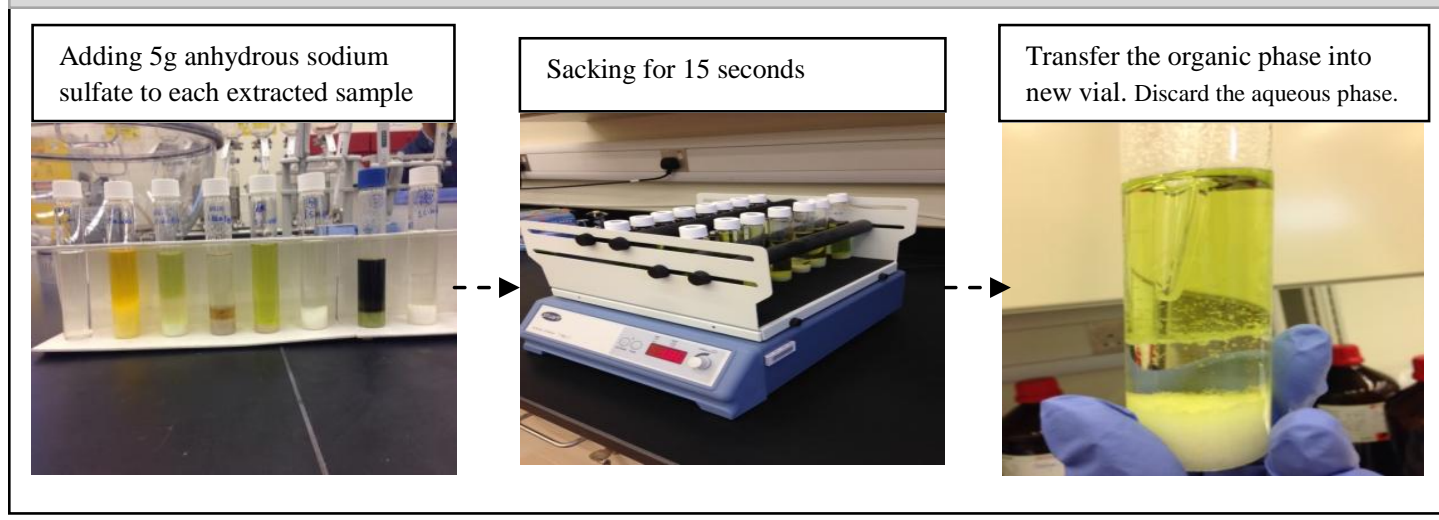

Two solid phase extraction techniques were used (Florisil and Silica Gel). The EPA method 3620C- Florisil Cleanup and Method 3630C- Silica Gel Cleanup were used as reference methods for cleaning the samples (Appendix 4 \& Appendix 5). All samples were cleaned up using $2 \mathrm{~g}$ Florisil Clean-Prep Cartridge. However, some interferants that are not removed by Florisil Cartridge would be removed by a second cleanup technique which was Silica Gel cleanup. Figure 12 shows the Florisil Cleanup procedure. 


\section{Figure 12: Cleanup procedure}

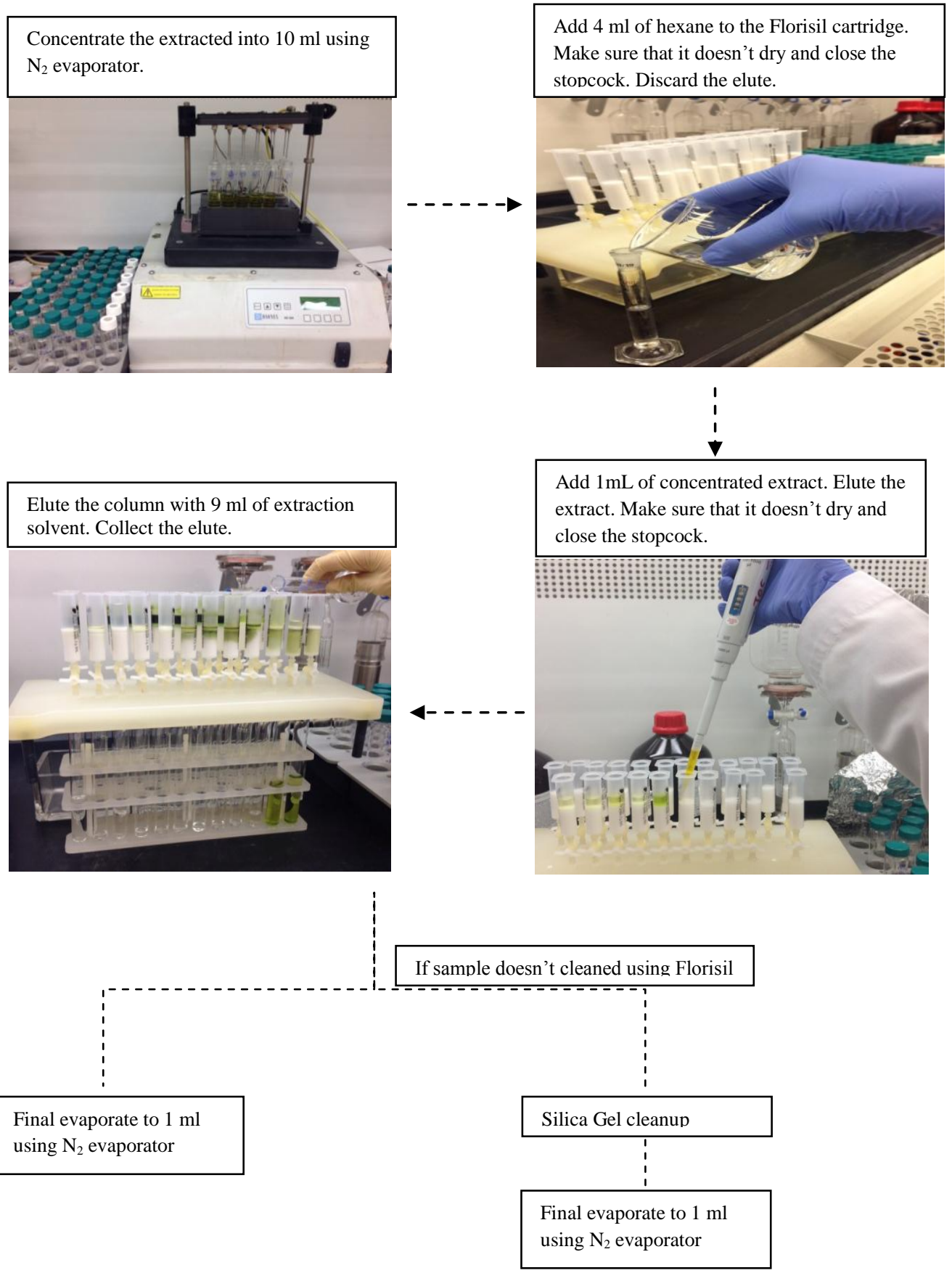




\subsection{Quality Control and Quality Assurance Measures (QC/QA)}

The Limit of detection and limit of quantitation were calculated for all analytes as mentioned in (Appendix 6). In general, "the Limit of detection (LOD) is defined as the lowest concentration of an analyte in a sample that can be detected under the stated conditions of the test. The Limit of quantitation (LOQ) is the lowest concentration of an analyte in a sample that can be determined with acceptable precision and accuracy under the stated conditions of test" (Analytical Procedures and Methods Validation, 2000). The LOD and LOQ were calculated using 10 samples of the lowest concentration of spike (10ppb) (Shrivastava \& Gupta, 2011). Refer to Appendix 6 for calculation data.

Table 9: Limit of Detection (LOD) and Limit of Quantitation (LOQ) calculated from the calibration line at low concentration.

\begin{tabular}{|c|r|r|}
\hline Analyte & LOD $/ \mathbf{p p b}$ & LOQ $/ \mathbf{p p b}$ \\
\hline a-BHC & 1.999 & 6.663 \\
\hline b-BHC & 1.538 & 5.125 \\
\hline Heptachlor & 2.293 & 7.641 \\
\hline Aldrin & 1.601 & 5.338 \\
\hline g-Chlordane & 2.061 & 6.870 \\
\hline Endosulfane I & 2.287 & 7.624 \\
\hline a-Chlordane & 2.577 & 8.593 \\
\hline Dieldrin & 1.923 & 6.408 \\
\hline Endrin & 1.923 & 6.408 \\
\hline Methoxychlor & 1.712 & 5.707 \\
\hline
\end{tabular}


The evaluation of the recoveries of studied pesticides were done by adding known concentration of an internal standard (Decachlorobiphenyl) to about 10\% of total number of samples. The Range from $93.6 \%$ to $106.6 \%$ was the percent recoveries in spiked samples. Table 10 shows the recoveries of the Decachlorobiphenyl.

\begin{tabular}{|c|c|c|c|}
\hline $\begin{array}{c}\text { Sample } \\
\#\end{array}$ & $\begin{array}{c}\text { Spiked concentration } \\
\text { /ppb }\end{array}$ & Recovered concentration/ppb & Recovery/\% \\
\hline 1 & 50.00 & 47.34 & 94.68 \\
\hline 2 & 50.00 & 46.80 & 93.60 \\
\hline 3 & 50.00 & 53.30 & 106.60 \\
\hline 4 & 50.00 & 53.00 & 106.00 \\
\hline 5 & 50.00 & 52.30 & 104.60 \\
\hline 6 & 50.00 & 48.40 & 96.80 \\
\hline 7 & 50.00 & 48.30 & 96.60 \\
\hline 8 & 50.00 & 50.90 & 101.80 \\
\hline 9 & 50.00 & 48.80 & 97.60 \\
\hline 10 & 50.00 & 50.18 & 100.36 \\
\hline
\end{tabular}

\subsection{Samples Analysis}

The samples analysis was conducted using a GC-electron capture detector (ECD), and by GC-MS scan mode (Figure 13). The GC/ECD analyses were performed on an Agilent $6890 \mathrm{~N}$ equipped with a splitless injector and a 7683 autoinjector (Agilent, Santa Clara, USA). The analysis by GC/MS was carried out on an Agilent 7890A MSD 5973 equipped with a split/splitless Inlet and a 7683B 
autoinjector (Agilent, Santa Clara, USA). Separations were conducted using an HP-1 $30 \mathrm{~m} 0.25 \mathrm{~mm} 0.25 \mu \mathrm{m}$ column for GC/ECD and Rxi-5SILMS $30 \mathrm{~m} 0.25 \mathrm{~mm} 0.25$ $\mu \mathrm{m}$ column (Agilent, Santa Clara, USA) for the GC/MS.

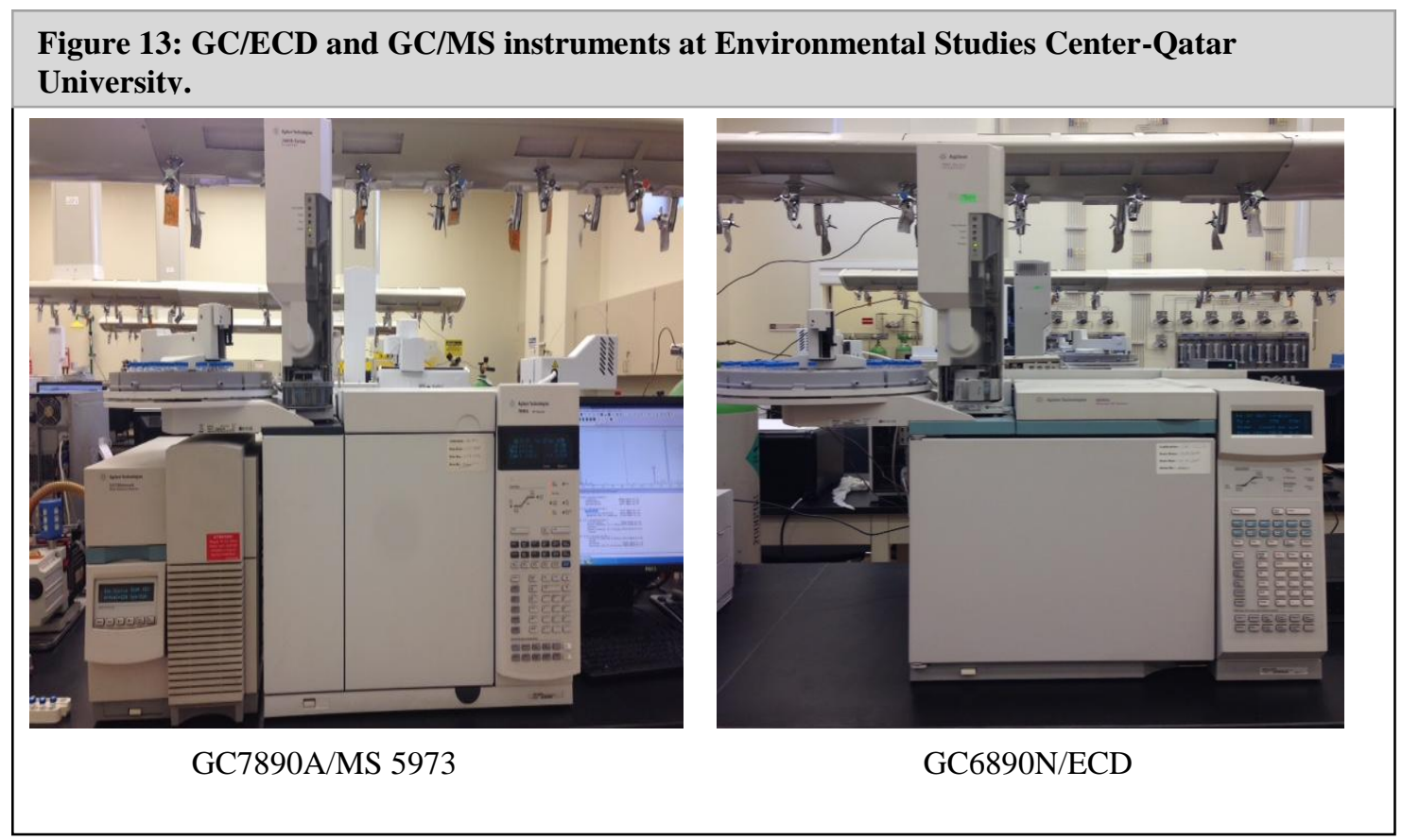

For the GC/ECD, samples were analyzed as follows: the program initial temperature was set at $110^{\circ} \mathrm{C}$ (held for $0.5 \mathrm{~min}$ ), increased to $320^{\circ} \mathrm{C}$ at $10^{\circ} \mathrm{C} / \mathrm{min}$ (held for $5 \mathrm{~min}$ ). Helium was used as carrier gas at a flow rate of $3.5 \mathrm{ml} / \mathrm{min}$, pressure at $20.90 \mathrm{psi}$ and average velocity at $85 \mathrm{~cm} / \mathrm{sec}$. Nitrogen gas was used as makeup gas at pressure 50 psi. The injection volume was $1 \mu 1$, and the injector temperature was held at $250^{\circ} \mathrm{C}$.

Analyses by GC/MS were carried out as follows: the program initial temperature was set at $70^{\circ} \mathrm{C}$ (held for $0.5 \mathrm{~min}$ ), increased to $250^{\circ} \mathrm{C}$ at $25^{\circ} \mathrm{C} / \mathrm{min}$, 
raised to $290^{\circ} \mathrm{C}$ at $5^{\circ} \mathrm{C} / \mathrm{min}$ (held for $3.5 \mathrm{~min}$ ). Helium was used as carrier gas at a flow rate of $1.4 \mathrm{ml} / \mathrm{min}$, pressure $11.747 \mathrm{psi}$, and average velocity $1.595 \mathrm{~min}$. The injection volume was $1 \mu \mathrm{l}$, and the injector temperature was held at $300^{\circ} \mathrm{C}$. The GC/MS data were acquired and processed with a wiley7n.1 and NIST98 Libraries.

\subsection{Statistical Data Analysis}

In this project two statistical analysis tests were used, pair-difference t-test and analysis of variance (ANOVA). The pair-difference t-test is simply used to test two independent populations have different mean values on some measure (Statistical Consultant, 2015). By using the t-test statistic we check the significant difference by determining the p-value between washed and unwashed samples. The analysis of variance (ANOVA) was used to compare between two factors.

To compare all possible pairs of means for heptachlor in parsley, using of the least significant difference (LSD) was necessary. The LSD formula is shown below:

$$
L S D=t_{\alpha} \sqrt{M S_{E}\left(\frac{1}{n_{i}}+\frac{1}{n_{j}}\right)}
$$

Where:

$\mathrm{t}=$ critical value from the $\mathrm{t}$-distribution table $\mathrm{MS}_{\mathrm{E}}=$ mean square error, obtained from the results of ANOVA test $\mathrm{n}=$ number of samples used to calculate the means

If the difference between means is greater than or equal LSD value, then the difference is significant. Otherwise, the difference is not significant. 


\section{RESULTS AND DISSCUSION}

A total 127 samples were analyzed, 101 samples of vegetables (cucumbers, tomatoes, potatoes, parsley, watercress) and 26 samples of fruits (strawberries, lemon). About 58 samples were local, and 69 were imported. The origin of analyzed samples is shown in Figure 14.

Figure 14: Origin of analyzed samples

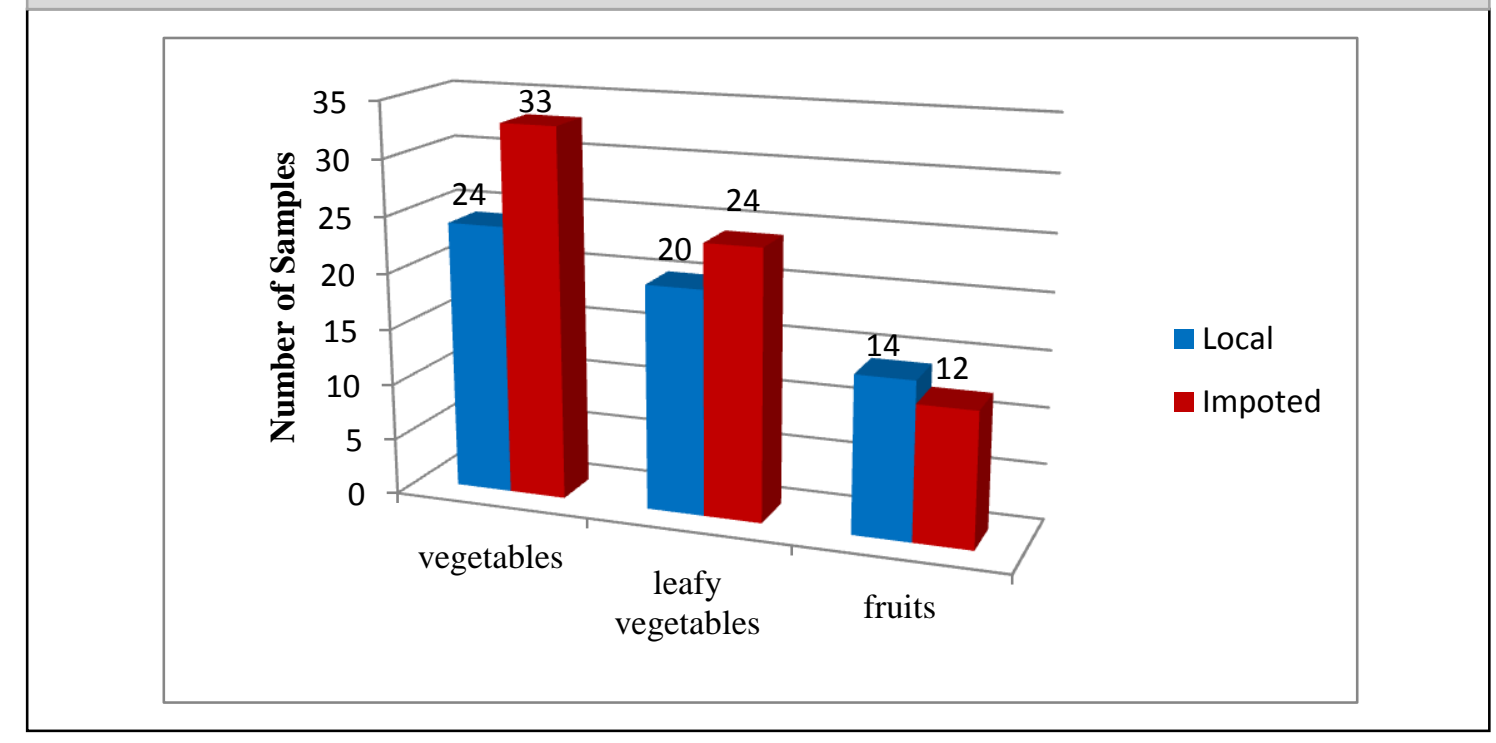

Figure 15 presents the number of samples according to its commodity. Since the season of production of local lemon and potatoes was inconsistent with the project time (the season production in May), only imported lemon and potatoes samples were analyzed. 
Figure 15: Distribution of samples by commodity

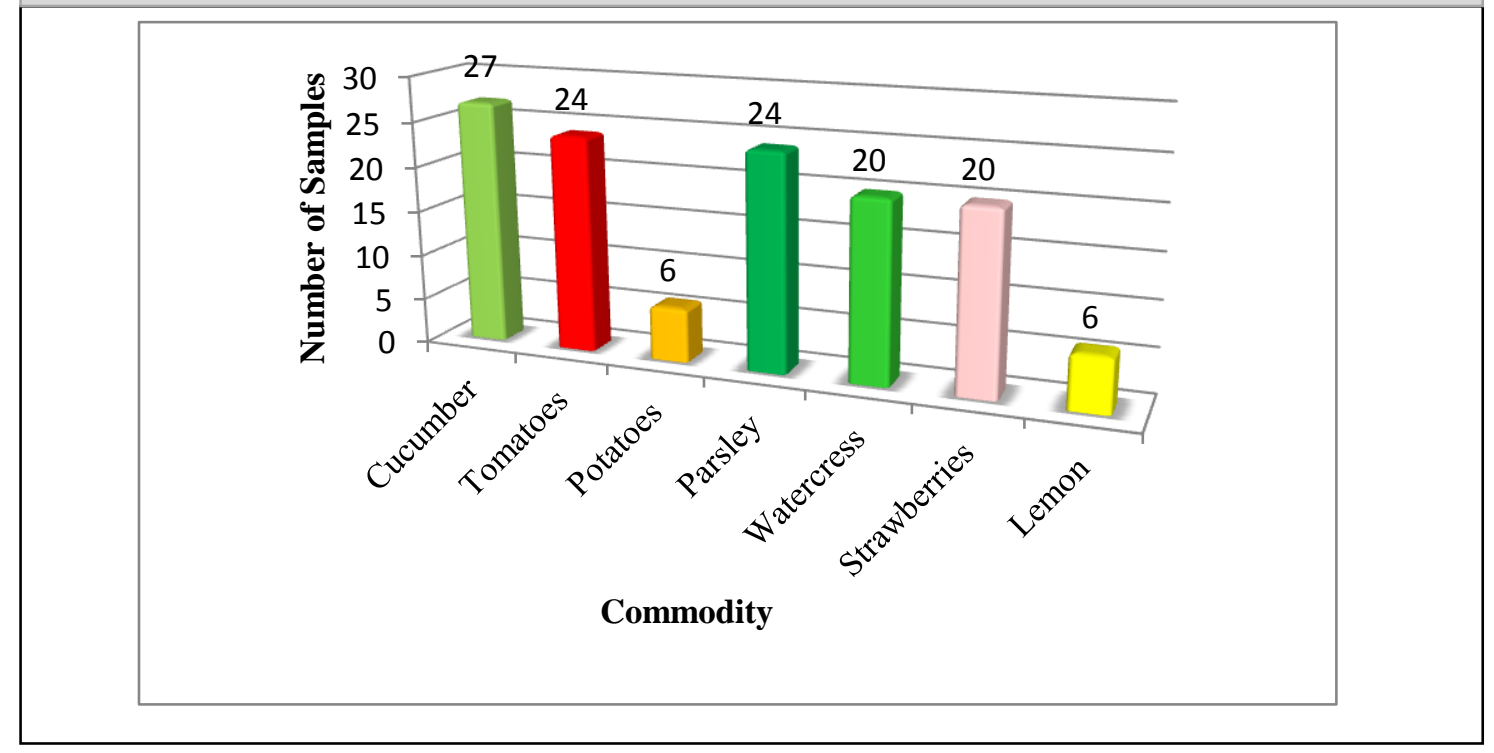

The imported vegetables and fruit samples were collected from three Markets in Qatar: Market A, Market B, and Market C as mentioned in Figure 9. These markets are the most popular places as most Qatar residents buy from them. Thus, in our collection of the imported samples from these markets, for each crop the high percentages of offering countries were considered. Figure 16 shows the percentages of selected vegetables and fruit in the three Markets (A, B \& C). 
Figure 16: Percentages of selected vegetables and fruit in the three Markets (A, B \& C).

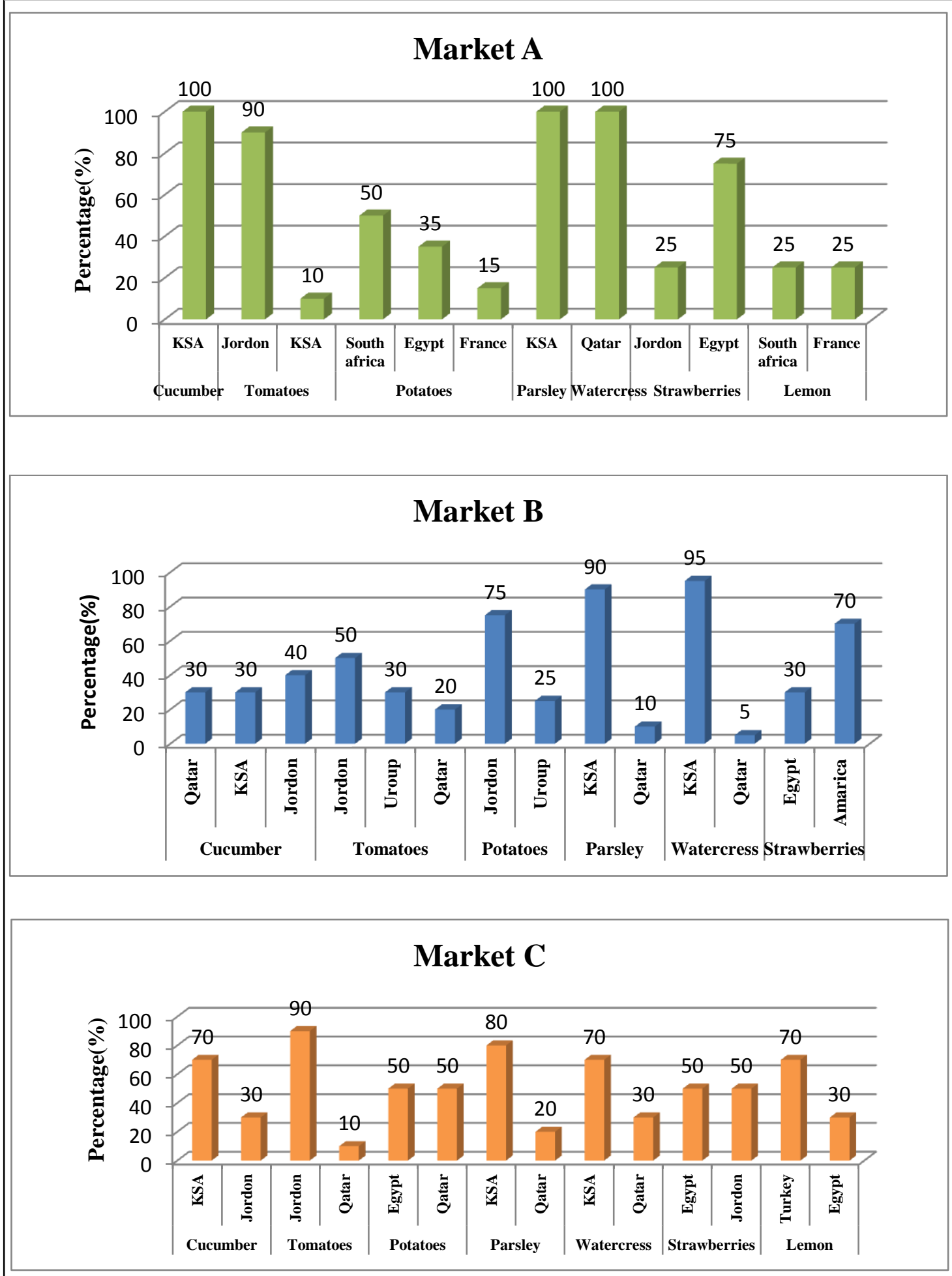




\subsection{Organochlorine Residues in vegetables and fruit samples}

This study is the first extensive study to determine the levels of pesticide residues on various vegetables and fruit commonly consumed in Qatar. Residues of 10 OCPs (Heptachlor, aldrin, dieldrin, Endrin, a-chlordane, g-chlordane, endosulfane I, methoxychlor, $\alpha$-BHC and $\beta-$ BHC) were identified for local and imported vegetables and fruit using GC/ECD.

According to the origin of samples, the number of samples containing residues above MRL is shown in Figure 17. The imported samples were higher than local samples in exceeding the MRL. About 57 samples (90\%) of the imported samples were above the MRL in containing at least 1 of the selected organochlorine pesticides, whereas about 22 samples (30\%) of local samples showed residues above the MRL in containing at least 1 of the selected organochlorine pesticides.

Figure 17: Occurrence of residues of pesticide in fruit and vegetables samples.

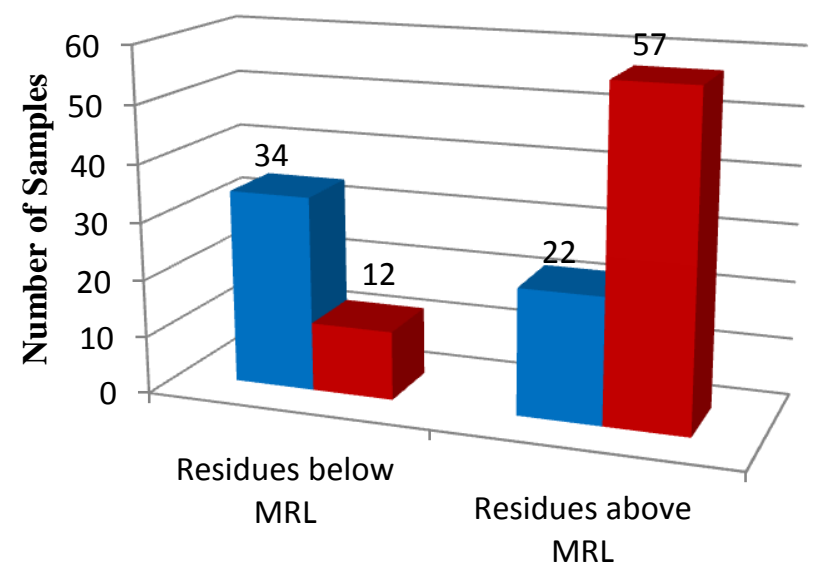

Local

- Imported

MRL found 
All local samples of cucumbers and tomatoes were residue-free or below the MRLs. In addition, all local strawberries samples were free of OCPs residue except two samples showed concentration of heptachlor higher than the MRL. However, only 12 samples of the total imported samples were free or below MRLs of OCPs residue. The rest of the imported samples contained at least one residue of OCPs that were above the MRLs.

Almost $63 \%$ of the 127 samples analyzed had at least one OCPs residue. In terms of co-occurrence of pesticide residues, 8 local samples and 24 imported samples were shown to contain one residue of the 10 selected OCPs residues. While 20 local samples and 41 imported samples contained two or more of the selected OCPs pesticide residues.

The MRL values of the samples were exceeded most often for heptachlor. In all types of imported vegetables (cucumbers, tomatoes, potatoes, parsley, watercress) and fruits (strawberries, lemon), heptachlor concentration was higher than the MRL

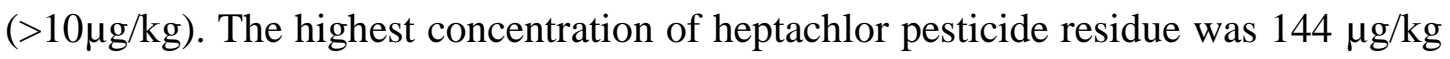
found in imported strawberries from Egypt.

Residues of OCPs in the imported samples were found most frequently are Heptachlor (57 samples), followed by endrin (21 samples), a-chlordane (19 samples), aldrin (13 samples) and dieldrin (13 samples). Whereas in local samples, the OCPs residue that were found most frequently were g-chlordane ( 22 samples), followed by heptachlor (18 samples), aldrin (15 samples), and endosulfane I (12 samples) as 
shown in Figure 18. Six imported samples contained g-chlordane, five samples contained endosulfane I, and only three samples contained methoxychlor. For local samples, 11 samples contained dieldrin, endrin and methoxychlor, and about 10 samples contained a-chlordane. The OCPs that are not found in any sample were $\alpha$ BHC and $\beta-$ BHC.

\section{Figure 18: Residues of OCPs found in local and imported samples}

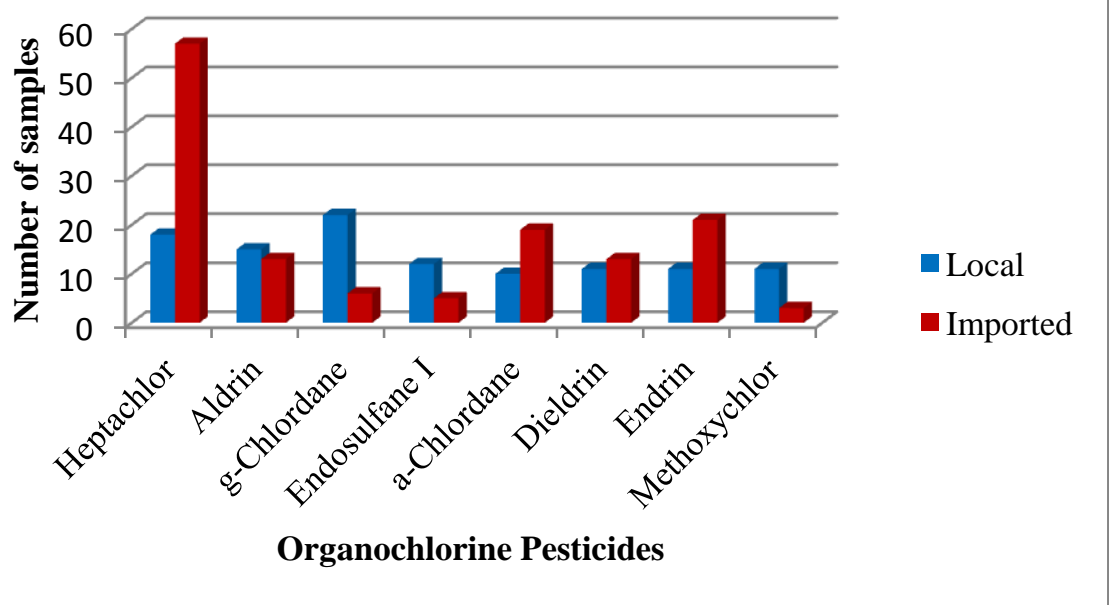

Over all, the most often found OCPs were heptachlor (found in 75 samples), gchlordane (found in 22 samples) and a-chlordane (found in 19 samples). The influence of incubation temperatures on heptachlor degradation was studied at $20^{\circ} \mathrm{C}$ and $30^{\circ} \mathrm{C}$ (Pokethitiyook \& Poolpak, 2012). At $30^{\circ} \mathrm{C}$, smaller amount of heptachlor residue was presented than that of $20^{\circ} \mathrm{C}$. This explained why the imported samples which were collected from markets showed high pesticides residues, since the temperature is low at market and it can influence pesticides accumulation. 
The concentration of heptachlor compound that were found in collected local and imported samples is shown in Figure 19. The MRL of heptachlor is 10ppb. Heptachlor was found in two commodity (watercress and parsley) with average concentration $18.71 \pm 0.65(\mathrm{SE})$ and $19.04 \pm 0.72(\mathrm{SE})$ respectively. While in imported samples, heptachlor was detected in all commodities. The highest concentration was detected in collected parsley samples with average concentration $29.32 \pm 2$, which means that they exceeded the MRL by about $20 \mathrm{ppb}$. The collected imported cucumber samples showed the least concentration of heptachlor with average concentration $14.73 \pm 0.83$; they just exceeded the MRL by $4 \mathrm{ppb}$. 
Figure 19: Residues of heptachlor in the local and imported samples
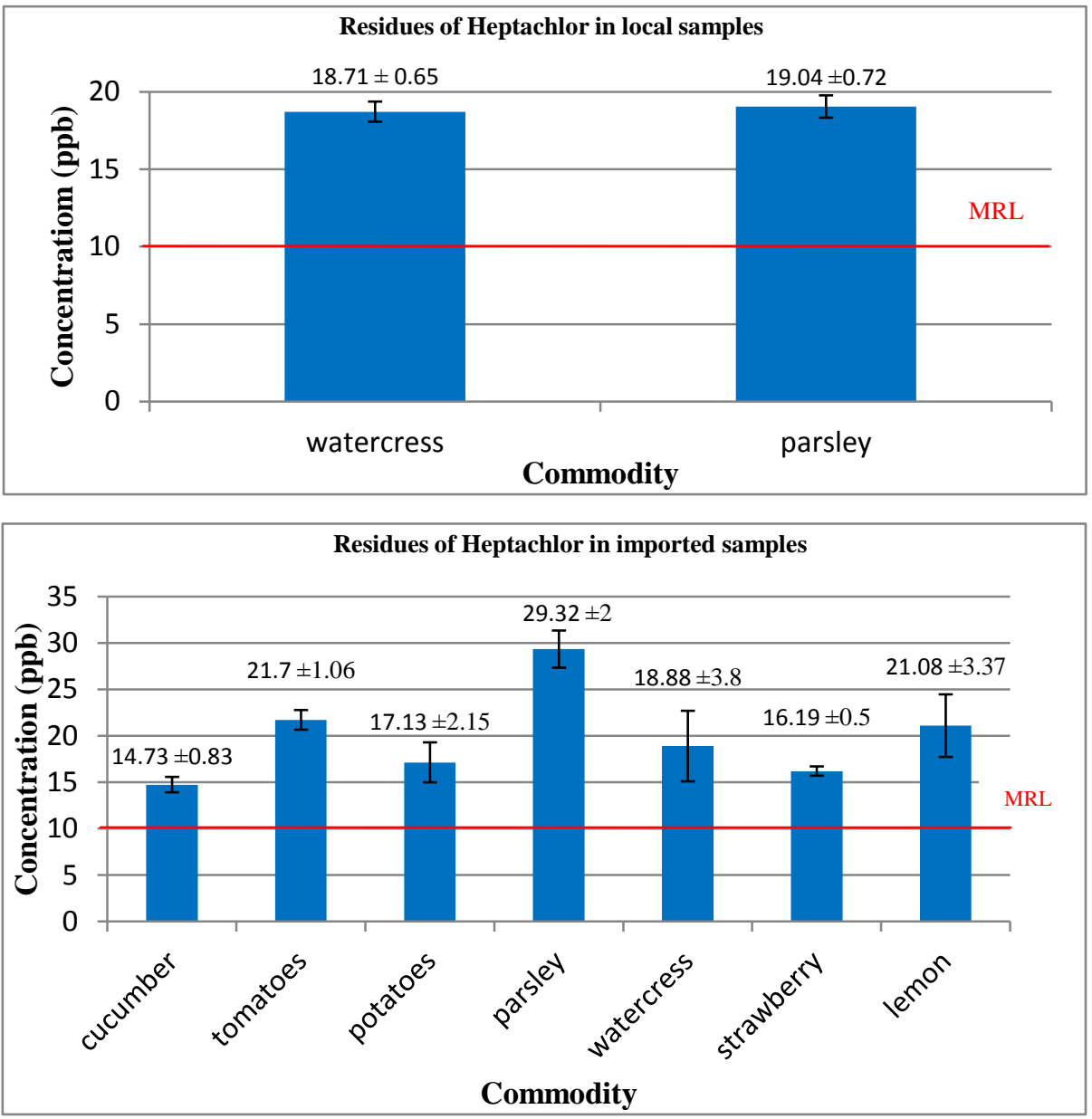


\subsection{Scanning of vegetables and fruit samples by GC/MS}

An Agilent 7890A mass spectrometric detector (MS 5973) was used to scan the samples under scan mode. The GC/MS data were acquired and processed with a wiley7n.1 and NIST98 Libraries.

Due to the complexity of the matrix, cleaning sample is necessary before GC/ MS. Thus, in this experiment the solid-phase extraction (SPE) such as florisil and silica were used. Nevertheless, recent advances in the clean-up techniques concentrate on the use of a combination of two or more SPE adsorbents commercially available. Weak anion-exchange sorbents such as aminopropyl $\left(\mathrm{NH}_{2}\right)$, primarysecondary amine (PSA), or diethylaminopropyl (DEA) modified silica together with strong anion-exchange sorbents are most often used adsorbents for clean-up of food samples (Yamazaki \& Ninomiya, 1999).

The total ion chromatograms obtained after injecting $1 \mu l$ of sample in the first instance gave the total profile of the volatiles and semi-volatiles characterizing that specific product. As an example, Figure 20 shows the recorded total ion chromatogram of the HP-1-capillary GC-MS analysis of imported cucumber sample. Many fatty acids in all the samples were detected by matching with wiley7n.1 and NIST98 Libraries. 
Figure 20: Total ion chromatogram of imported cucumber by GC/MS.

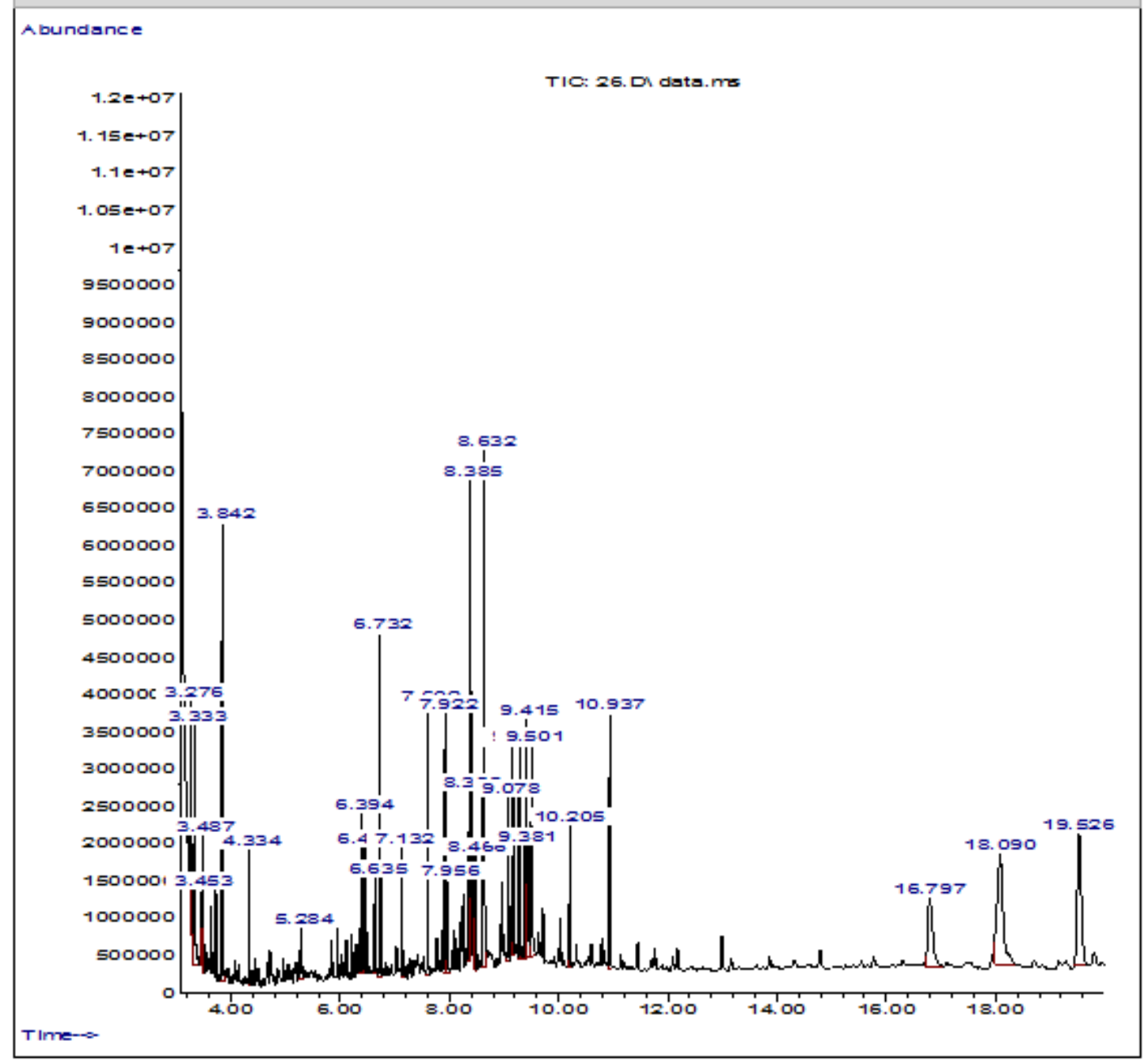

The $\mathrm{NH}_{2}$ and primary-secondary amine (PSA) sorbents provided the most effective clean-up among bonded-silica phases sine they can remove high amount of sample matrix interferences (Schenck \& Lehotay, 2000 \& Schenck et al, 2002). And because of its higher capacity, PSA was significantly better than $\mathrm{NH}_{2}$ for removal of fatty acids (Anastassiades et al, 2003 \& Saito et al, 2004). 
Since florisil and silica were used for cleanup, heavy matrix interferences were observed in most of the samples, consisting primarily of fatty acids. Anastassiades et al, 2003 \& Saito et al, 2004 showed that fatty acid matrix interferences can alter ionization efficiency when using MS detection. Thus the detection and identification of trace levels of pesticides in this complex profile can be very time-consuming and laborious.

\subsection{Statistical data analysis}

Two statistical analysis tests were used to determine significant differences between means. To compare between washed and unwashed, paired t-test was used. Analysis of variance (Factorial analysis) was used for determination of the significant differences among the countries where vegetables and fruits were imported from as well as washed and unwashed. In addition, the interaction between country and washing treatments were tested using LSD (Least Significant Differences) test.

Paired t-test analyses were performed to compare between residuals in washed and unwashed vegetables and fruits. Paired t-test revealed that in most of the comparisons between the washed and unwashed samples, no-significant differences were observed $(\mathrm{P}>0.05)$. It means that most of the pesticides remain on the skin of vegetables after washing with water such as cucumber, tomatoes, and potatoes (Gutierrez \& Londoño, 2009). The results are comparable with those were obtained by washing; this only removes loose surface residues and major portions of polar 
compounds. Non-polar pesticides are tenaciously held in the waxy layers of the peel of fruits and vegetables. Rialch 2012 reported that the pesticide residues that are on the surface of vegetables require two to three times washings. Soliman 2001, noted that reduction of organochlorine pesticides residues were more efficient by washing the vegetables with acetic acid or sodium chloride solutions compared to washing with tap water. This could explain why there were no differences in the presence of organochlorine substances between washed samples by tap water and unwashed samples.

Though, it seems that the effects of washing samples with tap water differ in organochlorine residues based on the type of vegetables and fruits. Statistically significant differences $(\mathrm{P} \leq 0.05)$ in presence of some organochlorine compounds between washed and unwashed imported samples were noted in three commodities (parsley, watercress and strawberries). Heptachlor compound in imported parsley showed difference in significant between the washed and unwashed samples $(\mathrm{P}=$ 0.0018) as shown on Table 11. Meanwhile, heptachlor in imported strawberries showed difference in significant between the washed and unwashed samples $(\mathrm{P}=$ 0.027). In imported watercress samples, the compound a-chlordane showed also significant difference between the washed and unwashed $(\mathrm{p}=0.017)$. Refer to (Appendix 10) for the t-test analysis data.

The pesticide residues from green leafy vegetables (such as: Parsley and watercress) are removed satisfactorily by normal processing such as washing (Rialch, 
2012). Kin \& Huat (2010), reported that washing strawberries with tap water, acetic acid, sodium chloride or sodium carbonate can be an effective method to reduce the intake of pesticide residues. Other researchers stated that tap water reduced the pesticides residues in strawberries samples, though acidic solution was more effective in the elimination of the OCs pesticides (Kin \& Huat 2010).

Analysis of variance (ANOVA) was performed using Minitab software to determine significant differences between two factors (washed/unwashed treatment and country source). The analysis was done for the compounds that showed residues in most of the samples for particular crop. Table 11 shows the analysis of variance for Heptachlor in parsley samples. 
Table 11: Pair-difference t-test for the imported parsley for the presence of heptachlor residue

\begin{tabular}{|c|c|}
\hline \multicolumn{2}{|c|}{ Parsley } \\
\hline \multicolumn{2}{|c|}{ Heptachlor } \\
\hline washed & unwashed \\
\hline 15.342 & 43.534 \\
\hline 12.525 & 25.657 \\
\hline 14.744 & 36.250 \\
\hline 16.784 & 37.367 \\
\hline 13.597 & 39.105 \\
\hline 13.090 & 20.379 \\
\hline
\end{tabular}

t-Test: Paired Two Sample for Means

\begin{tabular}{lrr}
\hline & Variable 1 & Variable 2 \\
\hline Mean & 14.34723501 & 33.715319 \\
Variance & 2.509094233 & 77.60202923 \\
Observations & 6 & 6 \\
Pearson Correlation & 0.674717695 & \\
Hypothesized Mean Difference & 0 & \\
df & 5 & \\
t Stat & -6.060360156 & \\
P(T<t) one-tail & 0.000882592 & \\
t Critical one-tail & 2.015048372 & \\
P(T<=t) two-tail & $\mathbf{0 . 0 0 1 7 6 5 1 8 3}$ & \\
t Critical two-tail & 2.570581835 & \\
\hline
\end{tabular}


Table 12: Analysis of variance data for Heptachlor in parsley samples.

Analysis of Variance for Heptachlor in parsley samples, using Adjusted SS for Tests

$\begin{array}{lclllcc}\text { Source } & \text { DF } & \text { Seq SS } & \text { Adj SS } & \text { Adj MS } & \text { F } & \text { P } \\ \text { Treat } & 1 & 565.57 & 559.33 & 559.33 & 15.00 & \mathbf{0 . 0 0 2} \\ \text { Country } & 2 & 80.58 & 80.71 & 40.35 & 1.08 & \mathbf{0 . 3 6 4} \\ \text { Treat*Country } & 2 & 660.15 & 660.15 & 330.08 & 8.85 & \mathbf{0 . 0 0 3} \\ & & & & & & \\ \text { Error } & \mathbf{1 5} & 559.26 & 559.26 & \mathbf{3 7 . 2 8} & & \\ \text { Total } & 20 & 1865.56 & & & & \end{array}$

The ANOVA analysis for heptachlor in parsley samples showed that there were significant difference in the treatment washed/unwashed $(\mathrm{P}=0.002)$, where no significant difference between counties $(\mathrm{P}=0.364)$, and significant difference in the interaction between washing treatment and countries showed highly significant differences $(\mathrm{P}=0.003)$ (Table 12). This means that washing decreased the heptachlor residues in parsley. Heptachlor concentration in the three different countries (KSA, Lebanon, and Qatar) showed no significant difference, i.e. the concentration in all countries was approximately the same.

Table 13 shows the calculated LSD for all possible pairs of mean. Table 14 shows the overall means of all possible interaction between the washing treatment and the countries (KSA, Lebanon and Qatar) for heptachlor in parsley. 
As shown in Table 13 the calculated LSD value between washed Qatari parsley and washed KSA parsley was (6.59), and the difference of mean between these two groups as shown in (Table 14) was (13.62) was higher than the LSD, which indicates significant difference. The mean of the washed KSA parsley samples were higher than the mean of the washed local parsley samples, this means that the washed local parsley is better than the washed KSA parsley. Meanwhile, the difference of mean between unwashed Qatari parsley and unwashed KSA parsley was greater than LSD value (6.59), which means that the difference was significant. The mean of the unwashed KSA parsley samples were higher than the mean of the unwashed local parsley samples, this means that the unwashed local parsley is better than the unwashed KSA parsley. For the comparison between the washed Qatari parsley and washed Lebanon parsley the LSD value was (6.68) and the mean difference was greater than the LSD, which means that the difference was significant. The mean of the washed Qatari parsley samples were higher than the mean of the washed Lebanon parsley samples, this means that the washed Lebanon's parsley is better than the washed local parsley. Whereas no significant difference was observed between the unwashed Qatari parsley and unwashed Lebanon parsley. 
Table 13: The calculated LSD for all possible pairs of means of heptachlor in parsley.

\begin{tabular}{||c|c|c|c|c|c|c|}
\hline \multicolumn{10}{|c|}{} & $\begin{array}{c}\text { Lebanon } \\
\text { (washed) }\end{array}$ & $\begin{array}{c}\text { KSA } \\
\text { (washed) }\end{array}$ & $\begin{array}{c}\text { Qatar } \\
\text { (unwashed) }\end{array}$ & $\begin{array}{c}\text { Qatar } \\
\text { (washed) }\end{array}$ & $\begin{array}{c}\text { Lebanon } \\
\text { (unwashed) }\end{array}$ & $\begin{array}{c}\text { KSA } \\
\text { (unwashed) }\end{array}$ \\
\hline $\begin{array}{c}\text { KSA } \\
\text { (unwashed) }\end{array}$ & 6.68 & 6.58 & 6.59 & 5.92 & 6.01 & 0.00 \\
\hline $\begin{array}{c}\text { Lebanon } \\
\text { (unwashed) }\end{array}$ & 9.32 & 6.68 & 6.68 & 6.68 & 0.00 & 6.01 \\
\hline $\begin{array}{c}\text { Qatar } \\
\text { (washed) }\end{array}$ & 6.68 & 6.59 & 6.59 & 0.00 & 6.68 & 5.92 \\
\hline $\begin{array}{c}\text { Qatar } \\
\text { (unwashed) }\end{array}$ & 6.68 & 6.59 & 0.00 & 6.59 & 6.68 & 6.59 \\
\hline $\begin{array}{c}\text { KSA } \\
\text { (washed) }\end{array}$ & 6.68 & 0.00 & 6.59 & 6.59 & 6.68 & 6.58 \\
\hline $\begin{array}{c}\text { Lebanon } \\
\text { (washed) }\end{array}$ & 0.00 & 6.68 & 6.68 & 6.68 & 9.32 & 6.68 \\
\hline
\end{tabular}

For the comparison between the imported parsley samples, no significant differences between the washed KSA samples and washed Lebanon samples and between the unwashed KSA samples and the unwashed Lebanon samples were observed. However, there was a difference in significant between the washed KSA samples and the unwashed Lebanon samples. The mean of washed KSA samples was greater than the mean of unwashed Lebanon samples. This indicated that the unwashed Lebanon's parsley is better than the washed KSA's parsley. Meanwhile, the comparison between the unwashed KSA samples and washed Lebanon samples showed significant difference. The mean value of unwashed KSA samples was greater than the mean of washed Lebanon samples. This means that the washed Lebanon' parsley is better than the unwashed KSA' parsley. 
Table 14: The overall means of all possible comparisons for heptachlor in parsley.

A: Overall mean of washed and unwashed parsley samples

\begin{tabular}{|l|c|c|}
\cline { 2 - 3 } \multicolumn{1}{c|}{} & Washed & Unwashed \\
\hline Mean & 19.89 & 30.29 \\
\hline
\end{tabular}

B: Overall mean of KSA, Lebanon, and Qatar parsley samples

\begin{tabular}{|l|c|c|c|}
\cline { 2 - 4 } \multicolumn{1}{c|}{} & KSA & Lebanon & Qatar \\
\hline Mean & 24.37 & 21.54 & 27.03 \\
\hline
\end{tabular}

C: All possible pairs of means

\begin{tabular}{|c|c|c|}
\cline { 2 - 3 } \multicolumn{1}{c|}{} & Washed & Unwashed \\
\hline KSA & 15.30 & 35.70 \\
\hline Lebanon & 13.34 & 29.74 \\
\hline Qatar & 25.14 & 28.92 \\
\hline
\end{tabular}

D: Mean differences between all possible groups

\begin{tabular}{|l|c|c|c|c|c|c|}
\hline & $\begin{array}{l}\text { Lebanon } \\
\text { (washed) }\end{array}$ & $\begin{array}{l}\text { KSA } \\
\text { (washed) }\end{array}$ & $\begin{array}{l}\text { Qatar } \\
\text { (unwashed) }\end{array}$ & $\begin{array}{l}\text { Qatar } \\
\text { (washed) }\end{array}$ & $\begin{array}{l}\text { Lebanon } \\
\text { (unwashed) }\end{array}$ & $\begin{array}{l}\text { KSA } \\
\text { (unwashed) }\end{array}$ \\
\hline $\begin{array}{l}\text { KSA } \\
\text { (unwashed) }\end{array}$ & $22.36^{*}$ & $20.40^{*}$ & $10.56^{*}$ & 6.79 & 5.96 & 0.00 \\
\hline $\begin{array}{l}\text { Lebanon } \\
\text { (unwashed) }\end{array}$ & $16.40^{*}$ & $14.44^{*}$ & 4.60 & 0.83 & 0.00 & $5.96^{*}$ \\
\hline $\begin{array}{l}\text { Qatar } \\
\text { (washed) }\end{array}$ & $15.57^{*}$ & $13.62^{*}$ & 3.77 & 0.00 & 0.83 & $6.79^{*}$ \\
\hline $\begin{array}{l}\text { Qatar } \\
\text { unwashed) }\end{array}$ & $11.80^{*}$ & $9.84^{*}$ & 0.00 & $3.77^{*}$ & $4.60^{*}$ & $10.56^{*}$ \\
\hline $\begin{array}{l}\text { KSA } \\
\text { (washed) }\end{array}$ & 1.95 & 0.00 & $9.84^{*}$ & $13.62^{*}$ & $14.44^{*}$ & $20.40^{*}$ \\
\hline $\begin{array}{l}\text { Lebanon } \\
\text { (washed) }\end{array}$ & 0.00 & 1.95 & 11.80 & $15.57^{*}$ & $16.40^{*}$ & $22.36^{*}$ \\
\hline
\end{tabular}

*The difference is significant. 
The ANOVA analysis of a-chlordane in watercress is shown in Table 15. Significant difference was observed between counties $(\mathrm{P}=0.002)$, i.e. a-chlordane residue was different depending on the country. The washing treatment and the interaction between the washing treatment and countries were not significant.

\section{Table 15: Analysis of variance data for a-chlordane in watercress samples.}

Analysis of Variance for a-Chlordane, using Adjusted SS for Tests

$\begin{array}{lclllcc}\text { Source } & \text { DF } & \text { Seq SS } & \text { Adj SS } & \text { Adj MS } & \text { F } & \text { P } \\ \text { Treat } & 1 & 119.03 & 56.11 & 56.11 & 0.59 & \mathbf{0 . 4 5 9} \\ \text { Country } & 1 & 1507.15 & 1474.54 & 1474.54 & 15.40 & \mathbf{0 . 0 0 2} \\ \text { Treat*Country } & 1 & 155.36 & 155.36 & 155.36 & 1.62 & \mathbf{0 . 2 2 7} \\ \text { Error } & 12 & 1148.73 & 1148.73 & 95.73 & & \\ \text { Total } & 15 & 2930.27 & & & & \end{array}$

For the methoxychlor in cucumber samples, the ANOVA analysis shown in Table 16 showed that no significant differences were shown between the washed/unwashed samples $(\mathrm{P}>0.05)$, countries and interaction between the washing treatment and countries. 
Table 3: Analysis of variance data for methoxychlor in cucumber samples.

Analysis of Variance for Methoxyc, using Adjusted SS for Tests

$\begin{array}{lcccccc}\text { Source } & \text { DF } & \text { Seq SS } & \text { Adj SS } & \text { Adj MS } & \text { F } & \text { P } \\ \text { Treat } & 1 & 2.578 & 1.779 & 1.779 & 1.35 & \mathbf{0 . 2 8 4} \\ \text { Country } & 1 & 0.505 & 0.580 & 0.580 & 0.44 & \mathbf{0 . 5 2 9} \\ \text { Treat*Country } & 1 & 0.969 & 0.969 & 0.969 & 0.73 & \mathbf{0 . 4 2 0} \\ \text { Error } & 7 & 9.254 & 9.254 & 1.322 & & \\ \text { Total } & 10 & 13.306 & & & & \end{array}$

Similarly, heptachlor in tomatoes showed also no significant differences in all the comparisons between the washing treatment, countries or interaction between the both as shown in Table 17.

Table 4: Analysis of variance data for heptachlor in tomatoes samples.

Analysis of Variance for Heptachl, using Adjusted SS for Tests

$\begin{array}{lllllll}\text { Source } & \text { DF } & \text { Seq SS } & \text { Adj SS } & \text { Adj MS } & F & P\end{array}$

$\begin{array}{lllllll}\text { Treat } & 1 & 186.1 & 186.1 & 186.1 & 1.62 & \mathbf{0 . 2 7 1}\end{array}$

$\begin{array}{lllllll}\text { Country } & 1 & 195.3 & 195.3 & 195.3 & 1.70 & \mathbf{0 . 2 6 2}\end{array}$

$\begin{array}{lllllll}\text { Treat*Country } & 1 & 73.3 & 73.3 & 73.3 & 0.64 & \mathbf{0 . 4 6 9}\end{array}$

$\begin{array}{lllll}\text { Error } & 4 & 458.4 & 458.4 & 114.6\end{array}$

$\begin{array}{lll}\text { Total } & 7 & 913.1\end{array}$ 


\section{CONCLUSION}

This study is the first study that provided important information regarding pesticide residues in vegetables and fruit in Qatar. 127 samples, which included 26 fruits and 101 vegetables, from local and imported sources were investigated for organochlorine pesticide residues. According to the results, the imported samples were much higher than local samples in exceeding the MRL. MRL values were exceeded most often for heptachlor OCPs. Most, if not all, of the pesticides residues found in local samples were detected on the leafy vegetables (parsley and watercress).

The statistical analysis of data was essential to identify and compare the results. The significant difference between the washed and unwashed samples was examined using t-test. And the significant differences between the two factors (washing treatment and countries) were studied using analysis of variance (ANOVA). The lowest significant differences (LSD) provided the significance between the interaction of washing treatment and countries.

The level of pesticide residues contamination may be considered a potential public health problem. The results also underscore the need for regular monitoring of large samples to determine the pesticide residues, especially for the imported samples. 


\section{RECOMMENDATION}

The findings of this study suggest the need for a monitoring program to investigate the occurrence of residues of pesticide in foodstuffs, especially imported food products. All government sectors like (Qatar University, Ministry of Environment and Supreme Council of Health) should work together in this field, perform many scientific researches and share their results to the concerned parties in order to investigate the pesticides issues in products sold in Qatar.

Future studies should consider the processing factors other than washing with tap water in order to account for the reduction or removal of pesticides such as: washing (with acetic acid, sodium chloride and soap) and peeling. Also as a recommendation, we need to look to other types of food that are sold in Qatar and may contain pesticides residues, such as grains and dates. Future studies also should look to the

presence of other type of pesticides such as organophosphorous and carbamates compounds. 


\section{REFERENCES}

A. Anastassiades, S.J. Lehotay, D. Štajnbaher, F.J. Schenck. (2003). J. AOAC Int., $86,412$.

Alan R. Boobis, Bernadette C. Ossendorp, Ursula Banasiak, Paul Y. Hamey,Istvan Sebestyen, Angelo Moretto. (2008). Cumulative risk assessment of pesticide residues in food. Toxicology Letters,180, 137-150.

Alankar Shrivastava, Vipin B Gupta. (2011). Methods for the determination of limit of detection and limit of quantitation of the analytical methods. Chronicles of Young Scientists, 2(1), 21-25.

Amy E. Brown. (2013). Mode of Action of Insecticides and Related Pest Control Chemicals for Production Agriculture, Ornamentals, and Turf. Retrieved From the University of Maryland website: http://pesticide.umd.edu

Analytical Procedures and Methods Validation.(2000). Food and Drug Administration. Retrieved From the Environmental Protection Agency website: http://www.fda.gov

Andersen, H.R., Vinggaard, A.M., Rasmussen, T.H., Gjermandsen, I.M., BonefeldJørgensen, E.C. (2002). Effects of currently used pesticides in assays for estrogenicity, androgenicity, and aromatase activity in vitro. Toxicol. Appl. Pharmacol., 179, 1-12.

Andréia Nunes Oliveira Jardim, Denise Carvalho Mello, Fernanda Caroline Silva Goes, Elcio Ferreira Frota Junior, Eloisa Dutra Caldas. (2014). Pesticide residues in cashew apple, guava, kaki and peach: GC-lECD, GC-FPD and 
LC-MS/MS multiresidue method validation, analysis and cumulative acute risk assessment. Food Chemistry, 164, 195-204.

Badawi, A.F., Cavalieri, E.L., Rogan, E.G. (2000). Effect of chlorinated hydrocarbons on expression of cytochrome P450 1A1, 1A2 and 1B1 and 2and 4 hydroxylation of 17beta-estradiol in female Sprague-Dawley rats. Carcinogenesis, 21, 1593-1599.

Bai, Y., Zhou, L., \& Wang, J. (2006). Organophosphorus pesticide residues in market foods in Shaanxi area, China. Food Chemistry, 98, 240-242.

Benjamin C.L. Lai, MD, MSc , Joseph K.C. Tsui, MD, FRCP(UK), FRCPC. (2001). Epidemiology of Parkinson's disease. BCMJ, 43 (3), 133- 137.

Bradlow, H.L., Davis, D.L., Lin, G., Sepkovic, D., Tiwari, R., 1995. Effects of pesticides on the ratio of 16 alpha/2-hydroxyestrone: a biologic marker of breast cancer risk. Environ. Health Perspect. 103, 147-150.

C. Bolognesi \& F.D. Merlo (2011). Pesticides: Human Health Effects. Reference Module in Earth Systems and Environmental Sciences. 438-453.

C. Bolognesi, F.D. Merlo. (2011). Pesticides: Human Health Effects. Reference Module in Earth Systems and Environmental Sciences. 438-453.

C.J. Wang \& Z.Q. Liu. (2007). Foliar uptake of pesticides—Present status and future challenge. Pesticide Biochemistry and Physiology, 87(1), 1-8. 
Cayo Corcellas, Ethel Eljarrat, Damià Barceló. (2015). First report of pyrethroid bioaccumulation in wild river fish: A case study in Iberian river basins (Spain). Environment International, 75, 110-116.

Chai Mee Kin \& Tan Guan Huat. (2010). Headspace solid-phase microextraction for the evaluation of pesticide residue contents in cucumber and strawberry after washing treatment. Food Chemistry, 123(3), 760-764.

Chen, C., Qian, Y., Chen, Q., Tao, C., Li, C., \& Li, Y. (2011). Evaluation of pesticide residues in fruits and vegetables from Xiamen, China. Food Control, 22, 1114-1120.

Claudia Bolognesi \& Gabriella Morasso. (2000). Genotoxicity of pesticides: potential risk for consumers. Trends in Food Science \& Technology, 11, (4-5), 182-187.

Crentsil Kofi Bempah, Jacob Asomaning, Daniel Ayirebi Ansong, Juliana Boateng and Stephen Boahen Asabere. (2012). Contamination levels of selected organochlorine and organophosphorous pesticides in Ghanaian fruits and vegetables. Nutrition and food science. Emir. J. Food Agric, 24 (4): 293-301.

Curley A, Jennings RW, Mann HT, et al. 1970. Measurement of endrin following epidemics of poisoning. Bull Environ Contam Toxicol, 5, 24-29. 
D.K. Essumang1, G.K. Togoh and L. Chokky.(2009). Pesticide residues in the water and fish (lagoon tilapia) samples from lagoons in Ghana. Chemical Society of Ethiopia, 23(1), 19-27.

Dana Boyd Barr, Anders O. Olsson, Lee-Yang Wong, Simeon Udunka, Samuel E. Baker, Ralph D. Whitehead Jr., Melina S. Magsumbol, Bryan L. Williams, Larry L. Needham. (2010). Urinary Concentrations of Metabolites of Pyrethroid Insecticides in the General U.S. Population: National Health and Nutrition Examination Survey 1999-2002. Environ Health Perspectives, $118,742-748$.

de Boer J, Law RJ (2003). Developments in the use of chromatographic techniques in marine laboratories for the determination of halogenated contaminants and polycyclic aromatic hydrocarbons. PubMed. Retrieved From the NCBI website: http://www.ncbi.nlm.nih.gov

Deichmann WB, MacDonald WE, Blum E, et al. 1970. Tumorigenicity of aldrin, dieldrin and endrin in the albino rat. Industrial Medicine, (39), 37-45.

Donald J. Ecobichon. (2001). Pesticide use in developing countries. Toxicology. 160 (1-3), 27-33.

Environmental Protaction Agency. (2014). What is a pesticides?. Retrieved From the Environmental Protection Agency website: http://www.epa.gov/pesticides/ 
F.J. Schenck, S.J. Lehotay, V. Vega. (2002). Comparison of solid-phase extraction sorbents for cleanup in pesticide residue analysis of fresh fruits and vegetables. Journal of Separation Science, 25, 883-890.

F.J. Schenck, S.J. Lehotay. (2000).Does further clean-up reduce the matrix enhancement effect in gas chromatographic analysis of pesticide residues in food?. J. Chromatogr. A., 868, 51-61.

FAO/WHO, 2004. Food and Agriculture Organization/World Health Organization, Food standards program. Codex Alimentarius Commission. Twenty-seventh Session, Geneva, Switzerland.

Fei Yang, Zhaoyang Bian, Xiaoshui Chen, Sansan Liu, Yang Liu and Gangling Tang. (2013). Analysis of 118 Pesticides in Tobacco after Extraction With the Modified QuEChRS Method by LC-MS-MS. Journal of Chromatographic Science, 1-5.

Food and Agriculture Organization. (2013). Resource Statistics - Pesticides Consumption, 2013. Retrieved From Knoema website: http://knoema.com/FAORSPestConsum2013

Food and Agriculture Organization/World Health Organization.(2013). Pesticide Residues in Food and Feed. Retrieved From the CODEX alimentarius website: http://www.codexalimentarius.net/pestres/data/pesticides

Gilbert Ross. (2005). Risks and benefits of DDT. American Council on Science and Health, 1771-1772. 
Gozde Turkoz Bakırcı, Dilek Bengu Yaman Acay, Fatih Bakırcı, Semih Otles. (2014). Pesticide residues in fruits and vegetables from the Aegean region,Turkey. Food Chemistry, 160, 379-392.

Gozde Turkoz Bakırc1, Yas_ar Hisıl. (2011). Fast and simple extraction of pesticide residues in selected fruits and vegetables using tetrafluoroethane and toluene followed by ultrahigh-performance liquid chromatography/tandem mass spectrometry. Food Chemistry, 135, 1901-1913.

Hjorth, K., Johansen, K., Holen, B., Andersson, A., Christensen, H. B., Siivinen, K., et al. (2011). Pesticide residues in fruits and vegetables from South America e A Nordic project. Food Control, 22, 1701-1706.

IARC. (2015 ). IARC Monographs Volume 112: evaluation of five organophosphate insecticides and herbicides. Retrieved From the International Agency for Research on Cancer website: http://www.iarc.fr

Isam Bashour. (2009). Pesticides, Fertilizers and Food Safety. Arab Environment: Future Challenges. Chapter 10, 137-144.

J.A. Gutierrez, A. Londoño. (2009). Determinación de plaguicidas organoclorados y organofosforados en tomates de cadena en las ciudades de Pereira y Armania, Colombia. Boletín Latinoamericano y del Caribe de Plantas Medicinales y Aromáticas, 8 (3), 165-171. 
J.L. Fern’andez Moreno, F.J. Arrebola Li'ebanas, A. Garrido Frenich, J.L. Mart'inez Vidal. (2006). Evaluation of different sample treatments for determining pesticide residues in fat vegetable matrices like avocado by low-pressure gas chromatography-tandem mass spectrometry. Journal of Chromatography, $1111,97-105$.

Jana Hajšlová, Tomáš Cajka. (2007). Gas chromatography-mass spectrometry (GCMS). Food Toxicants Analysis. 12, 419-473.

Jennifer Sass. (2014). Neonicotinoid pesticides - bad for bees, and may be bad for people too. Retrieved From the SWITCHBOARD website: http://switchboard.nrdc.org

Jolanta Fenik, Maciej Tankiewicz, Marek Biziuk.(2011). Properties and determination of pesticides in fruits and vegetables. Trends in Analytical Chemistry, 30(6), 814- 826.

K.M. Soliman. (2001). Changes in concentrations of pesticide residues in potatoes during washing and home preparation. Food and Chemical Toxicology, 39, 887-891.

Keith LH .(1996). Compilation of EPA's sampling and analysis methods. Boca Raton. 
Kmellara, B., Abrankoa, L., Fodora, P., \& Lehotay, S. J. (2010). Routine approach to qualitatively screening 300 pesticides and quantification of those frequently detected in fruit and vegetables using liquid chromatography tandem mass spectrometry (LC-MS/MS). Food Additives and Contaminants, 27(10), 14151430.

Kneževic` , Z., \& Serdar, M. (2009). Screening of fresh fruit and vegetables for pesticide residues on Croatian market. Food Control, 20, 419-422.

Li, J., Li, N., Ma, M., Giesy, J.P., Wang, Z. (2008). In vitro profiling of the endocrine disrupting potency of organochlorine pesticides. Toxicol. Lett, 183, 65-71.

M. H. EL-Saeid and M. T. Selim. (2013). Multiresidue Analysis of 86 Pesticides Using Gas Chromatography Mass Spectrometry: II-Nonleafy Vegetables. Journal of Chemistry. Retrieved From the Hindawi Publishing Corporation website: http://www.hindawi.com

M. Isabel Pinto, Gerhard Sontag, R.J. Bernardino, J.P. Noronha. (2010). Pesticides in water and the performance of the liquid-phase microextraction based techniques. A review. Microchemical Journal, 96, 225-237.

Margaret Cunningham. (2015).Use of Pesticides: Benefits and Problems Associated with Pesticides. Retrieved From the Study website: www.study.com/academy

Mariana Gonzalez, Karina S.B. Miglioranza, Julia E. Aizpún de Moreno \& Víctor J. Moreno. (2005). Evaluation of conventionally and organically produced 
vegetables for high lipophilic organochlorine pesticide (OCP) residues. Food and Chemical Toxicology, 43(2), 261-269.

Mario Suwalsky, Maritza Benites, Fernando Villena, Felipe Aguilar, Carlos P Sotomayor .(1997). The organochlorine pesticide heptachlor disrupts the structure of model and cell membranes. Biochimica et Biophysica Acta (BBA) - Biomembranes, 1326 (1), 115-123.

Md. Wasim Aktar,Dwaipayan Sengupta, and Ashim Chowdhury. (2009). Impact of pesticides use in agriculture: their benefits and hazards. Interdiscip Toxicology, 2(1), 1-12.

N. Ito, H. Nagasaki, H. Aoe, S. Sugihara, Y. Miyata. (1975). Development of hepatocellular carcinomas in rats treated with benzene hexachloride. J. Natl Cancer Inst., 54, 801-805.

National Implementation Plan (NIP) for Stockholm Convention on Persistent Organic Pollutants (POPs). (2011). Ministry of Environment. Retrieved From: http://chm.pops.int/Implementation/NIPs/NIPSubmissions

National Pesticides Information Center. (2011). Types of Pesticides. Retrieved From the National Pesticides Information Center website: http://www.npic.orst.edu

Nativelle-Serpentini, C., Richard, S., Seralini, G.E., Sourdaine, P. (2003). Aromatase activity modulation by lindane and bisphenol-A in human placental JEG-3 and transfected kidney E293 cells. Toxicol. In Vitro, 17, 413-422. 
Ortelli, D., Edder, P., \& Corvi, C. (2006). Multiresidue analysis of 74 pesticides in fruit and vegetables by liquid chromatography-electrospray-tandem mass spectrometry, 520, 33-45.

Osman, K. A., Al-Humaid, A. M., Al-Rehiayani, S. M., \& Al-Redha, K. N. (2010). Monitoring of pesticide residues in vegetables marketed in Al-Qassim region, Saudi Arabia. Ecotoxicology and Environmental Safety, 73, 1433-1439.

Padula G, Ponzinibbio MV, Picco S, Seoane A. (2012). Assessment of the adverse effects of the acaricide amitraz: in vitro evaluation of genotoxicity.PuLMed, 22(9), 657616.

Pico, Y., la Farre, M., Soler, C., \& Barcelo, D. (2007). Identification of unknown pesticides in fruits using ultra-performance liquid chromatography-quadrupole time of-flight mass spectrometry. Imazalil as a case study of quantification. Journal of Chromatography A, Anayitica Chimica Acta 1176(1-2), 123-134.

Pratibha Rialch . (2012). Removing Pesticides from Fruits and Vegetables. Retrieved From the Center for Science and Environment website: http://www.cseindia.org

Prayad Pokethitiyook \& Toemthip Poolpak. (2012). Heptachlor and Its Metabolite: Accumulation and Degradation in Sediment. InTech, Bangkok, Thailand.

Qing Miao, MSHongmei Liu, Weijun Kong, Bao Gong, Yun Qi, Meihua Yang. (2013). Rapid analysis of multi-pesticides in Morinda officinalis by GC- 
ECDwith accelerated solvent extraction assisted matrix solid phasedispersion and positive confirmation by GC-MS. Journal of Chromatography B, 974, 6574.

Quevedo, L., Norris, B., Benites, M. and Suwalsky, M. (1997). Interaction of the Organochlorine Pesticide Dieldrin with Phospholipid Bilayers. Verlag der Zeitschrift für Naturforschung, 450-458.

Quick MP, Shaw IC, Manser PA. 1989. A surprising case of endrin poisoning in dogs. Journal of the Forensic Science Society, 29(5):331-338.

R.C. Gupta. (2014). Carbamate Pesticides. Encyclopedia of Toxicology (Third Edition), 661-664.

Rafael Vargas-Bernal, Gabriel Herrera-Pérez and Esmeralda Rodríguez-Miranda. (2012). Evolution and Expectations ofja Enzymatic Biosensors for Pesticides. Soundararajan, 978-953.

Rafat Ahmad, Nida' M. Salem', Hussein Estaitieh. (2010). Occurrence of organochlorine pesticide residues in eggs, chicken and meat in Jordan. Chemosphere,78 (6), 667671.

Rathore, Hamir S., and Nollet, Leo M. L., eds. (2012). Pesticides : Evaluation of Environmental Pollution. USA: CRC.

Rawiwan Puatanachokchai, Keiichirou Morimura, Hideki Wanibuchi, Mayuko Oka, Anna Kinoshita, Fukui Mitsuru, Shuji Yamaguchi, Yoshihiko Funae, Shoji Fukushima (2006). Alpha-benzene hexachloride exerts hormesis in preneoplastic 
lesion formation of rat hepatocarcinogenesis with the possible role for hepatic detoxifying enzymes. Cancer Letters, 240(1), 102-113.

Ritz B, A Manthripragada, S Costello, S Lincoln, M Farrer, M Cockburn, J Bronstein. (2009). Dopamine transporter genetic variants and pesticides in Parkinson's disease. Environmental Health Perspectives. doi:10.1289/ehp.0800277.

Runhaar EA, Sangster B, Greve PA, et al. 1985. A case of fatal endrin poisoning. Hum Toxicol 4:241-247.

S. Angsubhakorn, N. Bhamarapravati, K. Romruen, S. Sahaphong, W. Thamavit, M. Miyamoto. (1981). Further study of $\alpha$-benzene hexachloride inhibition of aflatoxin B1 hepatocarcinogenesis. Br. J. Cancer, 43, 881-883.

S. Vaithinathan, B. Saradha, P.P. (2010). Mathur Methoxychlor induces apoptosis via mitochondria- and FasL-mediated pathways in adult rat testis. Chem. Biol. Interact., 185, 110-118.

S.M. Khan, L.M. Dauffenbach, J. Yeh. (2000). Mitochondria and caspases in induced apoptosis in human luteinized granulosa cells Biochem. Biophys. Res. Commun., $269,542-545$.

SafiatouBerthe Dem, 2007. pesticide residues in soil and water from four cotton growing area of Mali, West Africa. Journal of Agriculture, Food and Environment Sciences, 1, 1-9. 
Sait Bulut, Levent Akkaya, Veli Gök, Muhsin Konuk. (2011). Organochlorine pesticide (OCP) residues in cow's, buffalo's, and sheep's milk from Afyonkarahisar region, Turkey. Springer Science, Business Media, 181, 555-562.

Singh, Dileep K. (2012). Toxicology: Agriculture and Environment: Pesticide Chemistry and Toxicology. UAE: Bentham Science Publishers.

Sinha, N., Narayan, R., Shanker, R., Saxena, D.K.. (1995). Endosulfan induced biochemical changes in the testis of rats. Vet. Hum. Toxicol. 37, 547-549.

Stan, H. J. (2000). Pesticide residue analysis in foodstuffs applying capillary gas chromatography with mass spectrometric detection State-of-the-art use of modified DFG-multimethod S19 and automated data evaluation. Journal of Chromatography A, 892, 347-377.

T.M. Said, U. Paasch, H.J. Glander, A. Agarwal. (2004). Role of caspases in male infertility. Hum. Reprod, 10, 39-51.

Treon JF, Cleveland FP, Cappel J. 1955. Toxicity of endrin for laboratory animals. Agricultural and Food Chemistry, 3:842-848.

United State National Toxicology Program. (2015). Regulatory Actions for Years 2010 to 2015. NTP, US. Retrieved From the National Toxicology Program website: http://ntp.niehs.nih.gov \ 
United States Department of Agriculture. (2012). Electron Capture Detectors (ECD). Retrieved From the United States Department of Agriculture website: http://www.dm.usda.gov

W. Thamavit, T. Hiasa, N. Ito, N. Bhamarapravati.(1974).The inhibitory effect of $\alpha-$ benzene hexachloride on 3'-methyl-4-dimethyl-aminoazobenzene and DLethionine carcinogenesis in rats. Cancer Res., 34, 337-340.

Wells DE, Hess P. (2000). Separation, clean-up and recoveries of persistant trace organic contaminants from soils, sediment and biological matrices. Amsterdam.

World Health Organization (2010). The WHO recommended classification of pesticides by hazard and guidelines to classification: 2009 .

World Health Organization. (2006).The WHO recommended Classification of Pesticides by Hazard and Guidelines to Classification. Retrieved From the World Health Organization website: http://www.who.int

Xuejin Mao, YiqunWan, AipingYan, MingyueShen, YuanlongWei. (2012). Simultaneousdeterminationoforganophosphorus,organochlorine, pyrethriod andcarbamatepesticidesin Radix astragali by microwaveassistedextraction/dispersive-solidphase extraction coupledwithGC-MS. Talanta, $97,131-141$.

Y. Saito, S. Kodama, A. Matsunaga, A. Yamamoto. (2004). J. AOAC Int., 87 (6), 1356. 
Y. Shi, Y. Song, Y. Wang, Y. Wang, X. Liang, Y. Hu, H. Yu, X. Guan, J. Cheng, K. Yan. (2011). $\beta$-Benzene hexachloride induces apoptosis of rat Sertoli cells through generation of reactive oxygen species and activation of JNKs and FasL. Environ. Toxicol., 26, 124-135.

Y. Yamazaki, T. Ninomiya. (1999). Journal of AOAC Int., 82, 1474.

Statistical Consultant. (2015). T-Test. Retrieved From the Statistically Significant Consulting website: http://www.statisticallysignificantconsulting.com/Ttest.htm 


\section{A PPENDIX}

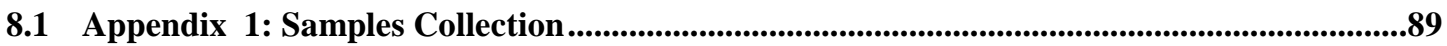

8.2 Appendix 2: The Scope and Application of EPA Method 8081A ..........................................93

8.3 Appendix 3: Accelerated Solvent Extraction of Pesticide Residues in Food Products.

Dionex Application Note 332, 2012. .....................................................................................................94

8.4 Appendix 4: The Scope and Application of EPA Method 3620C- Florisil Cleanup ...............98

8.5 Appendix 5: EPA Method 3630- Silica Gel Cleanup .......................................................................99

8.6 Appendix 6: Data on Limit of Detection (LOD) and Limit of Quantitation (LOQ) ............100

8.7 Appendix 7: Results for OCPs concentration in local vegetables and fruit...........................105

8.8 Appendix 8: Results for OCPs concentration in imported vegetables and fruit ..................110

8.9 Appendix 9: MRLs Results for OCPs concentration in local vegetables and fruit..............117

8.10 Appendix 10: T-test analysis results...........................................................................122 


\subsection{Appendix 1: Samples Collection}

Figure 1: Collection of local vegetables samples from Al-Mazrouah hall

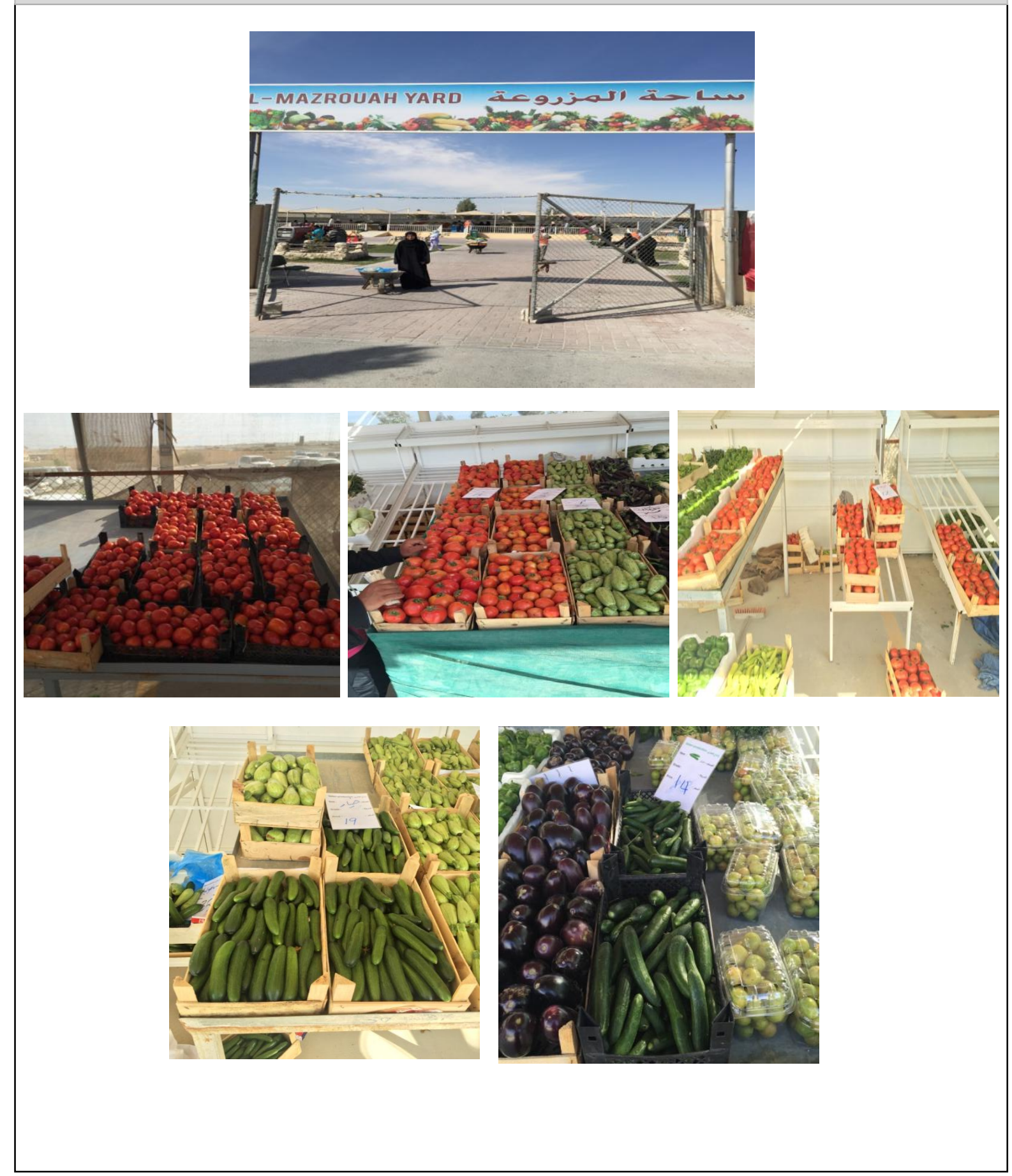


Figure 2: Collection of imported vegetables samples from markets.
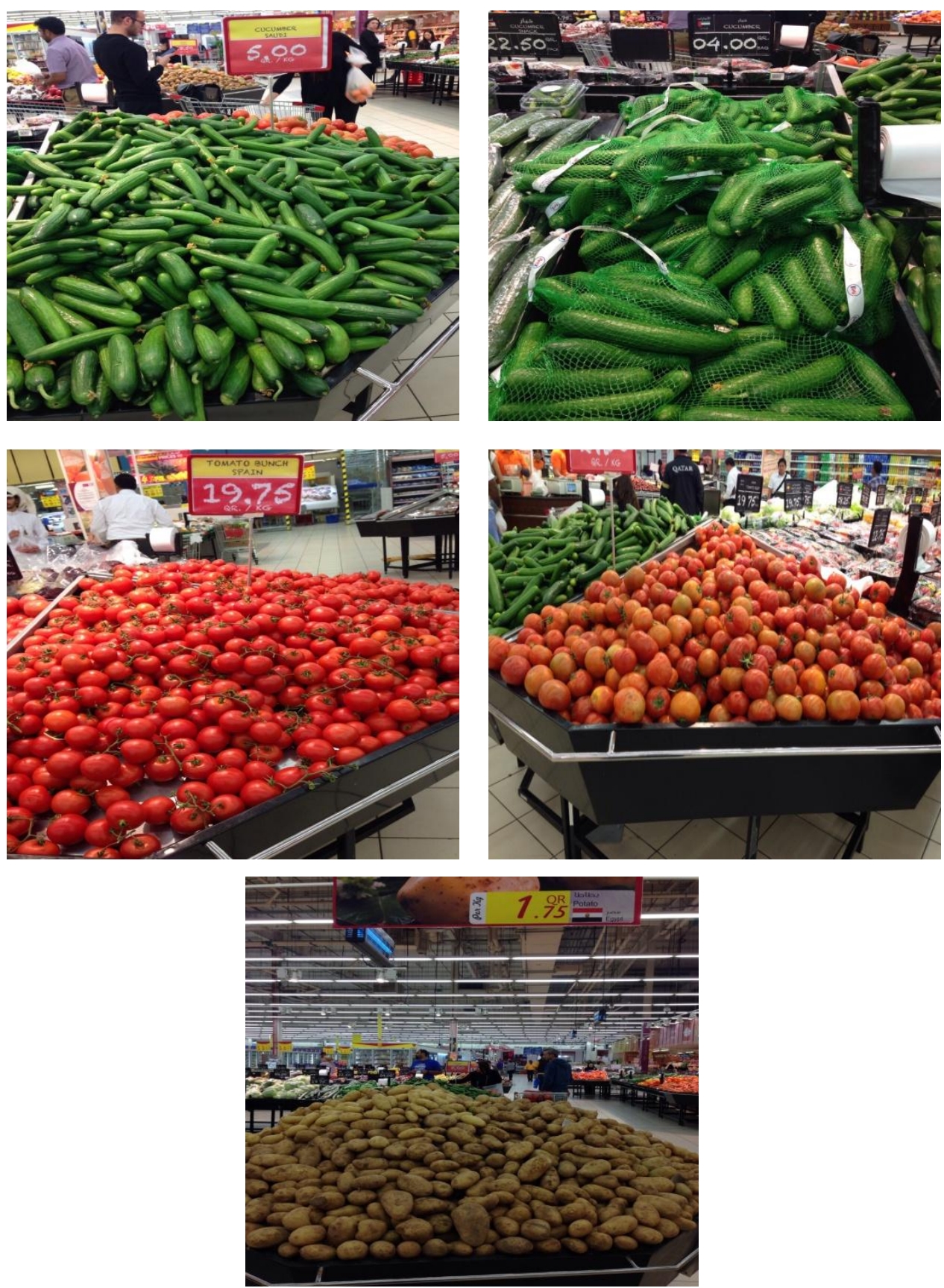
Figure 3: Collection of local leafy vegetables samples from Al-Mazrouah hall.

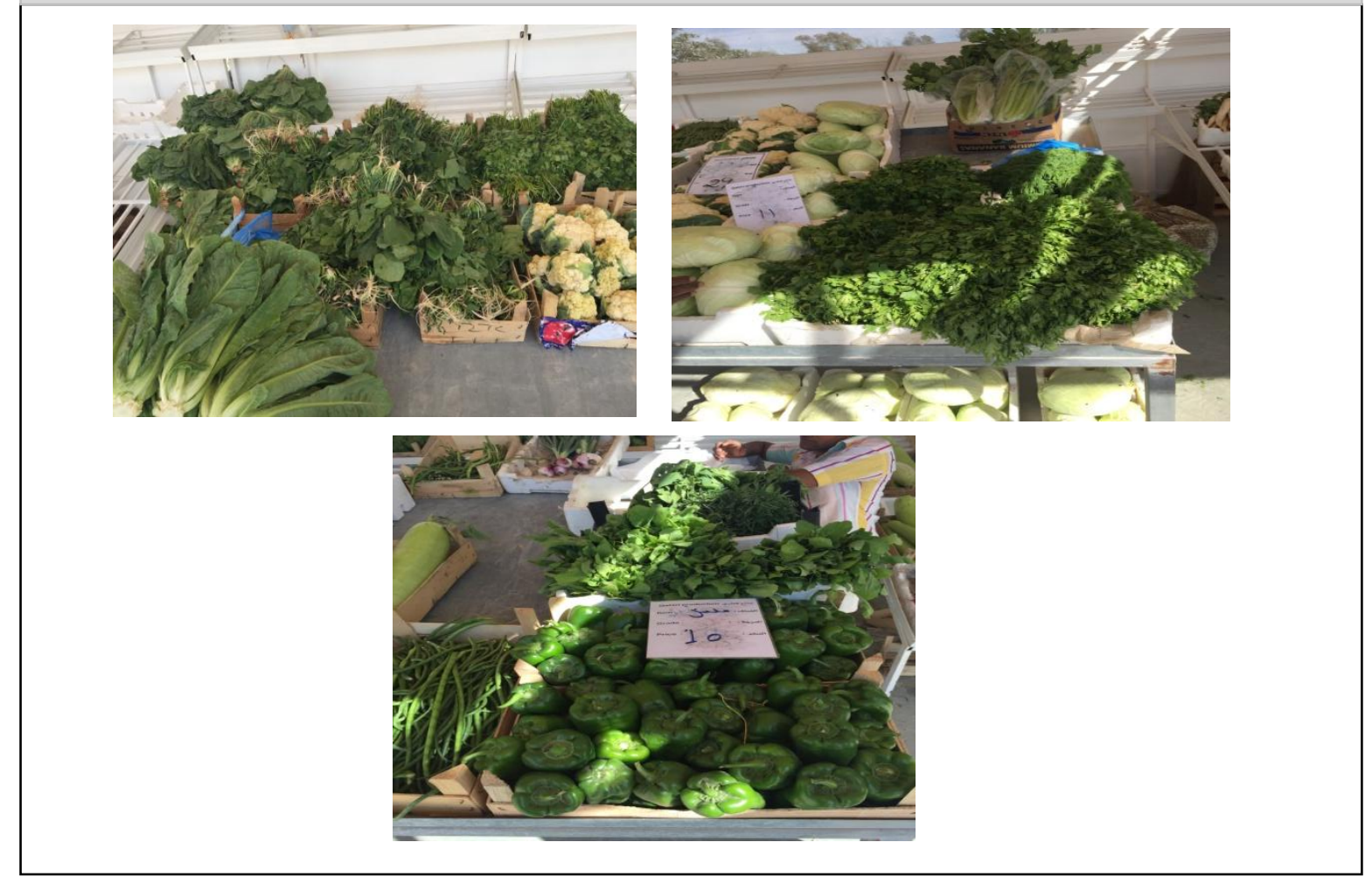

Figure 4: Collection of imported leafy vegetables samples from markets.
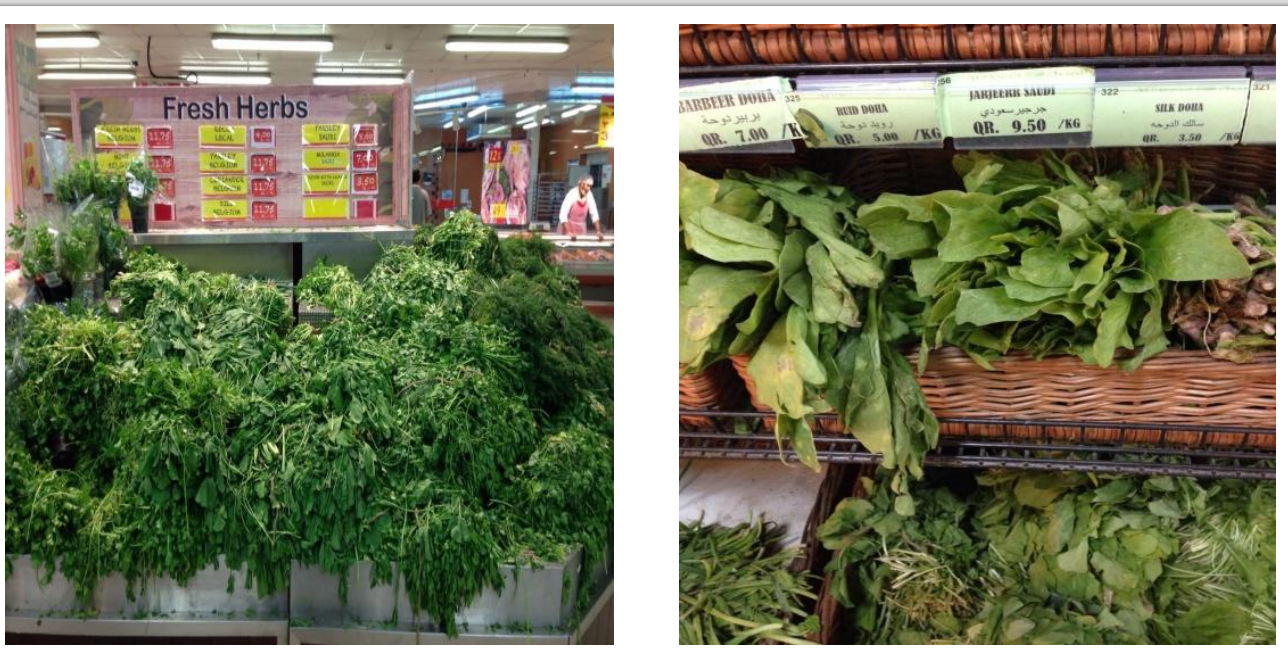
Figure 5: Collection of local fruit samples from Al-Mazrouah hall.
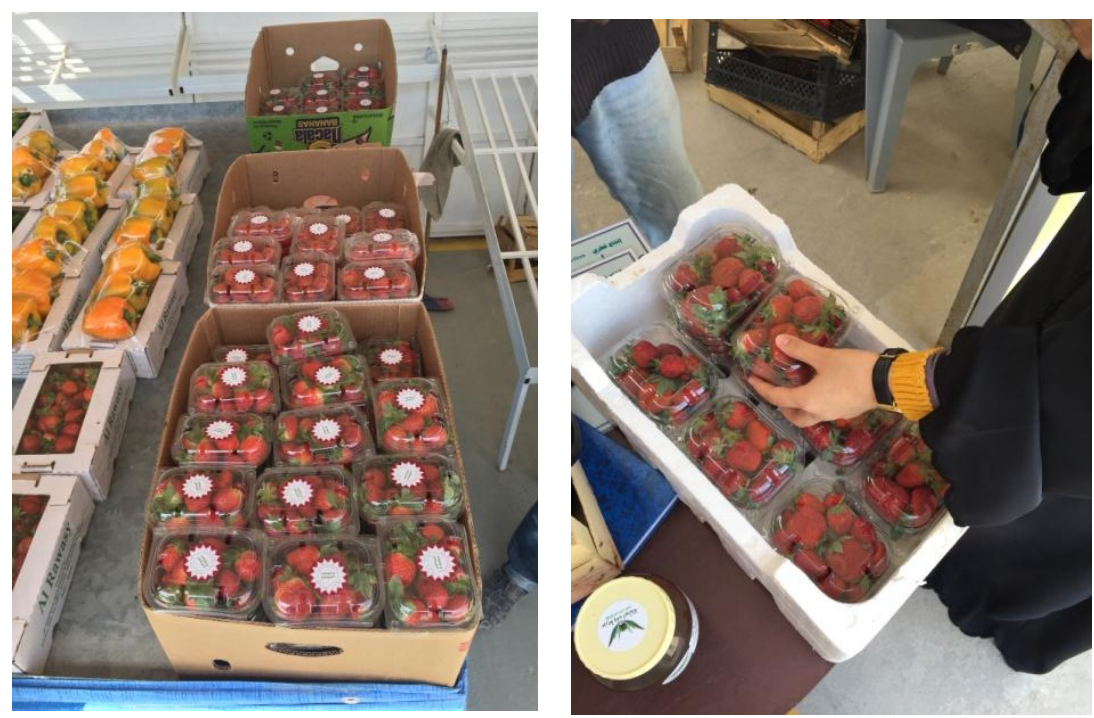

Figure 6: Collection of local fruit samples from Markets A, B \& C.

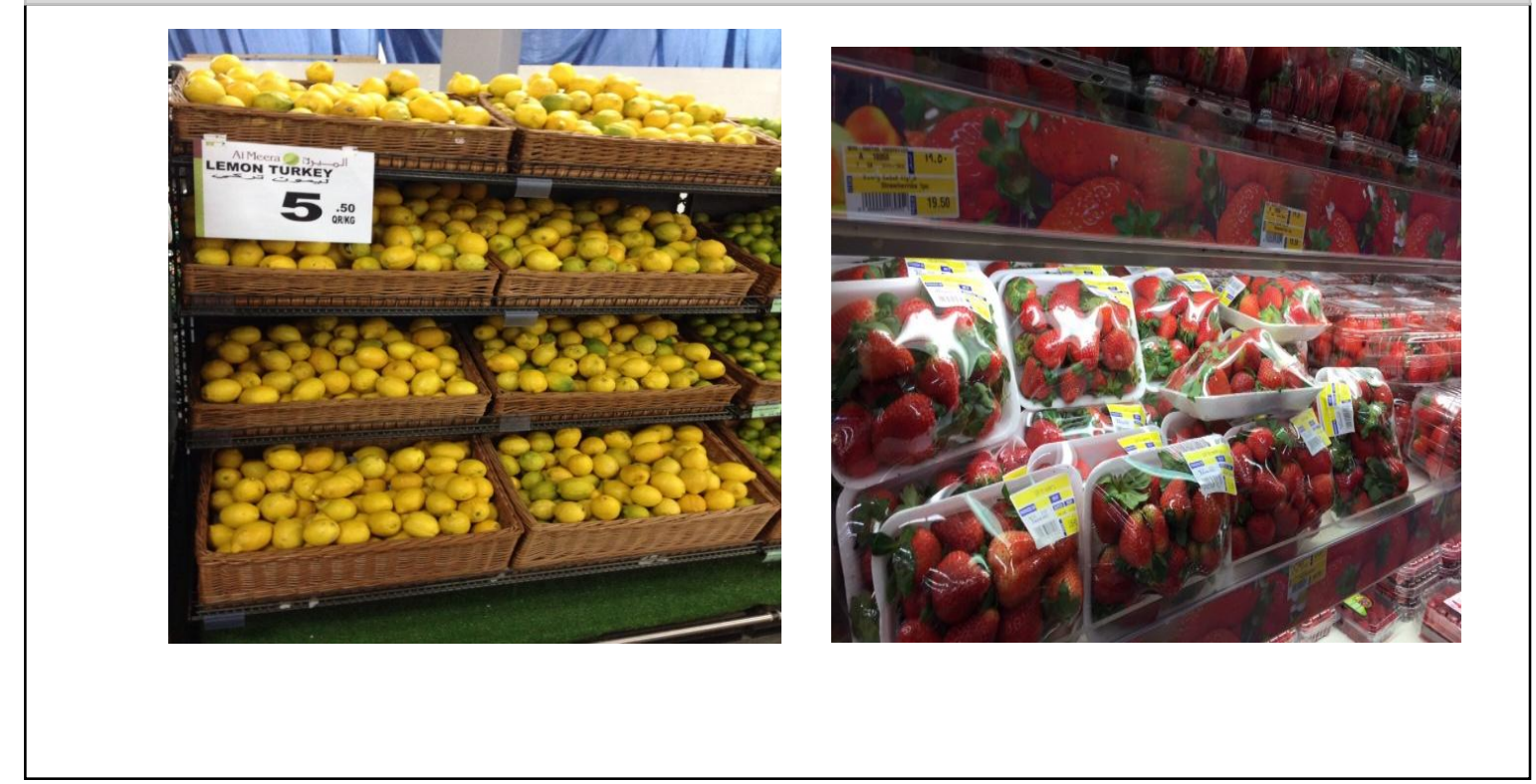




\subsection{Appendix 2: The Scope and Application of EPA Method 8081A METHOD 8081A \\ ORGANOCHLORINE PESTICIDES BY GAS CHROMATOGRAPHY}

\subsection{SCOPE AND APPLICATION}

1.1 Method 8081 is used to determine the concentrations of various organochlorine pesticides in extracts from solid and liquid matrices, using fused-silica, open-tubular, capillary columns with electron capture detectors (ECD). When compared to the packed columns, these columns offer improved resolution, better selectivity, increased sensitivity, and faster analysis. The compounds listed below may be determined by either a single- or dual-column analysis system.

\begin{tabular}{lr}
\hline Compound & CAS Registry No. \\
\hline & \\
\hline Aldrin & $309-00-2$ \\
$\alpha-B H C$ & $319-84-6$ \\
B-BHC & $319-85-7$ \\
Y-BHC (Lindane) & $58-89-9$ \\
O-BHC & $319-86-8$ \\
Chlorobenzilate & $510-15-6$ \\
$\alpha$-Chlordane & $5103-71-9$ \\
Y-Chlordane & $5103-74-2$ \\
Chlordane - not otherwise specified & $57-74-9$ \\
DBCP & $96-12-8$ \\
4,4'-DDD & $72-54-8$ \\
4,4'-DDE & $72-55-9$ \\
4,4'-DDT & $50-29-3$ \\
Diallate & $2303-16-4$ \\
Dieldrin & $60-57-1$ \\
Endosulfan I & $959-98-8$ \\
Endosulfan II & $33213-65-9$ \\
Endosulfan sulfate & $1031-07-8$ \\
Endrin & $72-20-8$ \\
Endrin aldehyde & $7421-93-4$ \\
Endrin ketone & $53494-70-5$ \\
Heptachlor & $76-44-8$ \\
Heptachlor epoxide & $1024-57-3$ \\
Hexachlorobenzene & $118-74-1$ \\
Hexachlorocyclopentadiene & $77-47-4$ \\
Isodrin & $465-73-6$ \\
Methoxychlor & $72-43-5$ \\
Toxaphene & $8001-35-2$ \\
\hline & \\
\hline \hline
\end{tabular}

1.2 This revision of Method 8081 no longer includes the PCBs as Aroclors in the list of target analytes. The analysis of PCBs should be undertaken using Method 8082 , which includes specific cleanup and quantitation procedures designed for PCB analysis. This change was made to obtain $\mathrm{PCB}$ data of better quality and to eliminate the complications inherent in a combined organochlorine pesticide and PCB method. Therefore, if the presence of PCBs is expected, use Method 8082 for 


\subsection{Appendix 3: Accelerated Solvent Extraction of Pesticide Residues in Food Products. Dionex Application Note 332, 2012.}

\section{Accelerated Solvent Extraction of Pesticide Residues in Food Products}

Introduction

Residue analysis in crops and food products is routinely performed in regulatory and industrial laboratories around the world. Many of the traditional procedures used to perform these extractions are time-consuming and solvent-intensive. Accelerated solvent extraction is an extraction technique that speeds the extraction process and reduces the total amount of solvent used. The system uses conventional liquid solvents at elevated temperatures and pressures, which results in increased extraction kinetics. Extraction of samples ranging from 1 to $30 \mathrm{~g}$ typically requires $12-17 \mathrm{~min}$ and $15-50 \mathrm{~mL}$ of solvent.

In the environmental industry, accelerated solvent extraction has been compared extensively to traditional preparation techniques, and has been found to generate similar extracts in a more efficient manner. Accelerated solvent extraction is now widely used in environmental applications to replace time- and solvent-intensive techniques such as Soxhlet and sonication. The principles of accelerated solvent extraction technology are based on conventional liquid extraction theory, so the transfer of existing solvent-based extraction processes to accelerated solvent extraction is simple. In addition, the ability to extract up to 24 samples unattended can result in a dramatic increase in laboratory efficiency.

\section{Equipment}

Thermo Scientific Dionex ASE 200 accelerated sovent extraction systern" equipped with 11,22 , or $33 \mathrm{~mL}$ cels

Thermo Scientific Dionex vials for collaction of extracts (40 mL, P/N 049465; 60 mL., P/N 049466)

\section{Cellulose filter disks (P/N 049458)}

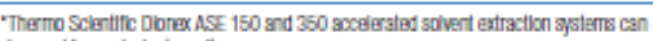
be used tor equalert results.

\section{Reagents}

Fisher Scientific Acatone, Optima grade

Fisher Scientific Acatonitrile, Optrma grade

Fisher Scientific Haxane, Optima grade

Thermo Scientific Dionex ASE Prep DE (P/N 062819)

Fisher Scientific sodium sulfate, anhydrous added after extraction

\section{Extraction Conditions}

\begin{tabular}{|c|c|}
\hline Terrperature: & $100^{\circ} \mathrm{C}$ \\
\hline Pressure: & 1500 psi* \\
\hline Heatup Time: & 5 min \\
\hline Static Time: & 5 min \\
\hline Flush Volume: & $60 \%$ \\
\hline Purge Time: & $100 \mathrm{~s}$ \\
\hline Static Cycles: & $1-2$ \\
\hline Total Extraction Time: & 14-18 min per sample \\
\hline Total Sohent Used: & $15-45 \mathrm{~mL}$ per sample \\
\hline
\end{tabular}


Sample Preparation

Weigh dry samples $(1-20 \mathrm{~g})$ and add directly to extraction cells containing a cellulose extraction filter. Grind wet samples $(1-10 \mathrm{~g})$ and mix with $6 \mathrm{~g}$ of Dionex ASE'M Prep DE (diatomaceous earth) using a mortar and pestle. Rinse the mortar and pestle with $2-3 \mathrm{~mL}$ of the extraction solvent. Add this volume to the sample in the extraction cell.

\section{Extraction}

Perform the sample extractions according to the outlined conditions. Following extraction, add $5 \mathrm{~g}$ of anhydrous sodium sulfate to the collection vial to absorb coextracted water. Shake the vial for $15 \mathrm{~s}$ and decant the water-free extract into a clean $60-\mathrm{mL}$ vial. Rinse the original vial with $5 \mathrm{~mL}$ of the extraction solvent and decant this volume into a second vial. Concentrate the combined volume to approximately $10 \mathrm{~mL}$ under nitrogen.

\section{Analytical}

Analyze organochlorine pesticides using a gas chromatograph with a $30 \mathrm{~m} \times 0.25 \mathrm{~mm}$ i.d. RTX-5 capillary column (Restek Corporation, Belefonte, USA). Set up a $1-\mu \mathrm{L}$ splitless injection volume with the injector at $275^{\circ} \mathrm{C}$ and the electron capture detector (ECD) maintained at $300^{\circ} \mathrm{C}$ with a nitrogen atmosphere. Program the run from $140^{\circ} \mathrm{C}(3 \mathrm{~min})$ to $265^{\circ} \mathrm{C}$ at $10^{\circ} \mathrm{C} / \mathrm{min}$. Quantify results using endosulfan $\mathrm{I}$ or endrin aldehyde as the internal standard. Pass pesticide extracts through carbon or C18 cleanup cartridges prior to analysis. Quantify results by GC analysis with ECD detection (U.S. EPA Method 8151) or GC with MS detection (U.S. EPA Method 8270).

Results and Discussion

Samples $(10 \mathrm{~g})$ of raw potato and banana were spiked with $100 \mu \mathrm{L}$ of a standard solution in hexane containing 12 organochlorine pesticides. Hexane with $10 \%$ acetone was chosen as the extraction solvent because it delivered good recoveries of the analytes with fewer interferences (co-extractables) than a 1:1 mixture. Resulting extracts were clear (after sodium sulfate treatment) upon concentration and suitable for GC/ECD analysis. The necessity of the drying step limits the amount of raw sample that can be extracted to $10 \mathrm{~g}$. Results are presented in Tables 1 and 2. These results represent three extractions with duplicate GC injections of each extract.
Tabla 1. Recovery of Organochlorine Pesticides Spiked onto Raw Banana at the 100 ppm Level"

\begin{tabular}{|c|c|c|c|}
\hline Compound & Av. Recovery (Y6) & SD (pg/kg) & RSD $\left(Y_{4}\right)$ \\
\hline$\alpha-\mathrm{BHC}$ & 100.3 & 2.3 & 2.3 \\
\hline$\beta-B H C$ & 1022 & 2.3 & 2.3 \\
\hline$\Upsilon$-BHC & 98.9 & 3.2 & 3.2 \\
\hline Heptachlor & 89.2 & 7.6 & 8.5 \\
\hline Aldrin & 89.4 & 2.2 & 2.5 \\
\hline Heptachlor Epoxide & 93.5 & 21 & 2.2 \\
\hline Dieldrin & 93.7 & 1.6 & 1.7 \\
\hline 4,4'-DDE & 92.1 & 1.8 & 1.9 \\
\hline 2,4'-DDD & 95.4 & 2.5 & 2.6 \\
\hline Endrin & 94.4 & 2.7 & 3.0 \\
\hline 4,4'-DOD & 88.0 & 2.7 & 3.0 \\
\hline 4,4'-DDT & 89.6 & 5.8 & 6.4 \\
\hline
\end{tabular}

$\cdot n=3$.

Tabla 2. Hecovery of Organochlorine Pesticides Spiked onto Paw Potato at the $100 \mathrm{ppm}$ Level"

\begin{tabular}{|c|c|c|c|}
\hline Compound & Av. Recovery ( 76 ) & SD (pg/kg) & RSD (\%) \\
\hline$\alpha-\mathrm{BHC}$ & 96.3 & 6.3 & 6.6 \\
\hline$\beta-\mathrm{BHC}$ & 108.6 & 2.3 & 2.1 \\
\hline Y-BHC & 97.4 & 6.6 & 6.8 \\
\hline Heptachlor & 93.9 & 3.5 & 3.7 \\
\hline Aldrin & 95.9 & 3.3 & 3.4 \\
\hline Heptachlor Epoxide & 95.2 & 24 & 26 \\
\hline Dieldrin & 97.1 & 0.55 & 0.57 \\
\hline 4,4'-DOE & 95.4 & 0.67 & 0.70 \\
\hline 2,4'-DDD & 95.7 & 0.85 & 0.89 \\
\hline Endrin & 97.8 & 1.8 & 1.9 \\
\hline 4,4'-DOD & 93.7 & 1.8 & 1.9 \\
\hline 4,4'-DOT & 93.0 & 4.5 & 4.8 \\
\hline
\end{tabular}


Table 3. Pacovery of Spiked Pesticides from Wheat by Accolarated Solvent Extraction

\begin{tabular}{|c|c|c|}
\hline Compound & $\begin{array}{l}\text { Spilke Lewel } \\
(\mathrm{pg} / \mathrm{kg})\end{array}$ & $\begin{array}{l}\text { Spilke Level } \\
\text { (pg/kg) }\end{array}$ \\
\hline o-Methoate & 74 & 85.4 \\
\hline Trifturalin & 44 & 99.6 \\
\hline Dichlorvos & 18 & 60.5 \\
\hline Phorate & 18 & 92.8 \\
\hline Demeton & 38 & 96.7 \\
\hline Dimathoate & 58 & 87.8 \\
\hline Carbofuran & 22 & 96.6 \\
\hline Atrazine & 14 & 92.8 \\
\hline Diazinon & 26 & 96.9 \\
\hline Disulfoton & 22 & 87.9 \\
\hline Triallate & 68 & 87.8 \\
\hline Parathion-mathyl & 40 & 115.7 \\
\hline Chlorpyrifos-mettyl & 8 & 115.4 \\
\hline Carbaryl & 92 & 54.1 \\
\hline Linuron & 102 & 83.6 \\
\hline Malathion & 22 & 104.5 \\
\hline Phorate-sulfone & 32 & 1057 \\
\hline Parathion & 84 & 101.2 \\
\hline Endosulfan-alpha & 56 & 94.1 \\
\hline Disulfoton-sulfone & 98 & 77.1 \\
\hline Imazali & 40 & 108.8 \\
\hline Endosulfan-beta & 68 & 93.3 \\
\hline Endosulfan sulfate & 20 & 77.0 \\
\hline Methoxychlor-o,p & 48 & 89.9 \\
\hline Diclofop-methyl & 36 & 81.8 \\
\hline Mathoxychlor-p,p' & 50 & 114.9 \\
\hline Azinphos-mattyl & 56 & 94.2 \\
\hline
\end{tabular}

A 5-g sample of ground wheat grain was spiked with $100 \mu \mathrm{L}$ of a standard solution containing 29 pesticides and herbicides at levels ranging from 8-102 ppb (see Table 3) and extracted at $100^{\circ} \mathrm{C}$ with acetonitrile. Spike levels and recovery results are shown in Table 3. Recoveries ranged from $54.1-115.7 \%$. The average recovery was $95.3 \%$ if the two outliers, dichlorvos and carbaryl, are excluded. Following the spike studies, 12 naturally incurred grain samples were extracted by the traditional wrist shaker extraction with acetonitrile, using postextraction solid phase extraction (SPE) deanup, and by accelerated solvent extraction using either acetone or acetonitrile as the extraction solvent. The accelerated solvent extraction took 12 min per sample and required 12-15 mL of solvent, while the shaker extraction took approximately $1 \mathrm{~h}$ per sample (including post-extraction SPE cleanup on carbon or C18) and used $130 \mathrm{~mL}$. of acetonitrile per sample. The accelerated solvent extraction extracts did not require post-extraction processing.

Extraction results for two compounds identified in these extracts, methyl chlorpyrifos and malathion, are shown in Table 4. The detected amounts compared well between the two techniques, with the accelerated solvent extraction values generally $10-20 \%$ higher. In all cases, samples with nondetectable levels (ND) were identified as such by both techniques. Acetonitrile and acetone appear to be good solvent choices for this application.

Table 4. Extraction of Incurred Pesticides in Wheat by accelerated solvent extraction and Cormentional Wrist Shaker Extraction

\begin{tabular}{|c|c|c|c|c|c|c|}
\hline \multirow{2}{*}{$\begin{array}{l}\text { Sample } \\
\text { No. }\end{array}$} & \multirow[b]{2}{*}{ Solvent } & \multirow{2}{*}{$\begin{array}{l}\text { Sample } \\
\text { Weight } \\
\text { (g) }\end{array}$} & \multicolumn{2}{|c|}{$\begin{array}{c}\text { Methyl Chlorpyrifos } \\
\text { (pg/kg) }\end{array}$} & \multicolumn{2}{|c|}{ Walathion (pg/kg) } \\
\hline & & & Shaker & \begin{tabular}{c|} 
Accelerated \\
Solvent \\
Extraction
\end{tabular} & $\begin{array}{l}\text { Wrist } \\
\text { Shaker }\end{array}$ & $\begin{array}{l}\text { Accelarated } \\
\text { Solvent } \\
\text { Extraction }\end{array}$ \\
\hline 1 & Acatone & 20.31 & 70 & 90 & 40 & 50 \\
\hline 2 & Acatone & 19.78 & 80 & 100 & 40 & 50 \\
\hline 3 & Acatone & 20.91 & 50 & 60 & 60 & 70 \\
\hline 4 & Acatone & 10.13 & ND & $\mathrm{ND}$ & ND & $\mathrm{ND}$ \\
\hline 5 & Acatone & 10.24 & 30 & 70 & 40 & 100 \\
\hline 6 & Acatone & 9.93 & ND & ND & ND & ND \\
\hline 7 & Acatone & 5.32 & ND & $\mathrm{ND}$ & ND & $\mathrm{ND}$ \\
\hline 8 & Acatone & 5.39 & ND & ND & ND & $\mathrm{ND}$ \\
\hline 9 & Acatonitrile & 19.85 & 60 & 80 & 60 & 80 \\
\hline 10 & Acatonitrile & 20.4 & 70 & 90 & 60 & 70 \\
\hline 11 & Acatonitrile & 5.30 & ND & ND & ND & ND \\
\hline
\end{tabular}

ND - not detected. 


\section{Conclusion}

Using accelerated solvent extraction, pesticide residue analysis laboratories can increase sample throughput while reducing overall solvent usage. The simplicity of the accelerated solvent extraction technique, combined with results showing excellent correlation to existing methods, have resulted in the rapid acceptance of accelerated solvent extraction for environmental analysis. The promulgation of U.S. EPA Method 3545 now provides a means for environmental test laboratories to take full advantage of accelerated solvent extraction technology. In addition to the wide range of target analytes covered under Method 3545 for organic pollutants in solid waste, accelerated solvent extraction has been applied successfully to the extraction of total petroleum hydrocarbons (TPH), dioxins, and furans from a variety of matrices. accelerated solvent extraction has also been applied to the extraction of explosives from soil, PCBs from fish and other marine tissues, and polyurethane foam (PUF) air sampling cartridges.

\section{Suppliers}

Fisher Scientific, 2000 Park Lane, Pittsburgh, PA 15275 1126 USA, Tel: 800-766-7000, www.fishersci.com.

Restek Corporation, 110 Benner Cir., Bellefonte, Pennsylvania, 16823 USA, Tel.: 814-353-1300, www.restekcorp.com.

"Extraction of TCL/PPL (Target Compound List/Priority Pollutant List) BNAs and Pesticides Using Accelerated Solvent Extraction with Analytical Validation by GC/MS and GC/ECD" Document 116064.A, Dionex Corporation (now part of Thermo Fisher Scientific), June 16, 1994.

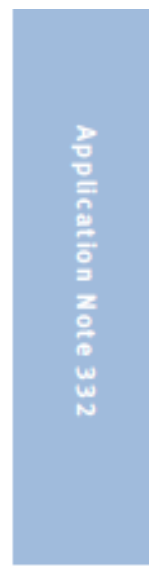

www.thermoscientific.com/dionex

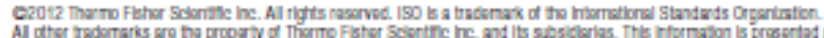

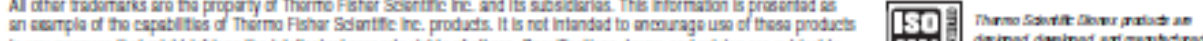

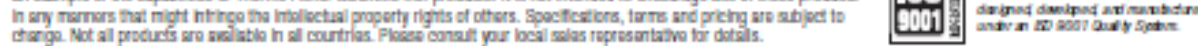

\section{Australla +61397574486 \\ Austrla +4316165125 \\ Benelux +31206839768 $+3233534294$ \\ China +85224283282 \\ Denmark +4536369090 France +33139300110 Germany +4961269910}

Brazll +551137315140 Indla +9122 2764 2735
Ireland +35316440064 Italy +390251621287 Japan +8 Jspan +816 68851213 Singapore +65 6289 1190
Sweden +4684733380 Switzerland +4162 2059966 Talwan +886287516655 UK +44 1276691722 USA and Canada +847 2957500
Thermo S C I EN T I F I C Part of Thermo Fisher Seientific

ANroess_E OSIZZ 


\title{
8.4 Appendix 4: The Scope and Application of EPA Method 3620C- Florisil Cleanup
}

\author{
METHOD 3620C
}

FLORISIL CLEANUP

\begin{abstract}
SW-846 is not intended to be an analytical training manual. Therefore, method procedures are written based on the assumption that they will be performed by analysts who are formally trained in at least the basic principles of chemical analysis and in the use of the subject technology.

In addition, SW-846 methods, with the exception of required method use for the analysis of method-defined parameters, are intended to be guidance methods which contain general information on how to perform an analytical procedure or technique which a laboratory can use as a basic starting point for generating its own detailed Standard Operating Procedure (SOP), either for its own general use or for a specific project application. The performance data included in this method are for guidance purposes only, and are not intended to be and must not be used as absolute QC acceptance criteria for purposes of laboratory accreditation.
\end{abstract}

\subsection{SCOPE AND APPLICATION}

1.1 Florisil( , a registered trade name of $\mathrm{U}$. S. Silica Co., is a magnesium silicate with basic properties. It is used to separate analytes from interfering compounds prior to sample analysis by a chromatographic method.

1.2 Florisil@ has been used for the cleanup of pesticide residues and other chlorinated hydrocarbons; the separation of nitrogen compounds from hydrocarbons; the separation of aromatic compounds from aliphatic-aromatic mixtures; and similar applications for use with fats, oils, and waxes. Additionally, Florisil® is considered good for separations with steroids, esters, ketones, glycerides, alkaloids, and some carbohydrates.

1.3 Florisil( cleanup may be accomplished by either using a glass chromatographic column packed with Florisilß or using solid-phase extraction cartridges containing Florisilß).

1.4 This method includes procedures for cleanup of sample extracts containing the following analyte groups:

$\begin{array}{ll}\text { Phthalate esters } & \text { Chlorinated hydrocarbons } \\ \text { Nitrosamines } & \text { Organochlorine pesticides } \\ \text { Nitroaromatics } & \text { Organophosphates } \\ \text { Haloethers } & \text { Organophosphorus pesticides } \\ \text { Aniline and aniline derivatives } & \text { PCBs }\end{array}$

Other analytes may potentially be cleaned up using this method provided that adequate performance is demonstrated.

1.5 Prior to employing this method, analysts are advised to consult the base method for each type of procedure that may be employed in the overall analysis (e.g., Methods 3500 , 3600,5000 , and 8000 ) for additional information on quality control procedures, development of QC acceptance criteria, calculations, and general guidance. Analysts also should consult the disclaimer statement at the front of the manual and the information in Chapter Two for guidance on the intended flexibility in the choice of methods, apparatus, materials, reagents, and

$$
3620 \mathrm{C}-1
$$

Revision 3 February 2007 


\title{
8.5 Appendix 5: EPA Method 3630- Silica Gel Cleanup
}

\author{
METHOD $3630 \mathrm{C}$
}

SILICA GEL CLEANUP

\subsection{SCOPE AND APPLICATION}

1.1 Silica gel (silicic acid) is a regenerative adsorbent of silica with weakly acidic properties. It is produced from sodium silicate and sulfuric acid. Silica gel can be used in column chromatography for the separation of analytes from interfering compounds of a different chemical polarity. It may be used activated, after heating to $150-160^{\circ} \mathrm{C}$, or deactivated with up to $10 \%$ water.

1.2 This method includes guidance for standard column cleanup of sample extracts containing polynuclear aromatic hydrocarbons, derivatized phenolic compounds, organochlorine pesticides, and PCBs as Aroclors.

1.3 This method also provides cleanup procedures using solid-phase extraction cartridges for pentafluorobenzyl bromide-derivatized phenols, organochlorine pesticides, and PCBs. This technique also provides the best separation of PCBs from most single component organochlorine pesticides. When only PCBs are to be measured, this method can be used in conjunction with sulfuric acid/permanganate cleanup (Method 3665).

1.4 Other analytes may be cleaned up using this method if the analyte recovery meets the criteria specified in Sec. 8.0.

1.5 This method is restricted to use by or under the supervision of trained analysts. Each analyst must demonstrate the ability to generate acceptable results with this method.

\subsection{SUMMARY OF METHOD}

2.1 This method provides the option of using either standard column chromatography techniques or solid-phase extraction cartridges. Generally, the standard column chromatography techniques use larger amounts of adsorbent and, therefore, have a greater cleanup capacity.

2.2 In the standard column cleanup protocol, the column is packed with the required amount of adsorbent, topped with a water adsorbent, and then loaded with the sample to be analyzed. Elution of the analytes is accomplished with a suitable solvent(s) that leaves the interfering compounds on the column. The eluate is then concentrated (if necessary).

2.3 The cartridge cleanup protocol uses solid-phase extraction cartridges packed with $1 \mathrm{~g}$ or $2 \mathrm{~g}$ of silica gel (silicic acid) adsorbent. Each cartridge is solvent washed immediately prior to use. Aliquots of sample extracts are loaded onto the cartridges, which are then eluted with suitable solvent(s). A vacuum manifold is required to obtain reproducible results. The collected fractions may be further concentrated prior to gas chromatographic analysis.

2.4 The appropriate gas chromatographic method is listed at the end of each technique. Analysis may also be performed by gas chromatography/mass spectrometry (Method 8270 ). 
8.6 Appendix 6: Data on Detection Limit (LOD) and Quantitation Limit (LOQ) Table1: Calculation of LOD and LOQ for a-BHC

\begin{tabular}{|l|c|c|}
\hline Column A & Column B & \\
\hline Analyte & a-BHC & Pesticides \\
\hline Spike Conc. & & 10 \\
\hline Units & 1 & ppb \\
\hline Replicate & 2 & 10.0560 \\
\hline Replicate & 3 & 10.5930 \\
\hline Replicate & 4 & 9.5870 \\
\hline Replicate & 5 & 8.6650 \\
\hline Replicate & 6 & 9.7530 \\
\hline Replicate & 7 & 10.8390 \\
\hline Replicate & 8 & 9.7580 \\
\hline Replicate & Average(B7..B14) & 9.6380 \\
\hline Mean & STDEV(B7..B14) & 0.6663 \\
\hline Std. Dev. & (t-value)*(B16) & 1.9989 \\
\hline LOD & $10 *$ B16 & 6.6631 \\
\hline LOQ & &
\end{tabular}

Table2: Calculation of LOD and LOQ for b-BHC

\begin{tabular}{|l|c|c|}
\hline Column A & Column B & \\
\hline Analyte & b-BHC & Pesticides \\
\hline Spike Conc. & & 10 \\
\hline Units & & ppb \\
\hline Replicate & 1 & 10.5000 \\
\hline Replicate & 2 & 10.1000 \\
\hline Replicate & 3 & 9.9000 \\
\hline Replicate & 4 & 9.8000 \\
\hline Replicate & 5 & 10.4000 \\
\hline Replicate & 6 & 10.0100 \\
\hline Replicate & 7 & 10.6000 \\
\hline Replicate & 8 & 8.9900 \\
\hline Mean & Average(B7..B14) & 10.0375 \\
\hline Std. Dev. & STDEV(B7..B14) & 0.5125 \\
\hline LOD & (t-value)(B16) & 1.5376 \\
\hline LOQ & $10 *$ B16 & 5.1255 \\
\hline
\end{tabular}


Table3: Calculation of LOD and LOQ for Heptachlor

\begin{tabular}{|l|c|c|}
\hline Column A & Column B & \\
\hline Analyte & Heptachlor & Pesticides \\
\hline Spike Conc. & & 10 \\
\hline Units & & ppb \\
\hline Replicate & 1 & 10.9850 \\
\hline Replicate & 2 & 10.5960 \\
\hline Replicate & 3 & 9.6570 \\
\hline Replicate & 4 & 9.6320 \\
\hline Replicate & 5 & 10.9520 \\
\hline Replicate & 6 & 9.7530 \\
\hline Replicate & 7 & 8.7620 \\
\hline Replicate & 8 & 9.8670 \\
\hline Mean & Average(B7..B14) & 10.0255 \\
\hline Std. Dev. & STDEV(B7..B14) & 0.7645 \\
\hline LOD & (t-value)*(B16) & 2.2934 \\
\hline LOQ & $10 *$ B16 & 7.6448 \\
\hline
\end{tabular}

Table4: Calculation of LOD and LOQ for Aldrin

\begin{tabular}{|l|c|c|}
\hline Column A & Column B & \\
\hline Analyte & Aldrin & Pesticides \\
\hline Spike Conc. & & 10 \\
\hline Units & & ppb \\
\hline Replicate & 1 & 12.1020 \\
\hline Replicate & 2 & 11.3560 \\
\hline Replicate & 3 & 12.0350 \\
\hline Replicate & 4 & 10.8960 \\
\hline Replicate & 5 & 10.9980 \\
\hline Replicate & 6 & 11.8560 \\
\hline Replicate & 7 & 11.9210 \\
\hline Replicate & 8 & 10.8640 \\
\hline Mean & Average(B7..B14) & 11.5035 \\
\hline Std. Dev. & STDEV(B7..B14) & 0.5338 \\
\hline LOD & (t-value)*(B16) & 1.6014 \\
\hline LOQ & $10 *$ B16 & 5.3380 \\
\hline
\end{tabular}


Table5: Calculation of LOD and LOQ for g-Chlordane

\begin{tabular}{|l|c|c|}
\hline Column A & Column B & \\
\hline Analyte & g-Chlordane & Pesticides \\
\hline Spike Conc. & & 10 \\
\hline Units & & ppb \\
\hline Replicate & 1 & 10.7590 \\
\hline Replicate & 2 & 9.8540 \\
\hline Replicate & 3 & 10.8350 \\
\hline Replicate & 4 & 10.3280 \\
\hline Replicate & 5 & 8.9560 \\
\hline Replicate & 6 & 9.7680 \\
\hline Replicate & 7 & 10.0230 \\
\hline Replicate & 8 & 11.0290 \\
\hline Mean & Average(B7..B14) & 10.1940 \\
\hline Std. Dev. & STDEV(B7..B14) & 0.6870 \\
\hline LOD & (t-value)*(B16) & 2.0611 \\
\hline LOQ & $10 *$ B16 & 6.8705 \\
\hline
\end{tabular}

Table6: Calculation of LOD and LOQ for Endosulfane I

\begin{tabular}{|l|c|c|}
\hline Column A & Column B & \\
\hline Analyte & Endosulfane I & Pesticides \\
\hline Spike Conc. & & 10 \\
\hline Units & & ppb \\
\hline Replicate & 1 & 10.6500 \\
\hline Replicate & 2 & 10.2560 \\
\hline Replicate & 3 & 9.6570 \\
\hline Replicate & 4 & 9.6310 \\
\hline Replicate & 5 & 10.9450 \\
\hline Replicate & 6 & 8.9700 \\
\hline Replicate & 7 & 9.7810 \\
\hline Replicate & 8 & 8.7530 \\
\hline Mean & Average(B7..B14) & 9.8304 \\
\hline Std. Dev. & STDEV(B7..B14) & 0.7624 \\
\hline LOD & (t-value)*(B16) & 2.2871 \\
\hline LOQ & $10 *$ B16 & 7.6238 \\
\hline
\end{tabular}


Table7: Calculation of LOD and LOQ for a-Chloordane

\begin{tabular}{|l|c|c|}
\hline Column A & Column B & \\
\hline Analyte & a-Chloordane & Pesticides \\
\hline Spike Conc. & & 10 \\
\hline Units & & ppb \\
\hline Replicate & 1 & 10.9840 \\
\hline Replicate & 2 & 9.5610 \\
\hline Replicate & 3 & 8.7520 \\
\hline Replicate & 4 & 9.7260 \\
\hline Replicate & 5 & 10.8630 \\
\hline Replicate & 6 & 11.0510 \\
\hline Replicate & 7 & 10.8860 \\
\hline Replicate & 8 & 9.7640 \\
\hline Mean & Average(B7..B14) & 10.1984 \\
\hline Std. Dev. & STDEV(B7..B14) & 0.8593 \\
\hline LOD & (t-value)(B16) & 2.5779 \\
\hline LOQ & $10 *$ B16 & 8.5930 \\
\hline
\end{tabular}

Table8: Calculation of LOD and LOQ for Dieldrin

\begin{tabular}{|l|c|c|}
\hline Column A & Column B & \\
\hline Analyte & Dieldrin & Pesticides \\
\hline Spike Conc. & & 10 \\
\hline Units & & ppb \\
\hline Replicate & 1 & 11.0150 \\
\hline Replicate & 3 & 10.9870 \\
\hline Replicate & 4 & 11.2050 \\
\hline Replicate & 5 & 9.8520 \\
\hline Replicate & 6 & 10.8610 \\
\hline Replicate & 7 & 9.6480 \\
\hline Replicate & 8 & 9.2870 \\
\hline Replicate & Average(B7..B14) & 10.9350 \\
\hline Mean & STDEV(B7..B14) & 0.4738 \\
\hline Std. Dev. & (t-value)*(B16) & 2.2480 \\
\hline LOD & $10 *$ B16 & 7.4935 \\
\hline LOQ & &
\end{tabular}


Table9: Calculation of LOD and LOQ for Endrin

\begin{tabular}{|l|c|c|}
\hline Column A & Column B & \\
\hline Analyte & Endrin & Pesticides \\
\hline Spike Conc. & & 10 \\
\hline Units & 1 & ppb \\
\hline Replicate & 2 & 10.5240 \\
\hline Replicate & 3 & 10.2680 \\
\hline Replicate & 4 & 9.8460 \\
\hline Replicate & 5 & 10.8320 \\
\hline Replicate & 6 & 9.8870 \\
\hline Replicate & 7 & 9.7630 \\
\hline Replicate & 8 & 10.8710 \\
\hline Replicate & Average(B7..B14) & 10.1180 \\
\hline Mean & STDEV(B7..B14) & 0.6408 \\
\hline Std. Dev. & (t-value)(B16) & 1.9225 \\
\hline LOD & $10 *$ B16 & 6.4084 \\
\hline LOQ & &
\end{tabular}

Table10: Calculation of LOD and LOQ for Methoxychlor

\begin{tabular}{|l|c|c|}
\hline Column A & Column B & \\
\hline Analyte & Methoxychlor & Pesticides \\
\hline Spike Conc. & & 10 \\
\hline Units & & ppb \\
\hline Replicate & 1 & 12.0640 \\
\hline Replicate & 2 & 11.7830 \\
\hline Replicate & 3 & 11.3520 \\
\hline Replicate & 4 & 10.9860 \\
\hline Replicate & 5 & 10.6830 \\
\hline Replicate & 6 & 12.1530 \\
\hline Replicate & 8 & 11.8710 \\
\hline Replicate & Average(B7..B14) & 10.8920 \\
\hline Mean & STDEV(B7..B14) & 11.4730 \\
\hline Std. Dev. & (t-value)(B16) & 0.5707 \\
\hline LOD & $10 *$ B16 & 1.7120 \\
\hline LOQ & & 5.7067 \\
\hline
\end{tabular}




\subsection{Appendix 7: Results for OCPs concentration in local vegetables and fruit}

Table 1: OCPs concentration in local cucumber

\begin{tabular}{|c|c|c|c|c|c|c|c|c|c|c|c|c|}
\hline \multirow{4}{*}{$\frac{\text { OCPs }}{\mathrm{a}-\mathrm{BHC}}$} & \multicolumn{12}{|c|}{ cucumber } \\
\hline & \multicolumn{6}{|c|}{ washed } & \multicolumn{6}{|c|}{ unwashed } \\
\hline & \multicolumn{4}{|c|}{ Farm\#649 } & \multicolumn{2}{|c|}{ Farm\#953 } & \multicolumn{4}{|c|}{ Farm\#649 } & \multicolumn{2}{|c|}{ Farm\#953 } \\
\hline & $<\mathrm{LOQ}$ & $<\mathrm{LOQ}$ & $\angle \mathrm{LOQ}$ & $\angle \mathrm{LOQ}$ & $\angle \mathrm{LOQ}$ & $\angle \mathrm{LOQ}$ & $<\mathrm{LOQ}$ & $<\mathrm{LOQ}$ & $<\mathrm{LOQ}$ & $<\mathrm{LOQ}$ & $\angle \mathrm{LOQ}$ & $\angle \mathrm{LOQ}$ \\
\hline $\mathrm{b}-\mathrm{BHC}$ & $\angle \mathrm{LOQ}$ & $\angle \mathrm{LOQ}$ & $\angle \mathrm{LOQ}$ & $\angle \mathrm{LOQ}$ & $\angle \mathrm{LOQ}$ & $\angle \mathrm{LOQ}$ & $<\mathrm{LOQ}$ & $\angle \mathrm{LOQ}$ & $\angle \mathrm{LOQ}$ & $\angle \mathrm{LOQ}$ & $\angle \mathrm{LOQ}$ & $\angle \mathrm{LOQ}$ \\
\hline Heptachlor & $<\mathrm{LOQ}$ & $<\mathrm{LOQ}$ & $\angle \mathrm{LOQ}$ & $\angle \mathrm{LOQ}$ & $\angle \mathrm{LOQ}$ & $\angle \mathrm{LOQ}$ & $<\mathrm{LOQ}$ & $<\mathrm{LOQ}$ & $\angle \mathrm{LOQ}$ & $\angle \mathrm{LOQ}$ & $\angle \mathrm{LOQ}$ & $\angle \mathrm{LOQ}$ \\
\hline Aldrin & $<\mathrm{LOQ}$ & $<\mathrm{LOQ}$ & $\angle \mathrm{LOQ}$ & $\angle \mathrm{LOQ}$ & $\angle \mathrm{LOQ}$ & 10.92 & $<\mathrm{LOQ}$ & $<\mathrm{LOQ}$ & $<\mathrm{LOQ}$ & $<\mathrm{LOQ}$ & 17.64 & $\angle \mathrm{LOQ}$ \\
\hline g-Chlordane & $<\mathrm{LOQ}$ & $<\mathrm{LOQ}$ & $\angle \mathrm{LOQ}$ & $\angle \mathrm{LOQ}$ & $<\mathrm{LOQ}$ & $\angle \mathrm{LOQ}$ & $<\mathrm{LOQ}$ & $<\mathrm{LOQ}$ & $<\mathrm{LOQ}$ & $<\mathrm{LOQ}$ & $\angle \mathrm{LOQ}$ & $\angle \mathrm{LOQ}$ \\
\hline Endosulfane I & $<\mathrm{LOQ}$ & $\angle \mathrm{LOQ}$ & $\angle \mathrm{LOQ}$ & $\angle \mathrm{LOQ}$ & $\angle \mathrm{LOQ}$ & $\angle \mathrm{LOQ}$ & $<\mathrm{LOQ}$ & $\angle \mathrm{LOQ}$ & $<\mathrm{LOQ}$ & $\angle \mathrm{LOQ}$ & $\angle \mathrm{LOQ}$ & $\angle \mathrm{LOQ}$ \\
\hline a-Chlordane & $<\mathrm{LOQ}$ & $<\mathrm{LOQ}$ & $\angle \mathrm{LOQ}$ & $\angle \mathrm{LOQ}$ & $\angle \mathrm{LOQ}$ & $\angle \mathrm{LOQ}$ & $<\mathrm{LOQ}$ & $\angle \mathrm{LOQ}$ & $<\mathrm{LOQ}$ & $<\mathrm{LOQ}$ & $<\mathrm{LOQ}$ & $\angle \mathrm{LOQ}$ \\
\hline Dieldrin & $<\mathrm{LOQ}$ & $\angle \mathrm{LOQ}$ & $\angle \mathrm{LOQ}$ & $\angle \mathrm{LOQ}$ & $\angle \mathrm{LOQ}$ & $\angle \mathrm{LOQ}$ & $<\mathrm{LOQ}$ & $\angle \mathrm{LOQ}$ & $<\mathrm{LOQ}$ & $\angle \mathrm{LOQ}$ & $\angle \mathrm{LOQ}$ & $\angle \mathrm{LOQ}$ \\
\hline Endrin & $<\mathrm{LOQ}$ & $\angle \mathrm{LOQ}$ & $\angle \mathrm{LOQ}$ & $\angle \mathrm{LOQ}$ & $\angle \mathrm{LOQ}$ & $\angle \mathrm{LOQ}$ & $<\mathrm{LOQ}$ & $\angle \mathrm{LOQ}$ & $<\mathrm{LOQ}$ & $<\mathrm{LOQ}$ & $\angle \mathrm{LOQ}$ & $\angle \mathrm{LOQ}$ \\
\hline Methoxychlor & $\angle \mathrm{LOQ}$ & $\angle \mathrm{LOQ}$ & $\angle \mathrm{LOQ}$ & $\angle \mathrm{LOQ}$ & $\angle \mathrm{LOQ}$ & $\angle \mathrm{LOQ}$ & $\angle \mathrm{LOQ}$ & $\angle \mathrm{LOQ}$ & $<\mathrm{LOQ}$ & $\angle \mathrm{LOQ}$ & $\angle \mathrm{LOQ}$ & $<\mathrm{LOQ}$ \\
\hline
\end{tabular}


Table 2: OCPs concentration in local tomatoes

\begin{tabular}{|c|c|c|c|c|c|c|c|c|c|c|c|c|}
\hline \multirow{4}{*}{$\begin{array}{c}\text { OCPs } \\
\mathrm{a}-\mathrm{BHC}\end{array}$} & \multicolumn{12}{|c|}{ Tomatoes } \\
\hline & \multicolumn{6}{|c|}{ washed } & \multicolumn{6}{|c|}{ unwashed } \\
\hline & \multicolumn{2}{|c|}{ Farm\#197 } & \multicolumn{2}{|c|}{ Farm\#953 } & \multicolumn{2}{|c|}{ Farm\#241 } & \multicolumn{2}{|c|}{ Farm\#197 } & \multicolumn{2}{|c|}{ Farm\#953 } & \multicolumn{2}{|c|}{ Farm\#241 } \\
\hline & $<\mathrm{LOQ}$ & $<\mathrm{LOQ}$ & $\angle \mathrm{LOQ}$ & $<\mathrm{LOQ}$ & $<\mathrm{LOQ}$ & $<\mathrm{LOQ}$ & $<\mathrm{LOQ}$ & $\angle \mathrm{LOQ}$ & $<\mathrm{LOQ}$ & $<\mathrm{LOQ}$ & $<\mathrm{LOQ}$ & $\angle \mathrm{LOQ}$ \\
\hline $\mathrm{b}-\mathrm{BHC}$ & $\angle \mathrm{LOQ}$ & $\angle \mathrm{LOQ}$ & $\angle \mathrm{LOQ}$ & $\angle \mathrm{LOQ}$ & $\angle \mathrm{LOQ}$ & $\angle \mathrm{LOQ}$ & $\angle \mathrm{LOQ}$ & $\angle \mathrm{LOQ}$ & $\angle \mathrm{LOQ}$ & $\angle \mathrm{LOQ}$ & $\angle \mathrm{LOQ}$ & $\angle \mathrm{LOQ}$ \\
\hline Heptachlor & $<\mathrm{LOQ}$ & $<\mathrm{LOQ}$ & $<\mathrm{LOQ}$ & $<\mathrm{LOQ}$ & $<\mathrm{LOQ}$ & $<\mathrm{LOQ}$ & $<\mathrm{LOQ}$ & $<\mathrm{LOQ}$ & $<\mathrm{LOQ}$ & $<\mathrm{LOQ}$ & $\angle \mathrm{LOQ}$ & $\angle \mathrm{LOQ}$ \\
\hline Aldrin & $\angle \mathrm{LOQ}$ & $\angle \mathrm{LOQ}$ & $\angle \mathrm{LOQ}$ & $\angle \mathrm{LOQ}$ & $\angle \mathrm{LOQ}$ & $\angle \mathrm{LOQ}$ & $\angle \mathrm{LOQ}$ & $\angle \mathrm{LOQ}$ & $\angle \mathrm{LOQ}$ & 7.06 & 11.99 & $\angle \mathrm{LOQ}$ \\
\hline g-Chlordane & $\angle \mathrm{LOQ}$ & $\angle \mathrm{LOQ}$ & $\angle \mathrm{LOQ}$ & $\angle \mathrm{LOQ}$ & $\angle \mathrm{LOQ}$ & $\angle \mathrm{LOQ}$ & $\angle \mathrm{LOQ}$ & $\angle \mathrm{LOQ}$ & $\angle \mathrm{LOQ}$ & $\angle \mathrm{LOQ}$ & $\angle \mathrm{LOQ}$ & $\angle \mathrm{LOQ}$ \\
\hline Endosulfane I & $\angle \mathrm{LOQ}$ & $\angle \mathrm{LOQ}$ & $\angle \mathrm{LOQ}$ & $<\mathrm{LOQ}$ & $\angle \mathrm{LOQ}$ & $\angle \mathrm{LOQ}$ & $<\mathrm{LOQ}$ & $\angle \mathrm{LOQ}$ & $\angle \mathrm{LOQ}$ & $<\mathrm{LOQ}$ & $\angle \mathrm{LOQ}$ & $\angle \mathrm{LOQ}$ \\
\hline a-Chlordane & $\angle \mathrm{LOQ}$ & $\angle \mathrm{LOQ}$ & $\angle \mathrm{LOQ}$ & $<\mathrm{LOQ}$ & $\angle \mathrm{LOQ}$ & $\angle \mathrm{LOQ}$ & $\angle \mathrm{LOQ}$ & $\angle \mathrm{LOQ}$ & $\angle \mathrm{LOQ}$ & $<\mathrm{LOQ}$ & $\angle \mathrm{LOQ}$ & $\angle \mathrm{LOQ}$ \\
\hline Dieldrin & $<\mathrm{LOQ}$ & $<\mathrm{LOQ}$ & $\angle \mathrm{LOQ}$ & $<\mathrm{LOQ}$ & $\angle \mathrm{LOQ}$ & $<\mathrm{LOQ}$ & $<\mathrm{LOQ}$ & $\angle \mathrm{LOQ}$ & $<\mathrm{LOQ}$ & $<\mathrm{LOQ}$ & $<\mathrm{LOQ}$ & $\angle \mathrm{LOQ}$ \\
\hline Endrin & $<\mathrm{LOQ}$ & $<\mathrm{LOQ}$ & $\angle \mathrm{LOQ}$ & $\angle \mathrm{LOQ}$ & $\angle \mathrm{LOQ}$ & $\angle \mathrm{LOQ}$ & $<\mathrm{LOQ}$ & $\angle \mathrm{LOQ}$ & $\angle \mathrm{LOQ}$ & $<\mathrm{LOQ}$ & $\angle \mathrm{LOQ}$ & $\angle \mathrm{LOQ}$ \\
\hline Methoxychlor & $\angle \mathrm{LOQ}$ & $\angle \mathrm{LOQ}$ & $\angle \mathrm{LOQ}$ & $<\mathrm{LOQ}$ & $<\mathrm{LOQ}$ & $\angle \mathrm{LOQ}$ & $\angle \mathrm{LOQ}$ & $\angle \mathrm{LOQ}$ & $\angle \mathrm{LOQ}$ & $<\mathrm{LOQ}$ & $<\mathrm{LOQ}$ & $\angle \mathrm{LOQ}$ \\
\hline
\end{tabular}


Table 3: OCPs concentration in local parsley

\begin{tabular}{|l|c|c|c|c|c|c|c|c|c|c|}
\cline { 2 - 14 } \multicolumn{1}{c|}{} & \multicolumn{9}{c|}{ Parsley } \\
\cline { 2 - 14 } \multicolumn{1}{c|}{ OCPs } & Farm\#224 & Farm\#963 & Farm\#696 & Farm\#1224 & Farm\#260 & Farm\#224 & Farm\#963 & Farm\#696 & Farm\#1224 & Farm\#260 \\
\hline a-BHC & $<\mathrm{LOQ}$ & $<\mathrm{LOQ}$ & $<\mathrm{LOQ}$ & $<\mathrm{LOQ}$ & $<\mathrm{LOQ}$ & $<\mathrm{LOQ}$ & $<\mathrm{LOQ}$ & $<\mathrm{LOQ}$ & $<\mathrm{LOQ}$ & $<\mathrm{LOQ}$ \\
\hline b-BHC & $<\mathrm{LOQ}$ & $<\mathrm{LOQ}$ & $<\mathrm{LOQ}$ & $<\mathrm{LOQ}$ & $<\mathrm{LOQ}$ & $<\mathrm{LOQ}$ & $<\mathrm{LOQ}$ & $<\mathrm{LOQ}$ & $<\mathrm{LOQ}$ & $<\mathrm{LOQ}$ \\
\hline Heptachlor & 17.11 & $<\mathrm{LOQ}$ & 33.56 & 31.84 & 33.14 & 22.75 & 24.20 & 28.52 & 25.10 & $<\mathrm{LOQ}$ \\
\hline Aldrin & $<\mathrm{LOQ}$ & 11.21 & 13.99 & 5.81 & $<\mathrm{LOQ}$ & 8.89 & 14.01 & 5.84 & $<\mathrm{LOQ}$ & $<\mathrm{LOQ}$ \\
\hline g-Chlordane & 22.03 & 15.37 & 10.59 & 18.16 & 14.65 & 18.06 & 15.17 & 8.44 & 12.00 & 19.45 \\
\hline Endosulfane I & 13.54 & 10.83 & 56.45 & 32.24 & 76.72 & 14.84 & 17.77 & 18.58 & 12.08 & 17.55 \\
\hline a-Chlordane & $<\mathrm{LOQ}$ & $<\mathrm{LOQ}$ & $<\mathrm{LOQ}$ & $<\mathrm{LOQ}$ & $<\mathrm{LOQ}$ & $<\mathrm{LOQ}$ & $<\mathrm{LOQ}$ & $<\mathrm{LOQ}$ & $<\mathrm{LOQ}$ & $<\mathrm{LOQ}$ \\
\hline Dieldrin & $<\mathrm{LOQ}$ & $<\mathrm{LOQ}$ & $<\mathrm{LOQ}$ & 6.54 & $<\mathrm{LOQ}$ & $<\mathrm{LOQ}$ & $<\mathrm{LOQ}$ & 23.04 & $<\mathrm{LOQ}$ & $<\mathrm{LOQ}$ \\
\hline Endrin & 7.25 & 8.74 & 7.23 & 7.07 & 7.72 & 8.17 & 6.76 & 7.74 & 6.92 & $<\mathrm{LOQ}$ \\
\hline Methoxychlor & 10.95 & 11.32 & 18.27 & 14.31 & $<\mathrm{LOQ}$ & 12.82 & 18.76 & 9.61 & 17.97 & 18.59 \\
\hline
\end{tabular}


Table 4: OCPs concentration in local watercress

\begin{tabular}{|l|c|c|c|c|c|c|c|c|c|c|}
\cline { 2 - 14 } \multicolumn{1}{c|}{} & \multicolumn{9}{c|}{ Watercress } \\
\cline { 2 - 14 } \multicolumn{1}{c|}{ OCPs } & MoE farm & Farm\# 576 & Farm\#963 & Farm\#183 & Farm\#701 & MoE farm & Farm\# 576 & Farm\#963 & Farm\#183 & Farm\#701 \\
\hline a-BHC & $\mathrm{LOQ}$ & $<\mathrm{LOQ}$ & $<\mathrm{LOQ}$ & $<\mathrm{LOQ}$ & $<\mathrm{LOQ}$ & $<\mathrm{LOQ}$ & $<\mathrm{LOQ}$ & $<\mathrm{LOQ}$ & $<\mathrm{LOQ}$ & $<\mathrm{LOQ}$ \\
\hline b-BHC & $\mathrm{LOQ}$ & $<\mathrm{LOQ}$ & $<\mathrm{LOQ}$ & $<\mathrm{LOQ}$ & $<\mathrm{LOQ}$ & $<\mathrm{LOQ}$ & $<\mathrm{LOQ}$ & $<\mathrm{LOQ}$ & $<\mathrm{LOQ}$ & $<\mathrm{LOQ}$ \\
\hline Heptachlor & 18.86 & 53.43 & 30.52 & 20.11 & 37.86 & 17.11 & 22.51 & 33.75 & 16.43 & 24.21 \\
\hline Aldrin & 9.22 & 10.17 & $<\mathrm{LOQ}$ & 19.57 & 18.76 & $<\mathrm{LOQ}$ & $<\mathrm{LOQ}$ & $<\mathrm{LOQ}$ & $<\mathrm{LOQ}$ & $<\mathrm{LOQ}$ \\
\hline g-Chlordane & 9.92 & 8.92 & 4.81 & 13.59 & 43.15 & 16.24 & 16.67 & 4.78 & 4.32 & 50.51 \\
\hline Endosulfane I & $<\mathrm{LOQ}$ & $<\mathrm{LOQ}$ & $<\mathrm{LOQ}$ & 9.23 & $<\mathrm{LOQ}$ & $<\mathrm{LOQ}$ & $<\mathrm{LOQ}$ & $<\mathrm{LOQ}$ & 10.10 & $<\mathrm{LOQ}$ \\
\hline a-Chlordane & 16.61 & 11.35 & 25.29 & 17.20 & 20.97 & 12.57 & 20.63 & 32.14 & 45.88 & 24.56 \\
\hline Dieldrin & 14.02 & 10.61 & 6.45 & 14.45 & 6.45 & 10.93 & 16.17 & 4.90 & 7.78 & $<\mathrm{LOQ}$ \\
\hline Endrin & $<\mathrm{LOQ}$ & $<\mathrm{LOQ}$ & $<\mathrm{LOQ}$ & $<\mathrm{LOQ}$ & $<\mathrm{LOQ}$ & $<\mathrm{LOQ}$ & $<\mathrm{LOQ}$ & 6.67 & $<\mathrm{LOQ}$ & 7.55 \\
\hline Methoxychlor & $<\mathrm{LOQ}$ & $<\mathrm{LOQ}$ & $<\mathrm{LOQ}$ & $<\mathrm{LOQ}$ & $<\mathrm{LOQ}$ & $<\mathrm{LOQ}$ & $<\mathrm{LOQ}$ & $<\mathrm{LOQ}$ & 15.16 & 7.16 \\
\hline
\end{tabular}


Table 5: OCPs concentration in local strawberries

\begin{tabular}{|c|c|c|c|c|c|c|c|c|c|c|c|c|c|c|}
\hline \multirow{4}{*}{$\begin{array}{c}\text { OCPs } \\
\text { a-BHC }\end{array}$} & \multicolumn{14}{|c|}{ Strawberries } \\
\hline & \multicolumn{7}{|c|}{ washed } & \multicolumn{7}{|c|}{ unwashed } \\
\hline & \multicolumn{5}{|c|}{ Farm\#301 } & \multicolumn{2}{|c|}{ Farm\#1223 } & \multicolumn{5}{|c|}{ Farm\#301 } & \multicolumn{2}{|c|}{ Farm\#1223 } \\
\hline & $\angle \mathrm{LOQ}$ & $\angle \mathrm{LOQ}$ & $<\mathrm{LOQ}$ & $<\mathrm{LOQ}$ & $\angle \mathrm{LOQ}$ & $\angle \mathrm{LOQ}$ & $\angle \mathrm{LOQ}$ & $\angle \mathrm{LOQ}$ & $\angle \mathrm{LOQ}$ & $\angle \mathrm{LOQ}$ & $\angle \mathrm{LOQ}$ & $\angle \mathrm{LOQ}$ & $\angle \mathrm{LOQ}$ & $<\mathrm{LOQ}$ \\
\hline $\mathrm{b}-\mathrm{BHC}$ & $\angle \mathrm{LOQ}$ & $\angle \mathrm{LOQ}$ & $<\mathrm{LOQ}$ & $<\mathrm{LOQ}$ & $\angle \mathrm{LOQ}$ & $\angle \mathrm{LOQ}$ & $\angle \mathrm{LOQ}$ & $\angle \mathrm{LOQ}$ & $\angle \mathrm{LOQ}$ & $\angle \mathrm{LOQ}$ & $\angle \mathrm{LOQ}$ & $\angle \mathrm{LOQ}$ & $\angle \mathrm{LOQ}$ & $<\mathrm{LOQ}$ \\
\hline Heptachlor & $\angle \mathrm{LOQ}$ & $\angle \mathrm{LOQ}$ & $\angle \mathrm{LOQ}$ & $\angle \mathrm{LOQ}$ & $\angle \mathrm{LOQ}$ & $\angle \mathrm{LOQ}$ & $\angle \mathrm{LOQ}$ & $\angle \mathrm{LOQ}$ & $\angle \mathrm{LOQ}$ & $\angle \mathrm{LOQ}$ & $\angle \mathrm{LOQ}$ & $\angle \mathrm{LOQ}$ & $\angle \mathrm{LOQ}$ & $\angle \mathrm{LOQ}$ \\
\hline Aldrin & $\angle \mathrm{LOQ}$ & $\angle \mathrm{LOQ}$ & $<\mathrm{LOQ}$ & $<\mathrm{LOQ}$ & $\angle \mathrm{LOQ}$ & $\angle \mathrm{LOQ}$ & $\angle \mathrm{LOQ}$ & $\angle \mathrm{LOQ}$ & $\angle \mathrm{LOQ}$ & $\angle \mathrm{LOQ}$ & $\angle \mathrm{LOQ}$ & $\angle \mathrm{LOQ}$ & 10.85 & 17.54 \\
\hline g-Chlordane & $\angle \mathrm{LOQ}$ & $\angle \mathrm{LOQ}$ & $<\mathrm{LOQ}$ & $<\mathrm{LOQ}$ & $\angle \mathrm{LOQ}$ & $\angle \mathrm{LOQ}$ & $\angle \mathrm{LOQ}$ & $\angle \mathrm{LOQ}$ & $\angle \mathrm{LOQ}$ & $\angle \mathrm{LOQ}$ & $\angle \mathrm{LOQ}$ & $\angle \mathrm{LOQ}$ & $\angle \mathrm{LOQ}$ & $\angle \mathrm{LOQ}$ \\
\hline Endosulfane I & $\angle \mathrm{LOQ}$ & $\angle \mathrm{LOQ}$ & $\angle \mathrm{LOQ}$ & $\angle \mathrm{LOQ}$ & $\angle \mathrm{LOQ}$ & $\angle \mathrm{LOQ}$ & $\angle \mathrm{LOQ}$ & $\angle \mathrm{LOQ}$ & $\angle \mathrm{LOQ}$ & $\angle \mathrm{LOQ}$ & $\angle \mathrm{LOQ}$ & $\angle \mathrm{LOQ}$ & $\angle \mathrm{LOQ}$ & $<\mathrm{LOQ}$ \\
\hline a-Chlordane & $\angle \mathrm{LOQ}$ & $\angle \mathrm{LOQ}$ & $<\mathrm{LOQ}$ & $<\mathrm{LOQ}$ & $\angle \mathrm{LOQ}$ & $\angle \mathrm{LOQ}$ & $\angle \mathrm{LOQ}$ & $<\mathrm{LOQ}$ & $\angle \mathrm{LOQ}$ & $\angle \mathrm{LOQ}$ & $\angle \mathrm{LOQ}$ & $\angle \mathrm{LOQ}$ & $\angle \mathrm{LOQ}$ & $\angle \mathrm{LOQ}$ \\
\hline Dieldrin & $\angle \mathrm{LOQ}$ & $\angle \mathrm{LOQ}$ & $<\mathrm{LOQ}$ & $<\mathrm{LOQ}$ & $\angle \mathrm{LOQ}$ & $\angle \mathrm{LOQ}$ & $\angle \mathrm{LOQ}$ & $\angle \mathrm{LOQ}$ & $\angle \mathrm{LOQ}$ & $\angle \mathrm{LOQ}$ & $\angle \mathrm{LOQ}$ & $\angle \mathrm{LOQ}$ & $\angle \mathrm{LOQ}$ & $\angle \mathrm{LOQ}$ \\
\hline Endrin & $\angle \mathrm{LOQ}$ & $\angle \mathrm{LOQ}$ & $\angle \mathrm{LOQ}$ & $<\mathrm{LOQ}$ & $\angle \mathrm{LOQ}$ & $\angle \mathrm{LOQ}$ & $\angle \mathrm{LOQ}$ & $\angle \mathrm{LOQ}$ & $\angle \mathrm{LOQ}$ & $\angle \mathrm{LOQ}$ & $\angle \mathrm{LOQ}$ & $\angle \mathrm{LOQ}$ & $\angle \mathrm{LOQ}$ & $\angle \mathrm{LOQ}$ \\
\hline Methoxychlor & $\angle \mathrm{LOQ}$ & $\angle \mathrm{LOQ}$ & $<\mathrm{LOQ}$ & $<\mathrm{LOQ}$ & $\angle \mathrm{LOQ}$ & $\angle \mathrm{LOQ}$ & $\angle \mathrm{LOQ}$ & $\angle \mathrm{LOQ}$ & $\angle \mathrm{LOQ}$ & $\angle \mathrm{LOQ}$ & $\angle \mathrm{LOQ}$ & $\angle \mathrm{LOQ}$ & $\angle \mathrm{LOQ}$ & $\angle \mathrm{LOQ}$ \\
\hline
\end{tabular}


8.8 Appendix 8: Results for OCPs concentration in imported vegetables and fruit

Table 1: OCPs concentration in imported cucumber

\begin{tabular}{|c|c|c|c|c|c|c|c|c|c|c|c|c|c|c|c|}
\hline \multirow{4}{*}{$\begin{array}{c}\text { OCPs } \\
\text { BHC }\end{array}$} & \multicolumn{15}{|c|}{ cucumber } \\
\hline & \multicolumn{8}{|c|}{ washed } & \multicolumn{7}{|c|}{ unwashed } \\
\hline & \multicolumn{5}{|c|}{ KSA } & \multicolumn{3}{|c|}{ UAE } & \multicolumn{5}{|c|}{ KSA } & \multicolumn{2}{|c|}{ UAE } \\
\hline & $\angle \mathrm{LOQ}$ & $\angle \mathrm{LOQ}$ & $\angle \mathrm{LOQ}$ & $\angle \mathrm{LOQ}$ & $<\mathrm{LOQ}$ & $\angle \mathrm{LOQ}$ & $\angle \mathrm{LOQ}$ & $\angle \mathrm{LOQ}$ & $\angle \mathrm{LOQ}$ & $\angle \mathrm{LOQ}$ & $<\mathrm{LOQ}$ & $<\mathrm{LOQ}$ & $\angle \mathrm{LOQ}$ & $<\mathrm{LOQ}$ & $<\mathrm{LOQ}$ \\
\hline b-BHC & $\angle \mathrm{LOQ}$ & $\angle \mathrm{LOQ}$ & $\angle \mathrm{LOQ}$ & $\angle \mathrm{LOQ}$ & $\angle \mathrm{LOQ}$ & $\angle \mathrm{LOQ}$ & $\angle \mathrm{LOQ}$ & $\angle \mathrm{LOQ}$ & $\angle \mathrm{LOQ}$ & $\angle \mathrm{LOQ}$ & $<\mathrm{LOQ}$ & $\angle \mathrm{LOQ}$ & $\angle \mathrm{LOQ}$ & $<\mathrm{LOQ}$ & $\angle \mathrm{LOQ}$ \\
\hline Heptachlor & $\angle \mathrm{LOQ}$ & $\angle \mathrm{LOQ}$ & $\angle \mathrm{LOQ}$ & 17.30 & $<\mathrm{LOQ}$ & 31.99 & $\angle \mathrm{LOQ}$ & 43.49 & 31.83 & 31.60 & 16.02 & $\angle \mathrm{LOQ}$ & 12.37 & 16.28 & 19.65 \\
\hline Aldrin & $\angle \mathrm{LOQ}$ & 7.60 & 11.79 & 10.30 & 7.43 & $\angle \mathrm{LOQ}$ & $\angle \mathrm{LOQ}$ & $\angle \mathrm{LOQ}$ & $\angle \mathrm{LOQ}$ & $\angle \mathrm{LOQ}$ & $<\mathrm{LOQ}$ & $\angle \mathrm{LOQ}$ & $\angle \mathrm{LOQ}$ & $\angle \mathrm{LOQ}$ & 18.44 \\
\hline g-Chlordane & $\angle \mathrm{LOQ}$ & $<\mathrm{LOQ}$ & $\angle \mathrm{LOQ}$ & $\angle \mathrm{LOQ}$ & $<\mathrm{LOQ}$ & $\angle \mathrm{LOQ}$ & $\angle \mathrm{LOQ}$ & $\angle \mathrm{LOQ}$ & $\angle \mathrm{LOQ}$ & $\angle \mathrm{LOQ}$ & $<\mathrm{LOQ}$ & $<\mathrm{LOQ}$ & $\angle \mathrm{LOQ}$ & $\angle \mathrm{LOQ}$ & $<\mathrm{LOQ}$ \\
\hline Endosulfane I & $\angle \mathrm{LOQ}$ & $\angle \mathrm{LOQ}$ & $\angle \mathrm{LOQ}$ & $\angle \mathrm{LOQ}$ & $<\mathrm{LOQ}$ & $\angle \mathrm{LOQ}$ & $\angle \mathrm{LOQ}$ & $\angle \mathrm{LOQ}$ & $\angle \mathrm{LOQ}$ & $\angle \mathrm{LOQ}$ & $<\mathrm{LOQ}$ & $\angle \mathrm{LOQ}$ & $\angle \mathrm{LOQ}$ & $\angle \mathrm{LOQ}$ & $\angle \mathrm{LOQ}$ \\
\hline a-Chlordane & $\angle \mathrm{LOQ}$ & $\angle \mathrm{LOQ}$ & $\angle \mathrm{LOQ}$ & $\angle \mathrm{LOQ}$ & $\angle \mathrm{LOQ}$ & $\angle \mathrm{LOQ}$ & $\angle \mathrm{LOQ}$ & $\angle \mathrm{LOQ}$ & $\angle \mathrm{LOQ}$ & $\angle \mathrm{LOQ}$ & $<\mathrm{LOQ}$ & $\angle \mathrm{LOQ}$ & $\angle \mathrm{LOQ}$ & $<\mathrm{LOQ}$ & $\angle \mathrm{LOQ}$ \\
\hline Dieldrin & $\angle \mathrm{LOQ}$ & $\angle \mathrm{LOQ}$ & $\angle \mathrm{LOQ}$ & $\angle \mathrm{LOQ}$ & $\angle \mathrm{LOQ}$ & $\angle \mathrm{LOQ}$ & $\angle \mathrm{LOQ}$ & $\angle \mathrm{LOQ}$ & $\angle \mathrm{LOQ}$ & $\angle \mathrm{LOQ}$ & $\angle \mathrm{LOQ}$ & $\angle \mathrm{LOQ}$ & $\angle \mathrm{LOQ}$ & $\angle \mathrm{LOQ}$ & $\angle \mathrm{LOQ}$ \\
\hline Endrin & $\angle \mathrm{LOQ}$ & $\angle \mathrm{LOQ}$ & $\angle \mathrm{LOQ}$ & $\angle \mathrm{LOQ}$ & $\angle \mathrm{LOQ}$ & 8.18 & 7.31 & 8.87 & 7.09 & $\angle \mathrm{LOQ}$ & $<\mathrm{LOQ}$ & $\angle \mathrm{LOQ}$ & 6.82 & $<\mathrm{LOQ}$ & $\angle \mathrm{LOQ}$ \\
\hline Methoxychlor & $\angle \mathrm{LOQ}$ & $\angle \mathrm{LOQ}$ & $\angle \mathrm{LOQ}$ & $\angle \mathrm{LOQ}$ & $<\mathrm{LOQ}$ & $\angle \mathrm{LOQ}$ & $\angle \mathrm{LOQ}$ & $\angle \mathrm{LOQ}$ & $\angle \mathrm{LOQ}$ & $\angle \mathrm{LOQ}$ & $<\mathrm{LOQ}$ & $<\mathrm{LOQ}$ & $\angle \mathrm{LOQ}$ & $<\mathrm{LOQ}$ & $<\mathrm{LOQ}$ \\
\hline
\end{tabular}


Table 2: OCPs concentration in imported tomatoes

\begin{tabular}{|c|c|c|c|c|c|c|c|c|c|c|c|c|}
\hline \multirow{4}{*}{$\begin{array}{c}\text { OCPs } \\
\mathrm{a}-\mathrm{BHC} \\
\end{array}$} & \multicolumn{12}{|c|}{ Tomatoes } \\
\hline & \multicolumn{6}{|c|}{ washed } & \multicolumn{6}{|c|}{ unwashed } \\
\hline & \multicolumn{3}{|c|}{ Jordon } & \multicolumn{3}{|c|}{ Spain } & \multicolumn{3}{|c|}{ Jordon } & \multicolumn{3}{|c|}{ Spain } \\
\hline & $\angle \mathrm{LOQ}$ & $<\mathrm{LOQ}$ & $\angle \mathrm{LOQ}$ & $\angle \mathrm{LOQ}$ & $<\mathrm{LOQ}$ & $<\mathrm{LOQ}$ & $\angle \mathrm{LOQ}$ & $\angle \mathrm{LOQ}$ & $\angle \mathrm{LOQ}$ & $<\mathrm{LOQ}$ & $<\mathrm{LOQ}$ & $\angle \mathrm{LOQ}$ \\
\hline $\mathrm{b}-\mathrm{BHC}$ & $\angle \mathrm{LOQ}$ & $<\mathrm{LOQ}$ & $\angle \mathrm{LOQ}$ & $\angle \mathrm{LOQ}$ & $\angle \mathrm{LOQ}$ & $\angle \mathrm{LOQ}$ & $\angle \mathrm{LOQ}$ & $\angle \mathrm{LOQ}$ & $\angle \mathrm{LOQ}$ & $\angle \mathrm{LOQ}$ & $<\mathrm{LOQ}$ & $\angle \mathrm{LOQ}$ \\
\hline Heptachlor & $\angle \mathrm{LOQ}$ & 34.35 & 24.97 & 26.54 & 16.25 & 25.12 & 38.65 & 17.79 & 52.07 & 42.14 & 16.71 & 37.16 \\
\hline Aldrin & $\angle \mathrm{LOQ}$ & 11.70 & 9.02 & $<\mathrm{LOQ}$ & $<\mathrm{LOQ}$ & 0.97 & $\angle \mathrm{LOQ}$ & 17.39 & $<\mathrm{LOQ}$ & 0.48 & 24.54 & 4.08 \\
\hline g-Chlordane & $\angle \mathrm{LOQ}$ & $<\mathrm{LOQ}$ & $\angle \mathrm{LOQ}$ & $\angle \mathrm{LOQ}$ & $\angle \mathrm{LOQ}$ & $<\mathrm{LOQ}$ & $\angle \mathrm{LOQ}$ & 8.10 & $\angle \mathrm{LOQ}$ & $\angle \mathrm{LOQ}$ & $<\mathrm{LOQ}$ & $\angle \mathrm{LOQ}$ \\
\hline Endosulfane I & $<\mathrm{LOQ}$ & $<\mathrm{LOQ}$ & $\angle \mathrm{LOQ}$ & $<\mathrm{LOQ}$ & $<\mathrm{LOQ}$ & $<\mathrm{LOQ}$ & $<\mathrm{LOQ}$ & $<\mathrm{LOQ}$ & $<\mathrm{LOQ}$ & $<\mathrm{LOQ}$ & $<\mathrm{LOQ}$ & $\angle \mathrm{LOQ}$ \\
\hline a-Chlordane & $\angle \mathrm{LOQ}$ & $\angle \mathrm{LOQ}$ & $\angle \mathrm{LOQ}$ & $\angle \mathrm{LOQ}$ & $\angle \mathrm{LOQ}$ & $\angle \mathrm{LOQ}$ & $\angle \mathrm{LOQ}$ & $\angle \mathrm{LOQ}$ & $\angle \mathrm{LOQ}$ & $\angle \mathrm{LOQ}$ & $\angle \mathrm{LOQ}$ & $\angle \mathrm{LOQ}$ \\
\hline Dieldrin & $\angle \mathrm{LOQ}$ & $\angle \mathrm{LOQ}$ & $\angle \mathrm{LOQ}$ & $\angle \mathrm{LOQ}$ & $\angle \mathrm{LOQ}$ & $\angle \mathrm{LOQ}$ & $\angle \mathrm{LOQ}$ & 13.29 & $\angle \mathrm{LOQ}$ & $\angle \mathrm{LOQ}$ & $\angle \mathrm{LOQ}$ & $\angle \mathrm{LOQ}$ \\
\hline Endrin & $<\mathrm{LOQ}$ & $<\mathrm{LOQ}$ & $<\mathrm{LOQ}$ & 6.80 & 6.58 & $<\mathrm{LOQ}$ & $<\mathrm{LOQ}$ & 6.40 & 7.42 & $<\mathrm{LOQ}$ & $<\mathrm{LOQ}$ & $\angle \mathrm{LOQ}$ \\
\hline Methoxychlor & $<\mathrm{LOQ}$ & $<\mathrm{LOQ}$ & $<\mathrm{LOQ}$ & $<\mathrm{LOQ}$ & $<\mathrm{LOQ}$ & $<\mathrm{LOQ}$ & $<\mathrm{LOQ}$ & $<\mathrm{LOQ}$ & $<\mathrm{LOQ}$ & $<\mathrm{LOQ}$ & $<\mathrm{LOQ}$ & $\angle \mathrm{LOQ}$ \\
\hline
\end{tabular}


Table 3: OCPs concentration in imported potatoes

\begin{tabular}{|l|c|c|c|c|c|c|}
\cline { 2 - 8 } \multicolumn{1}{c|}{} & \multicolumn{6}{c|}{ Potatoes } \\
\cline { 2 - 8 } \multicolumn{1}{c|}{ OCPs } & \multicolumn{5}{c|}{ Egshed } & \multicolumn{4}{c|}{ unwashed } \\
\hline a-BHC & $<\mathrm{LOQ}$ & $<\mathrm{LOQ}$ & $<\mathrm{LOQ}$ & $<\mathrm{LOQ}$ & $<\mathrm{LOQ}$ & $<\mathrm{LOQ}$ \\
\hline b-BHC & $<\mathrm{LOQ}$ & $<\mathrm{LOQ}$ & $<\mathrm{LOQ}$ & $<\mathrm{LOQ}$ & $<\mathrm{LOQ}$ & $<\mathrm{LOQ}$ \\
\hline Heptachlor & 19.09 & 11.52 & 17.89 & 14.80 & 42.31 & 24.17 \\
\hline Aldrin & $<\mathrm{LOQ}$ & $<\mathrm{LOQ}$ & $<\mathrm{LOQ}$ & $<\mathrm{LOQ}$ & $<\mathrm{LOQ}$ & $<\mathrm{LOQ}$ \\
\hline g-Chlordane & $<\mathrm{LOQ}$ & $<\mathrm{LOQ}$ & $<\mathrm{LOQ}$ & $<\mathrm{LOQ}$ & $<\mathrm{LOQ}$ & $<\mathrm{LOQ}$ \\
\hline Endosulfane I & $<\mathrm{LOQ}$ & $<\mathrm{LOQ}$ & $<\mathrm{LOQ}$ & $<\mathrm{LOQ}$ & $<\mathrm{LOQ}$ & $<\mathrm{LOQ}$ \\
\hline a-Chlordane & $<\mathrm{LOQ}$ & $<\mathrm{LOQ}$ & $<\mathrm{LOQ}$ & $<\mathrm{LOQ}$ & $<\mathrm{LOQ}$ & $<\mathrm{LOQ}$ \\
\hline Dieldrin & $<\mathrm{LOQ}$ & $<\mathrm{LOQ}$ & $<\mathrm{LOQ}$ & $<\mathrm{LOQ}$ & $<\mathrm{LOQ}$ & $<\mathrm{LOQ}$ \\
\hline Endrin & 6.91 & 6.45 & 6.86 & 7.36 & 6.55 & 7.39 \\
\hline Methoxychlor & $<\mathrm{LOQ}$ & $<\mathrm{LOQ}$ & $<\mathrm{LOQ}$ & $<\mathrm{LOQ}$ & $<\mathrm{LOQ}$ & $<\mathrm{LOQ}$ \\
\hline
\end{tabular}


Table 4: OCPs concentration in imported parsley

\begin{tabular}{|c|c|c|c|c|c|c|c|c|c|c|c|c|c|c|}
\hline \multirow{4}{*}{$\frac{\text { OCPs }}{\mathrm{a}-\mathrm{BHC}}$} & \multicolumn{14}{|c|}{ Parsley } \\
\hline & \multicolumn{7}{|c|}{ washed } & \multicolumn{7}{|c|}{ unwashed } \\
\hline & \multicolumn{5}{|c|}{ KSA } & \multicolumn{2}{|c|}{ Lebanon } & \multicolumn{5}{|c|}{ KSA } & \multicolumn{2}{|c|}{ Lebanon } \\
\hline & $\angle \mathrm{LOQ}$ & $\angle \mathrm{LOQ}$ & $\angle \mathrm{LOQ}$ & $<\mathrm{LOQ}$ & $\angle \mathrm{LOQ}$ & $\angle \mathrm{LOQ}$ & $\angle \mathrm{LOQ}$ & $\angle \mathrm{LOQ}$ & $\angle \mathrm{LOQ}$ & $\angle \mathrm{LOQ}$ & $\angle \mathrm{LOQ}$ & $\angle \mathrm{LOQ}$ & $\angle \mathrm{LOQ}$ & $\angle \mathrm{LOQ}$ \\
\hline $\mathrm{b}-\mathrm{BHC}$ & $\angle \mathrm{LOQ}$ & $<\mathrm{LOQ}$ & $<\mathrm{LOQ}$ & $\angle \mathrm{LOQ}$ & $\angle \mathrm{LOQ}$ & $<\mathrm{LOQ}$ & $\angle \mathrm{LOQ}$ & $\angle \mathrm{LOQ}$ & $\angle \mathrm{LOQ}$ & $\angle \mathrm{LOQ}$ & $\angle \mathrm{LOQ}$ & $\angle \mathrm{LOQ}$ & $\angle \mathrm{LOQ}$ & $\angle \mathrm{LOQ}$ \\
\hline Heptachlor & 55.34 & 42.53 & 27.10 & 34.74 & 36.78 & 63.60 & 23.09 & 43.53 & 25.66 & $\angle \mathrm{LOQ}$ & 36.25 & 37.37 & 9.10 & 20.38 \\
\hline Aldrin & $<\mathrm{LOQ}$ & $\angle \mathrm{LOQ}$ & $\angle \mathrm{LOQ}$ & $\angle \mathrm{LOQ}$ & $\angle \mathrm{LOQ}$ & $<\mathrm{LOQ}$ & 27.61 & $\angle \mathrm{LOQ}$ & $\angle \mathrm{LOQ}$ & $\angle \mathrm{LOQ}$ & $\angle \mathrm{LOQ}$ & $\angle \mathrm{LOQ}$ & $\angle \mathrm{LOQ}$ & $\angle \mathrm{LOQ}$ \\
\hline g-Chlordane & 7.10 & 27.59 & $<\mathrm{LOQ}$ & 10.42 & 6.99 & $<\mathrm{LOQ}$ & $<\mathrm{LOQ}$ & $<\mathrm{LOQ}$ & $\angle \mathrm{LOQ}$ & $\angle \mathrm{LOQ}$ & $\angle \mathrm{LOQ}$ & $\angle \mathrm{LOQ}$ & $\angle \mathrm{LOQ}$ & $\angle \mathrm{LOQ}$ \\
\hline Endosulfane I & 25.94 & 22.31 & $\angle \mathrm{LOQ}$ & 59.70 & 16.69 & $\angle \mathrm{LOQ}$ & $\angle \mathrm{LOQ}$ & $\angle \mathrm{LOQ}$ & $\angle \mathrm{LOQ}$ & $\angle \mathrm{LOQ}$ & $\angle \mathrm{LOQ}$ & $\angle \mathrm{LOQ}$ & $\angle \mathrm{LOQ}$ & $\angle \mathrm{LOQ}$ \\
\hline a-Chlordane & 43.05 & 25.31 & $<\mathrm{LOQ}$ & 11.51 & 14.40 & $<\mathrm{LOQ}$ & $<\mathrm{LOQ}$ & $<\mathrm{LOQ}$ & $\angle \mathrm{LOQ}$ & $\angle \mathrm{LOQ}$ & $\angle \mathrm{LOQ}$ & $\angle \mathrm{LOQ}$ & $\angle \mathrm{LOQ}$ & $\angle \mathrm{LOQ}$ \\
\hline Dieldrin & $\angle \mathrm{LOQ}$ & 10.24 & $\angle \mathrm{LOQ}$ & 24.49 & 19.53 & $\angle \mathrm{LOQ}$ & $\angle \mathrm{LOQ}$ & $\angle \mathrm{LOQ}$ & $\angle \mathrm{LOQ}$ & $\angle \mathrm{LOQ}$ & $\angle \mathrm{LOQ}$ & $\angle \mathrm{LOQ}$ & $\angle \mathrm{LOQ}$ & $\angle \mathrm{LOQ}$ \\
\hline Endrin & 7.72 & 9.08 & $<\mathrm{LOQ}$ & 6.68 & $\angle \mathrm{LOQ}$ & $<\mathrm{LOQ}$ & $<\mathrm{LOQ}$ & $\angle \mathrm{LOQ}$ & $\angle \mathrm{LOQ}$ & $\angle \mathrm{LOQ}$ & $\angle \mathrm{LOQ}$ & $\angle \mathrm{LOQ}$ & $\angle \mathrm{LOQ}$ & $\angle \mathrm{LOQ}$ \\
\hline Methoxychlor & 22.06 & 26.60 & $\angle \mathrm{LOQ}$ & $<\mathrm{LOQ}$ & 17.99 & $\angle \mathrm{LOQ}$ & $\angle \mathrm{LOQ}$ & $\angle \mathrm{LOQ}$ & $\angle \mathrm{LOQ}$ & $\angle \mathrm{LOQ}$ & $\angle \mathrm{LOQ}$ & $\angle \mathrm{LOQ}$ & $\angle \mathrm{LOQ}$ & $\angle \mathrm{LOQ}$ \\
\hline
\end{tabular}


Table 5: OCPs concentration in imported watercress

\begin{tabular}{|c|c|c|c|c|c|c|c|c|c|c|}
\hline \multirow{4}{*}{\begin{tabular}{l}
\multicolumn{2}{c}{ OCPs } \\
$\mathrm{a}-\mathrm{BHC}$ \\
\end{tabular}} & \multicolumn{10}{|c|}{ watercress } \\
\hline & \multicolumn{5}{|c|}{ washed } & \multicolumn{5}{|c|}{ unwashed } \\
\hline & \multicolumn{10}{|c|}{ KSA } \\
\hline & $\angle \mathrm{LOQ}$ & $\angle L O Q$ & $\angle \mathrm{LOQ}$ & $\angle \mathrm{LOQ}$ & $\angle \mathrm{LOQ}$ & $\angle \mathrm{LOQ}$ & $\angle \mathrm{LOQ}$ & $\angle \mathrm{LOQ}$ & $\angle \mathrm{LOQ}$ & $\angle \mathrm{LOQ}$ \\
\hline $\mathrm{b}-\mathrm{BHC}$ & $\angle \mathrm{LOQ}$ & $\angle \mathrm{LOQ}$ & $\angle \mathrm{LOQ}$ & $\angle \mathrm{LOQ}$ & $<\mathrm{LOQ}$ & $\angle \mathrm{LOQ}$ & $\angle \mathrm{LOQ}$ & $\angle \mathrm{LOQ}$ & $\angle \mathrm{LOQ}$ & $\angle \mathrm{LOQ}$ \\
\hline Heptachlor & 37.05 & 12.66 & $\angle \mathrm{LOQ}$ & 15.91 & 12.52 & $\angle \mathrm{LOQ}$ & $<\mathrm{LOQ}$ & 15.23 & 96.07 & 19.92 \\
\hline Aldrin & $<\mathrm{LOQ}$ & $<\mathrm{LOQ}$ & $<\mathrm{LOQ}$ & $<\mathrm{LOQ}$ & $<\mathrm{LOQ}$ & $\angle \mathrm{LOQ}$ & $<\mathrm{LOQ}$ & $<\mathrm{LOQ}$ & $\angle \mathrm{LOQ}$ & $\angle \mathrm{LOQ}$ \\
\hline g-Chlordane & $\angle \mathrm{LOQ}$ & $\angle \mathrm{LOQ}$ & $\angle \mathrm{LOQ}$ & $\angle \mathrm{LOQ}$ & $<\mathrm{LOQ}$ & $\angle \mathrm{LOQ}$ & $<\mathrm{LOQ}$ & $\angle \mathrm{LOQ}$ & $\angle \mathrm{LOQ}$ & $\angle \mathrm{LOQ}$ \\
\hline Endosulfane I & $\angle \mathrm{LOQ}$ & $<\mathrm{LOQ}$ & $<\mathrm{LOQ}$ & $\angle \mathrm{LOQ}$ & $\angle \mathrm{LOQ}$ & $\angle \mathrm{LOQ}$ & $<\mathrm{LOQ}$ & $<\mathrm{LOQ}$ & $\angle \mathrm{LOQ}$ & $\angle \mathrm{LOQ}$ \\
\hline a-Chlordane & $\angle \mathrm{LOQ}$ & $<\mathrm{LOQ}$ & $<\mathrm{LOQ}$ & $\angle \mathrm{LOQ}$ & $\angle \mathrm{LOQ}$ & $\angle \mathrm{LOQ}$ & $<\mathrm{LOQ}$ & 13.89 & 13.41 & 17.76 \\
\hline Dieldrin & $\angle \mathrm{LOQ}$ & $\angle \mathrm{LOQ}$ & $\angle \mathrm{LOQ}$ & $\angle \mathrm{LOQ}$ & $<\mathrm{LOQ}$ & $\angle \mathrm{LOQ}$ & $\angle \mathrm{LOQ}$ & 14.07 & 14.11 & 18.14 \\
\hline Endrin & $<\mathrm{LOQ}$ & $<\mathrm{LOQ}$ & $<\mathrm{LOQ}$ & $\angle \mathrm{LOQ}$ & $<\mathrm{LOQ}$ & $\angle \mathrm{LOQ}$ & $<\mathrm{LOQ}$ & 9.19 & 7.38 & 6.41 \\
\hline Methoxychlor & $\angle \mathrm{LOQ}$ & $\angle \mathrm{LOQ}$ & $\angle \mathrm{LOQ}$ & $\angle \mathrm{LOQ}$ & $\angle \mathrm{LOQ}$ & $\angle \mathrm{LOQ}$ & $\angle \mathrm{LOQ}$ & $\angle \mathrm{LOQ}$ & $\angle \mathrm{LOQ}$ & $\angle \mathrm{LOQ}$ \\
\hline
\end{tabular}


Table 6: OCPs concentration in imported strawberries

\begin{tabular}{|l|c|c|c|c|c|c|}
\cline { 2 - 8 } \multicolumn{1}{c|}{} & \multicolumn{6}{c|}{ Strawberries } \\
\cline { 2 - 8 } \multicolumn{1}{c|}{ OCPs } & \multicolumn{5}{c|}{ washed } & \multicolumn{5}{c|}{ Unwashed } \\
\hline a-BHC & $<\mathrm{LOQ}$ & $<\mathrm{LOQ}$ & $<\mathrm{LOQ}$ & $<\mathrm{LOQ}$ & $<\mathrm{LOQ}$ & $<\mathrm{LOQ}$ \\
\hline b-BHC & $<\mathrm{LOQ}$ & $<\mathrm{LOQ}$ & $<\mathrm{LOQ}$ & $<\mathrm{LOQ}$ & $<\mathrm{LOQ}$ & $<\mathrm{LOQ}$ \\
\hline Heptachlor & 88.09 & 17.64 & 15.68 & 16.08 & 144.35 & 15.38 \\
\hline Aldrin & $<\mathrm{LOQ}$ & $<\mathrm{LOQ}$ & $<\mathrm{LOQ}$ & $<\mathrm{LOQ}$ & $<\mathrm{LOQ}$ & $<\mathrm{LOQ}$ \\
\hline g-Chlordane & $<\mathrm{LOQ}$ & $<\mathrm{LOQ}$ & 7.71 & $<\mathrm{LOQ}$ & $<\mathrm{LOQ}$ & $<\mathrm{LOQ}$ \\
\hline Endosulfane I & $<\mathrm{LOQ}$ & $<\mathrm{LOQ}$ & $<\mathrm{LOQ}$ & $<\mathrm{LOQ}$ & $<\mathrm{LOQ}$ & $<\mathrm{LOQ}$ \\
\hline a-Chlordane & 20.34 & 8.94 & 21.13 & 13.65 & 11.29 & 15.56 \\
\hline Dieldrin & 16.87 & 9.87 & 21.41 & 15.27 & 9.86 & 16.69 \\
\hline Endrin & $<\mathrm{LOQ}$ & 6.55 & $<\mathrm{LOQ}$ & $<\mathrm{LOQ}$ & $<\mathrm{LOQ}$ & 7.83 \\
\hline Methoxychlor & $<\mathrm{LOQ}$ & $<\mathrm{LOQ}$ & $<\mathrm{LOQ}$ & $<\mathrm{LOQ}$ & $<\mathrm{LOQ}$ & $<\mathrm{LOQ}$ \\
\hline
\end{tabular}


Table 7: OCPs concentration in imported lemon

\begin{tabular}{|l|c|c|c|c|c|c|}
\cline { 2 - 8 } \multicolumn{1}{c|}{} & \multicolumn{6}{c|}{ Lemon } \\
\cline { 2 - 8 } \multicolumn{1}{c|}{ OCPs } & \multicolumn{5}{c|}{ washed } & \multicolumn{5}{c|}{ Turkey } \\
\hline a-BHC & $<\mathrm{LOQ}$ & $<\mathrm{LOQ}$ & $<\mathrm{LOQ}$ & $<\mathrm{LOQ}$ & $<\mathrm{LOQ}$ & $<\mathrm{LOQ}$ \\
\hline b-BHC & $<\mathrm{LOQ}$ & $<\mathrm{LOQ}$ & $<\mathrm{LOQ}$ & $<\mathrm{LOQ}$ & $<\mathrm{LOQ}$ & $<\mathrm{LOQ}$ \\
\hline Heptachlor & 37.83 & 39.67 & 12.30 & $<\mathrm{LOQ}$ & 15.71 & 19.90 \\
\hline Aldrin & $<\mathrm{LOQ}$ & $<\mathrm{LOQ}$ & $<\mathrm{LOQ}$ & $<\mathrm{LOQ}$ & 8.25 & $<\mathrm{LOQ}$ \\
\hline g-Chlordane & $<\mathrm{LOQ}$ & $<\mathrm{LOQ}$ & $<\mathrm{LOQ}$ & $<\mathrm{LOQ}$ & $<\mathrm{LOQ}$ & 9.58 \\
\hline Endosulfane I & $<\mathrm{LOQ}$ & $<\mathrm{LOQ}$ & $<\mathrm{LOQ}$ & $<\mathrm{LOQ}$ & $<\mathrm{LOQ}$ & 8.31 \\
\hline a-Chlordane & 10.68 & 8.54 & 6.72 & 6.65 & 6.00 & 6.14 \\
\hline Dieldrin & $<\mathrm{LOQ}$ & $<\mathrm{LOQ}$ & $<\mathrm{LOQ}$ & $<\mathrm{LOQ}$ & $<\mathrm{LOQ}$ & $<\mathrm{LOQ}$ \\
\hline Endrin & $<\mathrm{LOQ}$ & $<\mathrm{LOQ}$ & $<\mathrm{LOQ}$ & $<\mathrm{LOQ}$ & $<\mathrm{LOQ}$ & $<\mathrm{LOQ}$ \\
\hline Methoxychlor & $<\mathrm{LOQ}$ & $<\mathrm{LOQ}$ & $<\mathrm{LOQ}$ & $<\mathrm{LOQ}$ & $<\mathrm{LOQ}$ & $<\mathrm{LOQ}$ \\
\hline
\end{tabular}


8.9 Appendix 9: MRLs Results for OCPs concentration in local vegetables and fruit.

\begin{tabular}{|c|c|c|c|c|c|c|c|c|c|c|c|c|}
\hline \multirow{4}{*}{$\frac{\text { OCPs }}{\text { a-BHC }}$} & \multicolumn{12}{|c|}{ cucumber } \\
\hline & \multicolumn{9}{|c|}{ washed } & \multicolumn{3}{|c|}{ unwashed } \\
\hline & \multicolumn{4}{|c|}{ Farm\#649 } & \multicolumn{2}{|c|}{ Farm\#953 } & \multicolumn{4}{|c|}{ Farm\#649 } & \multicolumn{2}{|c|}{ Farm\#953 } \\
\hline & $\triangle \mathrm{MRL}$ & $\triangle M R L$ & $\triangle M R L$ & $\angle \mathrm{MRL}$ & $\angle M R L$ & $\triangle \mathrm{MRL}$ & $\angle M R L$ & $\angle M R L$ & $\angle M R L$ & $\triangle M R L$ & $\angle \mathrm{MRL}$ & $\angle \mathrm{MRL}$ \\
\hline $\mathrm{b}-\mathrm{BHC}$ & $\triangle \mathrm{MRL}$ & $\triangle M R L$ & $\triangle M R L$ & $\triangle M R L$ & $\triangle M R L$ & $\triangle M R L$ & $\triangle M R L$ & $\angle M R L$ & $\triangle M R L$ & $\angle \mathrm{MRL}$ & $\triangle \mathrm{MRL}$ & $\angle \mathrm{MRL}$ \\
\hline Heptachlor & $\triangle M R L$ & $\triangle M R L$ & $\triangle M R L$ & $\triangle M R L$ & $\angle M R L$ & $\triangle M R L$ & $\angle M R L$ & 19.63 & 33.98 & $\angle \mathrm{MRL}$ & $\triangle M R L$ & $\angle \mathrm{MRL}$ \\
\hline Aldrin & $\triangle M R L$ & $\triangle M R L$ & $\triangle M R L$ & $\triangle M R L$ & $\triangle M R L$ & $\triangle M R L$ & $\triangle M R L$ & $\triangle M R L$ & $\triangle M R L$ & $\angle \mathrm{MRL}$ & $\triangle M R L$ & $\triangle \mathrm{MRL}$ \\
\hline g-Chlordane & $\angle \mathrm{MRL}$ & $\triangle M R L$ & $\triangle M R L$ & $\triangle \mathrm{MRL}$ & $\angle \mathrm{MRL}$ & $\triangle \mathrm{MRL}$ & $\angle \mathrm{MRL}$ & $<M R L$ & $\angle \mathrm{MRL}$ & $\angle \mathrm{MRL}$ & $\triangle \mathrm{MRL}$ & $<M R L$ \\
\hline Endosulfane I & $\angle \mathrm{MRL}$ & $\triangle M R L$ & $\triangle M R L$ & $\triangle M R L$ & $\angle \mathrm{MRL}$ & $\triangle \mathrm{MRL}$ & $\triangle \mathrm{MRL}$ & $\angle \mathrm{MRL}$ & $\angle \mathrm{MRL}$ & $\angle M R L$ & $\triangle \mathrm{MRL}$ & $\angle \mathrm{MRL}$ \\
\hline a-Chlordane & $\triangle M R L$ & $\triangle M R L$ & $\triangle M R L$ & $\triangle M R L$ & $\triangle M R L$ & $\triangle M R L$ & $\angle M R L$ & $\angle M R L$ & $\triangle M R L$ & $\triangle M R L$ & $\triangle M R L$ & $\angle M R L$ \\
\hline Dieldrin & $\triangle M R L$ & $\triangle M R L$ & $\triangle M R L$ & $\triangle M R L$ & $\triangle M R L$ & $\triangle M R L$ & $\angle M R L$ & $\angle M R L$ & $\triangle M R L$ & $\triangle M R L$ & $\triangle M R L$ & $\angle M R L$ \\
\hline Endrin & $\triangle \mathrm{MRL}$ & $\triangle M R L$ & $\triangle M R L$ & $\triangle M R L$ & $\angle M R L$ & $\triangle M R L$ & $<M R L$ & $\angle M R L$ & $\angle M R L$ & $\angle M R L$ & $\triangle M R L$ & $\angle M R L$ \\
\hline Methoxychlor & $\angle M R L$ & $\triangle M R L$ & $\triangle M R L$ & $\triangle M R L$ & $\triangle \mathrm{MRL}$ & $\triangle \mathrm{MRL}$ & $\triangle M R L$ & $\triangle M R L$ & $\triangle \mathrm{MRL}$ & $<\mathrm{MRL}$ & $\triangle \mathrm{MRL}$ & $\angle M R L$ \\
\hline
\end{tabular}




\begin{tabular}{|c|c|c|c|c|c|c|c|c|c|c|c|c|}
\hline \multirow{4}{*}{$\begin{array}{c}\text { OCPs } \\
\text { a-BHC }\end{array}$} & \multicolumn{12}{|c|}{ Tomatoes } \\
\hline & \multicolumn{8}{|c|}{ washed } & \multicolumn{4}{|c|}{ unwashed } \\
\hline & \multicolumn{2}{|c|}{ Farm\#197 } & \multicolumn{2}{|c|}{ Farm\#953 } & \multicolumn{2}{|c|}{ Farm $\# 241$} & \multicolumn{2}{|c|}{ Farm\#197 } & \multicolumn{2}{|c|}{ Farm\#953 } & \multicolumn{2}{|c|}{ Farm\#241 } \\
\hline & $\angle \mathrm{MRL}$ & $<\mathrm{MRL}$ & $\triangle M R L$ & $\triangle M R L$ & $\triangle M R L$ & $\triangle M R L$ & $<M R L$ & $\angle M R L$ & $\triangle M R L$ & $<M R L$ & $\triangle M R L$ & $\triangle M R L$ \\
\hline $\mathrm{b}-\mathrm{BHC}$ & $\triangle \mathrm{MRL}$ & $\angle \mathrm{MRL}$ & $\triangle \mathrm{MRL}$ & $\angle \mathrm{MRL}$ & $\triangle M R L$ & $\angle \mathrm{MRL}$ & $<M R L$ & $\triangle M R L$ & $\angle \mathrm{MRL}$ & $\triangle M R L$ & $\triangle M R L$ & $\triangle \mathrm{MRL}$ \\
\hline Heptachlor & $\triangle \mathrm{MRL}$ & $\triangle M R L$ & $\angle \mathrm{MRL}$ & $\triangle M R L$ & $\triangle M R L$ & $\triangle M R L$ & $\triangle M R L$ & $\triangle M R L$ & $\triangle M R L$ & $\triangle M R L$ & $\triangle M R L$ & $\triangle \mathrm{MRL}$ \\
\hline Aldrin & $\triangle \mathrm{MRL}$ & $\triangle M R L$ & $\angle \mathrm{MRL}$ & $\angle M R L$ & $\angle \mathrm{MRL}$ & $\triangle M R L$ & $<\mathrm{MRL}$ & $\angle \mathrm{MRL}$ & $\angle \mathrm{MRL}$ & $\angle \mathrm{MRL}$ & $<M R L$ & $\triangle M R L$ \\
\hline g-Chlordane & $\angle \mathrm{MRL}$ & $\angle M R L$ & $\angle \mathrm{MRL}$ & $\angle M R L$ & $\angle \mathrm{MRL}$ & $\triangle M R L$ & $\triangle \mathrm{MRL}$ & $\angle \mathrm{MRL}$ & $\angle M R L$ & $\angle \mathrm{MRL}$ & $\triangle \mathrm{MRL}$ & $\triangle \mathrm{MRL}$ \\
\hline Endosulfane I & $\angle \mathrm{MRL}$ & $\angle \mathrm{MRL}$ & $\angle \mathrm{MRL}$ & $\angle \mathrm{MRL}$ & $\angle \mathrm{MRL}$ & $\triangle \mathrm{MRL}$ & $\triangle \mathrm{MRL}$ & $\triangle \mathrm{MRL}$ & $\angle \mathrm{MRL}$ & $\triangle \mathrm{MRL}$ & $\triangle \mathrm{MRL}$ & $\triangle M R L$ \\
\hline a-Chlordane & $\triangle M R L$ & $\triangle M R L$ & $\angle \mathrm{MRL}$ & $\triangle M R L$ & $\triangle M R L$ & $\triangle M R L$ & $\triangle \mathrm{MRL}$ & $\triangle M R L$ & $\triangle M R L$ & $\triangle M R L$ & $\triangle \mathrm{MRL}$ & $\triangle M R L$ \\
\hline Dieldrin & $\angle \mathrm{MRL}$ & $\angle M R L$ & $\angle \mathrm{MRL}$ & $\angle M R L$ & $\angle M R L$ & $\angle M R L$ & $<\mathrm{MRL}$ & $\triangle M R L$ & $\angle M R L$ & $\angle \mathrm{MRL}$ & $\triangle M R L$ & $\triangle \mathrm{MRL}$ \\
\hline Endrin & $\angle \mathrm{MRL}$ & $\angle M R L$ & $\angle \mathrm{MRL}$ & $\angle M R L$ & $\angle \mathrm{MRL}$ & $\angle M R L$ & $<M R L$ & $<\mathrm{MRL}$ & $\angle M R L$ & $\angle \mathrm{MRL}$ & $\angle \mathrm{MRL}$ & $\triangle \mathrm{MRL}$ \\
\hline Methoxychlor & $\angle \mathrm{MRL}$ & $<\mathrm{MRL}$ & $\angle M R L$ & $\angle \mathrm{MRL}$ & $\angle M R L$ & $\triangle M R L$ & $\triangle M R L$ & $\angle M R L$ & $\angle \mathrm{MRL}$ & $<\mathrm{MRL}$ & $\angle \mathrm{MRL}$ & $\triangle M R L$ \\
\hline
\end{tabular}




\begin{tabular}{|c|c|c|c|c|c|c|c|c|c|c|}
\hline \multirow[b]{3}{*}{ OCPs } & \multicolumn{10}{|c|}{ Parsley } \\
\hline & \multicolumn{5}{|c|}{ washed } & \multicolumn{5}{|c|}{ unwashed } \\
\hline & Farm\#224 & Farm\#963 & Farm\#696 & Farm\#1224 & Farm\#260 & Farm\#224 & Farm\#963 & Farm $\# 696$ & Farm\#1224 & Farm $\# 260$ \\
\hline $\mathrm{a}-\mathrm{BHC}$ & $\triangle \mathrm{MRL}$ & $\angle \mathrm{MRL}$ & $\triangle \mathrm{MRL}$ & $\triangle \mathrm{MRL}$ & $\triangle \mathrm{MRL}$ & $\triangle \mathrm{MRL}$ & $\triangle M R L$ & $\triangle \mathrm{MRL}$ & $\triangle \mathrm{MRL}$ & $\angle \mathrm{MRL}$ \\
\hline $\mathrm{b}-\mathrm{BHC}$ & $\triangle \mathrm{MRL}$ & $\triangle M R L$ & $\triangle \mathrm{MRL}$ & $\triangle \mathrm{MRL}$ & $\triangle \mathrm{MRL}$ & $\triangle \mathrm{MRL}$ & $\triangle \mathrm{MRL}$ & $\triangle M R L$ & 10.90 & $\triangle \mathrm{MRL}$ \\
\hline Heptachlor & 17.11 & $\angle M R L$ & 33.56 & 31.84 & 33.14 & 22.75 & 24.20 & 28.52 & 25.10 & $\triangle M R L$ \\
\hline Aldrin & $\triangle \mathrm{MRL}$ & $\triangle \mathrm{MRL}$ & 13.99 & $\triangle \mathrm{MRL}$ & $\triangle \mathrm{MRL}$ & $\angle \mathrm{MRL}$ & $\triangle \mathrm{MRL}$ & $\angle \mathrm{MRL}$ & $\triangle \mathrm{MRL}$ & $\angle \mathrm{MRL}$ \\
\hline g-Chlordane & 22.03 & $\angle M R L$ & 10.59 & $\triangle M R L$ & $\angle M R L$ & $\triangle M R L$ & $\triangle M R L$ & $\angle M R L$ & $\triangle M R L$ & $\triangle M R L$ \\
\hline Endosulfane I & 132.54 & 109.83 & 56.45 & 32.24 & 76.72 & 146.84 & 175.77 & 98.58 & 52.08 & 71.55 \\
\hline a-Chlordane & $\triangle \mathrm{MRL}$ & $\triangle \mathrm{MRL}$ & $\triangle \mathrm{MRL}$ & $\triangle \mathrm{MRL}$ & $\triangle \mathrm{MRL}$ & $\triangle \mathrm{MRL}$ & $\triangle M R L$ & $\triangle M R L$ & $\triangle \mathrm{MRL}$ & $\triangle \mathrm{MRL}$ \\
\hline Dieldrin & $\triangle M R L$ & $\angle \mathrm{MRL}$ & $\triangle M R L$ & $\triangle M R L$ & $\triangle M R L$ & $<M R L$ & $\triangle M R L$ & 23.04 & $\triangle M R L$ & $\triangle \mathrm{MRL}$ \\
\hline Endrin & $\triangle \mathrm{MRL}$ & $\triangle M R L$ & $\triangle \mathrm{MRL}$ & $\triangle \mathrm{MRL}$ & $\triangle M R L$ & $\triangle \mathrm{MRL}$ & $\triangle \mathrm{MRL}$ & $\triangle \mathrm{MRL}$ & $\triangle \mathrm{MRL}$ & $\triangle \mathrm{MRL}$ \\
\hline Methoxychlor & 10.95 & 11.32 & 48.27 & 14.31 & $\angle M R L$ & 12.82 & 18.76 & $\angle \mathrm{MRL}$ & 97.97 & 78.59 \\
\hline
\end{tabular}




\begin{tabular}{|c|c|c|c|c|c|c|c|c|c|c|}
\hline \multirow[b]{3}{*}{ OCPs } & \multicolumn{10}{|c|}{ Watercress } \\
\hline & \multicolumn{5}{|c|}{ washed } & \multicolumn{5}{|c|}{ unwashed } \\
\hline & MoE farm & Farm\# 576 & Farm\#963 & Farm\#183 & Farm\#701 & MoE farm & Farm\# 576 & Farm $\# 963$ & Farm\#183 & Farm $\# 701$ \\
\hline $\mathrm{a}-\mathrm{BHC}$ & $\triangle \mathrm{MRL}$ & $\triangle \mathrm{MRL}$ & $\triangle M R L$ & $\triangle M R L$ & $\angle \mathrm{MRL}$ & $\angle \mathrm{MRL}$ & $\triangle M R L$ & $\angle \mathrm{MRL}$ & $\triangle M R L$ & $\triangle \mathrm{MRL}$ \\
\hline $\mathrm{b}-\mathrm{BHC}$ & $\triangle \mathrm{MRL}$ & $\triangle \mathrm{MRL}$ & $\triangle M R L$ & $\triangle \mathrm{MRL}$ & $\triangle \mathrm{MRL}$ & $\triangle \mathrm{MRL}$ & $\triangle M R L$ & $\triangle \mathrm{MRL}$ & $\triangle M R L$ & $\triangle \mathrm{MRL}$ \\
\hline Heptachlor & 18.86 & 53.43 & 304.52 & 202.11 & 370.86 & 176.11 & 220.51 & 330.75 & 1631.43 & 241.21 \\
\hline Aldrin & $\triangle \mathrm{MRL}$ & $\triangle \mathrm{MRL}$ & $\triangle \mathrm{MRL}$ & $\triangle \mathrm{MRL}$ & $\triangle \mathrm{MRL}$ & $\angle \mathrm{MRL}$ & $\triangle M R L$ & $\triangle \mathrm{MRL}$ & $\triangle \mathrm{MRL}$ & $\triangle \mathrm{MRL}$ \\
\hline g-Chlordane & $\triangle M R L$ & $\triangle M R L$ & $\triangle M R L$ & $\triangle M R L$ & 43.15 & $\triangle M R L$ & $\triangle M R L$ & $\triangle M R L$ & $\triangle M R L$ & 50.51 \\
\hline Endosulfane I & $\triangle M R L$ & $\triangle \mathrm{MRL}$ & $\triangle \mathrm{MRL}$ & $\triangle M R L$ & $\triangle \mathrm{MRL}$ & $\triangle M R L$ & $\triangle \mathrm{MRL}$ & $\triangle M R L$ & 10.10 & $\triangle M R L$ \\
\hline a-Chlordane & 12.61 & 11.35 & 25.29 & 17.20 & 20.97 & 16.57 & 20.63 & 32.14 & 45.88 & 24.56 \\
\hline Dieldrin & 14.02 & 10.61 & $\angle M R L$ & 14.45 & $\angle \mathrm{MRL}$ & 10.93 & 16.17 & $<\mathrm{MRL}$ & $\angle M R L$ & $<\mathrm{MRL}$ \\
\hline Endrin & $\triangle M R L$ & $\triangle \mathrm{MRL}$ & $\triangle M R L$ & $\triangle M R L$ & $\angle \mathrm{MRL}$ & $\triangle \mathrm{MRL}$ & $\triangle \mathrm{MRL}$ & $\triangle \mathrm{MRL}$ & $\angle \mathrm{MRL}$ & $\angle \mathrm{MRL}$ \\
\hline Methoxychlor & $\triangle \mathrm{MRL}$ & $\triangle \mathrm{MRL}$ & $\triangle \mathrm{MRL}$ & $\triangle \mathrm{MRL}$ & $\triangle M R L$ & $\triangle \mathrm{MRL}$ & $\triangle \mathrm{MRL}$ & $\triangle \mathrm{MRL}$ & $\triangle M R L$ & $\triangle \mathrm{MRL}$ \\
\hline
\end{tabular}




\begin{tabular}{|c|c|c|c|c|c|c|c|c|c|c|c|c|c|c|}
\hline \multirow{4}{*}{$\begin{array}{c}\text { OCPs } \\
\text { a-BHC }\end{array}$} & \multicolumn{14}{|c|}{ Strawberries } \\
\hline & \multicolumn{9}{|c|}{ washed } & \multicolumn{5}{|c|}{ unwashed } \\
\hline & \multicolumn{5}{|c|}{ Farm\#301 } & \multicolumn{2}{|c|}{ Farm\#1223 } & \multicolumn{5}{|c|}{ Farm\#301 } & \multicolumn{2}{|c|}{ Farm\#1223 } \\
\hline & $\angle \mathrm{MRL}$ & $\angle M R L$ & $\angle \mathrm{MRL}$ & $\triangle \mathrm{MRL}$ & $\angle M R L$ & $\angle \mathrm{MRL}$ & $\angle \mathrm{MRL}$ & $\angle \mathrm{MRL}$ & $\angle M R L$ & $\angle M R L$ & $\triangle M R L$ & $\angle M R L$ & $\angle M R L$ & $\triangle \mathrm{MRL}$ \\
\hline $\mathrm{b}-\mathrm{BHC}$ & $\angle M R L$ & $\angle M R L$ & $\angle M R L$ & $\triangle M R L$ & $\angle M R L$ & $\angle \mathrm{MRL}$ & $\triangle M R L$ & $\angle M R L$ & $\angle M R L$ & $\angle M R L$ & $\triangle M R L$ & $\angle M R L$ & $\angle \mathrm{MRL}$ & $\triangle M R L$ \\
\hline Heptachlor & $\angle M R L$ & 24.75 & $\angle \mathrm{MRL}$ & 26.13 & $\triangle M R L$ & $\angle M R L$ & $\angle \mathrm{MRL}$ & $\triangle \mathrm{MRL}$ & $\angle M R L$ & $\angle M R L$ & $\triangle M R L$ & $\angle M R L$ & $\angle M R L$ & $\triangle M R L$ \\
\hline Aldrin & $\angle \mathrm{MRL}$ & $\angle \mathrm{MRL}$ & $\triangle M R L$ & $\triangle \mathrm{MRL}$ & $\triangle M R L$ & $\angle M R L$ & $\triangle M R L$ & $\triangle \mathrm{MRL}$ & $\triangle M R L$ & $\triangle M R L$ & $\triangle M R L$ & $\triangle \mathrm{MRL}$ & $\angle M R L$ & $\triangle M R L$ \\
\hline g-Chlordane & $\angle \mathrm{MRL}$ & $\angle \mathrm{MRL}$ & $\angle \mathrm{MRL}$ & $\triangle M R L$ & $\angle M R L$ & $<M R L$ & $\angle \mathrm{MRL}$ & $\angle \mathrm{MRL}$ & $\angle M R L$ & $\angle \mathrm{MRL}$ & $\angle \mathrm{MRL}$ & $\angle M R L$ & $\angle M R L$ & $\triangle \mathrm{MRL}$ \\
\hline Endosulfane I & $\triangle M R L$ & $\angle M R L$ & $\triangle M R L$ & $\triangle \mathrm{MRL}$ & $\triangle M R L$ & $\triangle M R L$ & $\triangle M R L$ & $\triangle M R L$ & $\angle M R L$ & $\angle M R L$ & $\triangle M R L$ & $\triangle M R L$ & $\triangle M R L$ & $\triangle M R L$ \\
\hline a-Chlordane & $\angle M R L$ & $\angle M R L$ & $\angle M R L$ & $\triangle M R L$ & $\triangle M R L$ & $\triangle M R L$ & $\angle M R L$ & $\angle M R L$ & $\triangle M R L$ & $\angle M R L$ & $\triangle M R L$ & $\triangle M R L$ & $\triangle M R L$ & $\triangle M R L$ \\
\hline Dieldrin & $\triangle M R L$ & $\triangle M R L$ & $\triangle M R L$ & $\triangle \mathrm{MRL}$ & $\triangle M R L$ & $\triangle M R L$ & $\triangle M R L$ & $\triangle M R L$ & $\triangle M R L$ & $\triangle M R L$ & $\triangle M R L$ & $\triangle M R L$ & $\triangle M R L$ & $\triangle \mathrm{MRL}$ \\
\hline Endrin & $\angle \mathrm{MRL}$ & $\angle M R L$ & $\angle \mathrm{MRL}$ & $\triangle \mathrm{MRL}$ & $\angle M R L$ & $\angle \mathrm{MRL}$ & $\angle \mathrm{MRL}$ & $\angle \mathrm{MRL}$ & $\angle M R L$ & $\angle M R L$ & $\triangle M R L$ & $\angle M R L$ & $\triangle M R L$ & $\triangle \mathrm{MRL}$ \\
\hline Methoxychlor & $\angle \mathrm{MRL}$ & $\angle \mathrm{MRL}$ & $\triangle \mathrm{MRL}$ & $\triangle M R L$ & $\triangle M R L$ & $\angle \mathrm{MRL}$ & $\angle \mathrm{MRL}$ & $\angle \mathrm{MRL}$ & $\angle M R L$ & $\angle \mathrm{MRL}$ & $\triangle M R L$ & $\angle M R L$ & $\angle \mathrm{MRL}$ & $\triangle M R L$ \\
\hline
\end{tabular}


8.10 Appendix 10: T-test analysis results.

Table1: Pair-difference t-test for the imported cucumber in the presence of methoxychlor residue.

\begin{tabular}{|c|r|}
\hline \multicolumn{2}{|c|}{ Cucumber } \\
\hline \multicolumn{2}{|c|}{ Methoxychlor } \\
\hline washed & unwashed \\
\hline 0.609 & 3.570 \\
\hline 0.554 & 2.996 \\
\hline 1.219 & 1.682 \\
\hline 1.756 & 0.912 \\
\hline 0.051 & 2.349 \\
\hline 2.298 & 0.443 \\
\hline
\end{tabular}

not significant
t-Test: Paired Two Sample for Means

\begin{tabular}{lrr}
\hline & Variable 1 & Variable 2 \\
\hline Mean & 1.081163219 & 1.992164781 \\
Variance & 0.703026976 & 1.458152148 \\
Observations & 6 & 6 \\
Pearson Correlation & -0.849037029 & \\
Hypothesized Mean Difference & 0 & \\
df & 5 & \\
t Stat & -1.132801353 & \\
$\mathrm{P}(\mathrm{T}<=t)$ one-tail & 0.15433884 & \\
t Critical one-tail & 2.015048372 & \\
$\mathrm{P}(\mathrm{T}<=t)$ two-tail & $\mathbf{0 . 3 0 8 6 7 7 6 7 9}$ & \\
$\mathrm{t}$ Critical two-tail & 2.570581835 & \\
\hline
\end{tabular}


Table2: Pair-difference t-test for the imported tomatoes in the presence of heptachlor residue.

\begin{tabular}{|c|r|}
\hline \multicolumn{2}{|c|}{ Tomatoes } \\
\hline \multicolumn{2}{|c|}{ Heptachlor } \\
\hline washed & unwashed \\
\hline 34.349 & 17.792 \\
\hline 24.972 & 52.065 \\
\hline 26.535 & 42.137 \\
\hline 16.254 & 16.713 \\
\hline 25.118 & 37.158 \\
\hline
\end{tabular}

not significant
t-Test: Paired Two Sample for Means

\begin{tabular}{lrr}
\hline & Variable 1 & Variable 2 \\
\hline Mean & 25.44545364 & 33.17301575 \\
Variance & 41.31912733 & 240.1573809 \\
Observations & 5 & 5 \\
Pearson Correlation & 0.034783793 & \\
Hypothesized Mean Difference & 0 & \\
df & \multicolumn{2}{c}{4} \\
t Stat & -1.04284439 & \\
P(T<-t) one-tail & 0.177949245 & \\
t Critical one-tail & 2.131846782 & \\
P(T<-t) two-tail & $\mathbf{0 . 3 5 5 8 9 8 4 9 1}$ \\
t Critical two-tail & 2.776445105 & \\
\hline
\end{tabular}


Table3: Pair-difference t-test for the imported potatoes in the presence of heptachlor residue.

\begin{tabular}{|c|r|}
\hline \multicolumn{2}{|c|}{ Potatoes } \\
\hline \multicolumn{2}{|c|}{ Heptachlor } \\
\hline washed & unwashed \\
\hline 19.095 & 14.799 \\
\hline 11.522 & 42.306 \\
\hline 17.893 & 24.166 \\
\hline
\end{tabular}

not significant
t-Test: Paired Two Sample for Means

\begin{tabular}{lrr}
\hline & Variable 1 & Variable 2 \\
\hline Mean & 16.16991928 & 27.09017314 \\
Variance & 16.5627588 & 195.5703389 \\
Observations & 3 & 3 \\
Pearson Correlation & -0.981380043 & \\
Hypothesized Mean Difference & 0 & \\
df & 2 & \\
t Stat & -1.051059367 & \\
P $(T<=t)$ one-tail & 0.201746447 & \\
t Critical one-tail & 2.91998558 & \\
P $(T<=t)$ two-tail & 0.403492893 & \\
t Critical two-tail & 4.30265273 & \\
\hline
\end{tabular}


Table4: Pair-difference t-test for the imported potatoes in the presence of methoxychlor residue.

\begin{tabular}{|c|c|}
\hline \multicolumn{2}{|c|}{ Potatoes } \\
\hline \multicolumn{2}{|c|}{ g-Chlordane } \\
\hline washed & unwashed \\
\hline 6.279 & 6.165 \\
\hline 4.938 & 4.907 \\
\hline 5.176 & 5.113 \\
\hline
\end{tabular}

not significant
t-Test: Paired Two Sample for Means

\begin{tabular}{lrr}
\hline & Variable 1 & Variable 2 \\
\hline Mean & 5.464341653 & 5.395115635 \\
Variance & 0.511678985 & 0.455607976 \\
Observations & 3 & 3 \\
Pearson Correlation & 0.999889869 & \\
Hypothesized Mean Difference & 0 & \\
df & 2 & \\
t Stat & 2.880370745 & \\
P $(\mathrm{T}<-t)$ one-tail & 0.051179348 & \\
t Critical one-tail & 2.91998558 & \\
P $(\mathrm{T}<-t)$ two-tail & $\mathbf{0 . 1 0 2 3 5 8 6 9 6}$ & \\
t Critical two-tail & 4.30265273 & \\
\hline
\end{tabular}


Table5: Pair-difference t-test for the imported potatoes in the presence of endrin residue.

\begin{tabular}{|r|r|}
\hline \multicolumn{2}{|c|}{ Potatoes } \\
\hline \multicolumn{2}{|c|}{ Endrin } \\
\hline washed & unwashed \\
\hline 6.912 & 7.360 \\
\hline 6.445 & 6.549 \\
\hline 6.859 & 7.385 \\
\hline
\end{tabular}

not significant
t-Test: Paired Two Sample for Means

\begin{tabular}{lrr}
\hline & Variable 1 & Variable 2 \\
\hline Mean & 6.738782609 & 7.098076142 \\
Variance & 0.065278775 & 0.226654097 \\
Observations & 3 & 3 \\
Pearson Correlation & 0.991580476 & \\
Hypothesized Mean Difference & 0 & \\
df & 2 & \\
t Stat & -2.76363383 & \\
P $(T<-t)$ one-tail & 0.054892989 & \\
t Critical one-tail & 2.91998558 & \\
P $(T<-t)$ two-tail & $\mathbf{0 . 1 0 9 7 8 5 9 7 8}$ & \\
t Critical two-tail & 4.30265273 & \\
\hline
\end{tabular}


Table6: Pair-difference t-test for the imported cucumber in the presence of a-chlordane residue.

\begin{tabular}{|r|r|}
\hline \multicolumn{2}{|c|}{ Watercress } \\
\hline \multicolumn{2}{|c|}{ a-Chlordane } \\
\hline washed & unwashed \\
\hline 4.885 & 13.890 \\
\hline 4.786 & 13.412 \\
\hline 4.857 & 17.760 \\
\hline
\end{tabular}

significant
t-Test: Paired Two Sample for

Means

\begin{tabular}{lrr}
\hline & Variable 1 & Variable 2 \\
\hline Mean & 4.842234663 & 15.0206741 \\
Variance & 0.002601217 & 5.68446544 \\
Observations & 3 & 3 \\
Pearson Correlation & 0.340016408 & \\
Hypothesized Mean Difference & 0 & \\
df & \multicolumn{2}{|c}{} \\
& - & \\
t Stat & 7.446946606 & \\
P $(T<=t)$ one-tail & 0.008779233 & \\
t Critical one-tail & 2.91998558 & \\
P $(T<=t)$ two-tail & $\mathbf{0 . 0 1 7 5 5 8 4 6 5}$ & \\
t Critical two-tail & 4.30265273 & \\
\hline
\end{tabular}


Table7: Pair-difference t-test for the imported Strawberries in the presence dieldrin residue.

\begin{tabular}{|r|r|}
\hline \multicolumn{2}{|c|}{ Strawberries } \\
\hline \multicolumn{2}{|c|}{ Dieldrin } \\
\hline washed & unwashed \\
\hline 16.868 & 15.269 \\
\hline 9.866 & 9.864 \\
\hline 21.413 & 16.691 \\
\hline
\end{tabular}

not significant
t-Test: Paired Two Sample for Means

\begin{tabular}{lrr}
\hline & Variable 1 & Variable 2 \\
\hline Mean & 16.04906622 & 13.94140543 \\
Variance & 33.83864853 & 12.97586416 \\
Observations & 3 & 3 \\
Pearson Correlation & 0.979538107 & \\
Hypothesized Mean Difference & 0 & \\
df & 2 & \\
t Stat & 1.5206375 & \\
P $(\mathrm{r}<-t)$ one-tail & 0.133866655 & \\
t Critical one-tail & 2.91998558 & \\
P $(\mathrm{T}<-t)$ two-tail & 0.26773331 & \\
t Critical two-tail & 4.30265273 & \\
\hline
\end{tabular}


Table8: Pair-difference t-test for the imported Strawberries in the presence g-chlordane residue.

\begin{tabular}{|r|r|}
\hline \multicolumn{2}{|c|}{ Lemon } \\
\hline \multicolumn{2}{|c|}{ g-Chlordane } \\
\hline washed & unwashed \\
\hline 4.288 & 5.987 \\
\hline 6.751 & 5.037 \\
\hline 6.472 & 9.585 \\
\hline
\end{tabular}

not significant
t-Test: Paired Two Sample for Means

\begin{tabular}{lrr}
\hline & Variable 1 & Variable 2 \\
\hline Mean & 5.837025806 & 6.86947779 \\
Variance & 1.820023672 & 5.755089471 \\
Observations & 3 & 3 \\
Pearson Correlation & 0.21864691 & \\
Hypothesized Mean Difference & 0 & \\
df & 2 & \\
t Stat & -0.720519108 & \\
P $(\mathrm{T}<=t)$ one-tail & 0.273019429 & \\
t Critical one-tail & 2.91998558 & \\
P $(\mathrm{T}<=t)$ two-tail & 0.546038858 & \\
t Critical two-tail & 4.30265273 & \\
\hline
\end{tabular}


Table9: Pair-difference t-test for the imported lemon in the presence of a-chlordane residue.

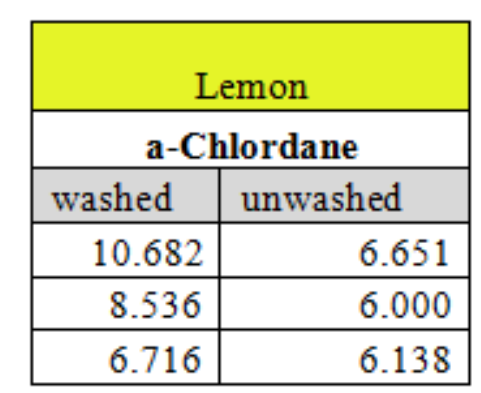

not significant
t-Test: Paired Two Sample for Means

\begin{tabular}{lrr}
\hline & Variable 1 & Variable 2 \\
\hline Mean & 8.644634438 & 6.262766518 \\
Variance & 3.942144711 & 0.117534556 \\
Observations & 3 & 3 \\
Pearson Correlation & 0.778676385 & \\
Hypothesized Mean Difference & 0 & \\
df & 2 & \\
t Stat & 2.382024522 & \\
P $(T<=t)$ one-tail & 0.070063635 & \\
t Critical one-tail & 2.91998558 & \\
P $(T<=t)$ two-tail & $\mathbf{0 . 1 4 0 1 2 7 2 7 1}$ & \\
t Critical two-tail & 4.30265273 & \\
\hline
\end{tabular}


Table10: Pair-difference t-test for the imported lemon in the presence of methoxychlor residue.

\begin{tabular}{|c|r|}
\hline \multicolumn{2}{|c|}{ Lemon } \\
\hline \multicolumn{2}{|c|}{ Methoxychlor } \\
\hline washed & unwashed \\
\hline 0.580 & 0.096 \\
\hline 1.440 & 0.314 \\
\hline 1.616 & 0.033 \\
\hline
\end{tabular}

not significant
t-Test: Paired Two Sample for

Means

\begin{tabular}{lrr}
\hline & Variable 1 & Variable 2 \\
\hline Mean & 1.211913693 & 0.14789415 \\
Variance & 0.306812804 & 0.021756221 \\
Observations & 3 & 3 \\
Pearson Correlation & 0.147620081 & \\
Hypothesized Mean Difference & 0 & \\
df & 2 & \\
t Stat & 3.340057874 & \\
P $(T<-t)$ one-tail & 0.039571408 & \\
t Critical one-tail & 2.91998558 & \\
P $(T<=t)$ two-tail & $\mathbf{0 . 0 7 9 1 4 2 8 1 6}$ & \\
tCritical two-tail & 4.30265273 & \\
\hline
\end{tabular}

